\title{
Dissolved rare earth elements distribution in the Solomon Sea
}

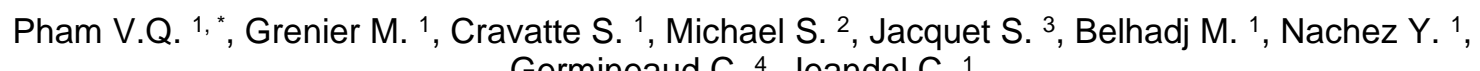
Germineaud C. ${ }^{4}$, Jeandel C. ${ }^{1}$

${ }^{1}$ LEGOS, Université de Toulouse, (CNRS, UPS, IRD, CNES), Toulouse, France

2 School of Oceanography, University of Washington, Seattle, WA 98105, USA

${ }^{3}$ Aix Marseille Université (CNRS/INSU), Université de Toulon, IRD, Mediterranean Institute of Oceanography (MIO), UM110, 13288 Marseille, France

${ }^{4}$ Université Grenoble Alpes, CNRS, IRD, Grenoble-INP, IGE, Grenoble, France

* Corresponding author : V. Q. Pham, email address : viet.pham@legos.obs-mip.fr

\begin{abstract}
:
Trace Elements and Isotopes (TEls) were measured as part of the GEOTRACES PANDORA cruise (JulyAugust 2012, R/V L'Atalante), among them Rare Earth Elements (REEs) as pertinent tracers of landocean inputs and water mass transformations. This work discusses results of 19 dissolved REE (dREE) profiles measured using a trispike method in the Coral Sea and inside and at the exits of the Solomon Sea, a semi-enclosed sea with complex topography and straits. Overall, dREEs -except the insoluble $\mathrm{Ce}-$ show nutrient like profiles, i.e. depleted at the surface and enriched at depth. Illustrative $\mathrm{Nd}$ concentrations range from $\sim 5 \mathrm{pmol} / \mathrm{kg}$ at the surface to $>25 \mathrm{pmol} / \mathrm{kg}$ at $5000 \mathrm{~m}$ depth. However, local dREE enrichments are observed, mostly in the Straits (Indispensable, Solomon and Vitiaz Straits) and along the island coasts. A box model allows calculating and discussing the fate of the dREEs in the different water layers flowing through the Solomon Sea. Finally, subtle variations revealed by $\mathrm{La}, \mathrm{Ce}, \mathrm{Eu}$ anomalies and the normalized light versus heavy REE ratio (expressed as $\mathrm{Ndn} / \mathrm{Ybn}$ ) allows the identification of specific mechanisms affecting the distribution of the different dREEs. The positive Eu anomaly observed in the surface layers reflects the basaltic origin of external inputs, consistent with the intensive weathering and/or volcanic activity affecting the surrounding islands. These data also confirm that the distributions of heavy dREEs (like $\mathrm{Yb}$ ) are better correlated to the dSi concentrations than that of the other REEs.
\end{abstract}

Keywords : Solomon Sea, Coral Sea, Dissolved rare Earth Element distribution, Lithogenic inputs, GEOTRACES 


\section{Introduction}

[1] In the southwest Pacific Ocean, the northern branch of the westward South Equatorial Current is conveyed equatorward by the low-latitude western boundary currents (LLWBCS). These currents are flowing through the semi-enclosed Solomon Sea as final pathway between the subtropical Pacific and the Equator (Fine et al., 1994; Grenier et al., 2014; Johnson and McPhaden, 1999). The LLWBCs are joining the equatorial current system, in particular the eastward Equatorial Undercurrent feeding the "cold equatorial tongue" in the eastern equatorial Pacific. The properties of the water masses they transport have thus the potential to impact the equatorial thermocline stratification as well as native ecosystems of the western Pacific with potential downstream effects on the eastern Pacific ones (Figure1, Germineaud et al., 2016). Hence, the Solomon Sea is a hot spot to study the water modifications when flowing from the Subtropical to the Equatorial region.

[2] The Solomon Sea is surrounded by high and intensively weathered islands (Milliman et al 1999). Together with its complex topography and hydrography, these characteristics make this area a potential source of trace elements to the waters flowing through it. Preceding studies aimed at characterizing the chemistry of the LLWBCs upstream and downstream of the Solomon Sea (i.e: Grenier et al., 2014; Grenier et al., 2013; Slemons et al., 2010; Mackey et al., 2002; Zhang and Nozaki, 1996). However, the Solomon Sea itself was never documented so far, becoming with time a sort of "missing piece" of the geochemical map of this area.

[3] Two exploratory oceanographic cruises were undertaken in the framework of the SPICE (Southwest Pacific Ocean Circulation and Climate Experiment) and GEOTRACES (www.geotraces.org) programs (Ganachaud et al., 2014; Ganachaud et al., 2017). The Pandora cruise (July 2012) documented a large number of hydrographic and biogeochemical parameters in the Coral and Solomon Seas while two years later the MoorSPICE cruise (March 2014) repeated the hydrographic measurements.

[4] Dissolved chemical elements and their isotopes (so called as geochemical tracers) provide a better understanding and quantification of water mass histories and characterize the sources of key nutrient species to the oceans (Crusius et al., 1996; Elrod et al., 2004; Haley et al., 2004; Johnson et al., 2003; Nozaki, 1986). Among the "tracer world", the rare earth elements (REE) and isotopic composition of neodymium are used to quantify any lithogenic enrichment, scavenging processes and/or water mass transport when occurring in a given area (Goldstein and Hemming, 2003; Jeandel et al., 2013; Lacan and Jeandel, 2001; Tachikawa et al., 2003). Rare earth element (REE) is a group of 14 elements displaying extreme coherent characteristics from lanthanum (La) to lutetium (Lu). The light REE (LREE) refers to the lower atomic number REEs from 57 (La) to $61(\mathrm{Nd})$; Samarium (Sm) Europium (Eu) and Gadolinium (Gd) stand for medium REE (MREE), while Dysprosium (Dy) to Lutetium are heavy REEs (HREE). Within this group, the atomic weight increases while the atomic size decreases which yields chemical fractionation processes to occur during geochemical processes by means of an ordered response through the group as a function of atomic number. In the oceanic environment, most of the previous studies concluded that not only the internal processes (i.e: Akagi, 2013; Akagi et al., 2011; De Baar et al., 1985a; Jong Hyeon 
and Byrne, 1993; Tachikawa et al., 1999) but also the external ones (i.e: Nozaki and Alibo, 2003a; Nozaki and Alibo, 2003b; Sholkovitz et al., 1994; Rousseau et al., 2015; Wang and Yamada., 2007) could fractionate the REE distribution. The internal processes occurring all along the water column can be resumed as dissolved-particulate exchanges which result from biological uptake-remineralization and/or adsorption-desorption onto reactive particle coatings and/or (co)precipitation-dissolution. In addition, dREE could be released to the open ocean from river discharge, atmospheric dust, hydrothermal plume or exchange at the landocean interface, considered as external inputs. Understanding the fate of these important tracers in the modern ocean is therefore a key issue.

[5] This work characterizes the dREE concentrations along the whole water column at 21 stations collected between the entrance of the Coral Sea and the exiting straits of the Solomon Sea. The geochemical data are coupled with the associated hydrological parameters and the water mass transports, providing an essential view on water mass pathways. This strategy allows us to describe and quantify the modification of geochemical parameters during south-north transit of the waters through the Solomon Sea. Our results are also compared with other geochemical parameters (e.g: Al, Mn) which are concurring to validate the enrichment of lithogenic origin observed in the Solomon Sea. Relationships between $\mathrm{dREE}$, dissolved $\mathrm{Ba}$ and nutrient data are also discussed in order to reveal the influence of the biological activity REE fractionation.

[6] Section 2 describes the sampling procedure, sample preservation and analytical protocol while section 3 presents the hydrological context. Section 4 presents the resulting dREE profiles and their PAAS-normalized patterns. Section 5 is the discussion: it presents a simple box model to estimate the dREE Solomon Sea budgets in different density layers, the enrichment of the waters along their pathways, and provides a discussion around the fractionation observed in the REE patterns (La, Ce, Eu anomalies), the presumed associated mechanisms and the control of the HREE fate by the dissolved silica.

\section{Material and Methods}

\subsection{Sample collection}

[7] 143 seawater samples were collected at 21 stations during the PANDORA cruise (JulyAugust 2012, onboard R/V Atalante). The sampling locations are reported in Figure 1b. Nine stations (stations 04, 10, 13, 20, 21, 29, 34, 36 and 82) were located in the Coral Sea and at the southern entrance of the Solomon Sea in order to characterize the water masses entering the Solomon Sea. Stations 04 and 10 were sampled to characterize the North Vanuatu Jet (NVJ) and North Caledonia Jet (NCJ), respectively. Stations 13, 20 and 21 were collected before and after the Indispensable Strait in order to identify any modification of the waters when flowing through this strait. Stations 29, 34 and 36 tried to catch the complex hydrological features at the entrance of the Solomon Sea (Cravatte et al., 2011; Davis et al., 2012; Germineaud et al., 2016). The remaining 12 stations are located in the "body" of the Solomon Sea as well as in the 3 straits through which waters are flowing out (i.e: Vitiaz Strait, St George's Channel and Solomon Strait). 
[8] Salinity (S), potential temperature $(\theta)$ and dissolved oxygen $\left(\mathrm{dO}_{2}\right)$ were measured on board using sensors mounted at the base of the rosette. Salinity and oxygen sensors were calibrated and adjusted after the cruise using the chemical measurements of these parameters on discrete samples (Ganachaud et al., 2017). Shipboard and Lowered Acoustic Doppler Current Profiler (ADCP) data and other samples for various chemical analyses were also acquired during the cruise for the seawater characterization in trace metals, nutrients and other biological and chemical parameters. The online cruise report (http://www.obsvlfr.fr/proof/php/pandora/xdat alist1.php?xxop=pandora\&xxcamp=pandora) and the synthesis article of Ganachaud et al. (2017) provide more details on the numerous operations conducted in the framework of PANDORA.

[9] Seawater samples dedicated to dREE analysis were collected using 2212 L Niskin bottles mounted on a rosette. Aliquots of $500 \mathrm{~mL}$ were rapidly filtered through $0.4 \mu \mathrm{M}$ pore size, $47 \mathrm{~mm}$ diameter SUPOR membranes in the R/V Atalante humid laboratory. Filtered water was transferred into pre-cleaned low density polyethylene (LDPE) bottles and immediately acidified to $\mathrm{pH} \leq 2$ by addition of suprapur $\mathrm{HCl} 30 \%$. All consumable material was acid-cleaned before the cruise. Note that samples from station 82 and some duplicates from station 73 and 77 were not filtered. Replicate samples were also taken at some stations in order to validate the data, identify particle/dissolved interaction and control the blank of the filtration system (e.g. at station 73).

\subsection{Analytical procedure}

[10] dREE concentrations were determined using the LEGOS protocol (Lacan and Jeandel, 2001; Tachikawa et al., 1999). Briefly, dREE were extracted from the seawater aliquot by a co-precipitation with iron hydroxides, followed by purification through ion-exchange column and measured with a High Resolution Inductively Coupled Plasma Mass Spectrometer (HRICP-MS). In details, a trispike solution containing ${ }^{150} \mathrm{Nd}(97.84 \%),{ }^{153} \mathrm{Eu}(97.84 \%)$, and ${ }^{174} \mathrm{Yb}$ (94.9\%) was added to the acidified seawater aliquots of $250 \mathrm{~mL}$ or $500 \mathrm{~mL}$. Approximately 2.5 $\mathrm{mg}$ of purified $\mathrm{FeCl}_{3}$ diluted in $0.1 \mathrm{M} \mathrm{HCl}$ was then added to the samples. The homogenization was ensured by a continuous shaking of the sample during $24 \mathrm{~h}$ and a subsequent $24 \mathrm{~h}$ resting state before performing the co-precipitation. Then, the $\mathrm{pH}$ was increased to $8 \pm 0.5$ by adding suprapur $\mathrm{NH}_{4} \mathrm{OH}$ yielding the iron hydroxides to co-precipitate the dREE. The dREE-Fe precipitate was then rinsed and separated from the seawater by successive centrifugations. This rinsing step was repeated between 5 to 7 times and the precipitate was later dissolved in $1 \mathrm{~mL}$ of $6 \mathrm{M} \mathrm{HCl}$ and then loaded on an anion exchange column packed with $2 \mathrm{~mL}$ of AG1-X8 resin, in order to purify the dREE fraction from Fe. dREEs were then eluted from the column using $4 \mathrm{~mL}$ of $6 \mathrm{M} \mathrm{HCl}$ and evaporated to dryness. Finally, the residue was dissolved again with $5 \mathrm{~mL} \mathrm{HNO} 30.32 \mathrm{M}$ spiked with an internal standard (In-Re, $100 \mathrm{ppt}$ ), which is the appropriate solution to measure the concentrations on a sector field Inductively Coupled Plasma Mass Spectrometer (THERMO ELEMENT XR ${ }^{\mathrm{TM}}$ ICP-MS).

[11] Recoveries of the whole experiment (including sensitivity variations during the ICPMS sequence) were precisely determined by comparing the $\mathrm{Nd}$, $\mathrm{Eu}$ and $\mathrm{Yb}$ concentrations calculated by Isotopic Dilution (ID-CONC) with that measured by external calibration (EXTCONC). The ratio (EXT-CONC)/(ID-CONC) for these 3 elements were then linearly 
(interpolated and extrapolated to be applied to the remaining dREE concentrations, measured by external calibration only. On the average, recoveries of more than $80 \%$ were obtained for the light REE, and around $77 \%$ for the middle and heavy REE. Our method based on 2 or 3 spikes followed by an (inter/extra)polation was validated by comparing results obtained using 10 spikes on the same seawater samples, either in the framework of $\mathrm{T}$. Rousseau thesis (Rousseau et al., 2013) or in the recent work of M. Behrens (Behrens et al., 2016). During the ICP-MS analysis, the use of a desolvating nebulizer system (ARIDUS II) considerably minimized the oxide interference formation (Chung et al., 2009; Grenier et al., 2013; Pahnke et al., 2012). This is notably effective for the barium oxide formation reduction, which subsequently improves the analytical accuracy for ${ }^{151} \mathrm{Eu}$ and ${ }^{153} \mathrm{Eu}$.

[12] Replicate measurements were conducted on filtered (4 replicates, station 73, 1650 m) and non-filtered samples ( 3 replicates at $1650 \mathrm{~m}$ of station 73 and 4 replicates at $1200 \mathrm{~m}$ of station 82). Filtered light REE (dLREE) concentrations agree within $8 \%$ for La, $14 \%$ for Ce and $4 \%$ for $\operatorname{Pr}$ and $\mathrm{Nd}$; filtered middle (dMREE) and heavy (dHREE) concentrations agree within $8 \%$ for $\mathrm{Sm}, 11 \%$ for $\mathrm{Eu}$ and less than $4 \%$ for the remaining REE. Non-filtered concentrations are agreeing within less than $4 \%$ for all the LREE (including Ce) and $7 \%$ for MREE and HREE.

[13] The average chemical blank values were established on 20 measurements. Blank levels represent less than $2 \%$ of the LREE signals and less than $0.7 \%$ for MREE and HREE ones. Due to the very low Ce concentration in our samples, the dCe blanks represent $14 \pm 9 \%$ of the sample signal. In addition, the blank of our on-board filtration system was checked by filtering twice the same samples. No noticeable variation of concentration was observed, assessing the cleanliness of our systems. Finally, our full dREE analytical procedure was validated by our successful participation to two GEOTRACES intercalibration exercises (Behrens et al., 2016; van de Flierdt et al., 2012).

[14] Together with REE analysis, the dissolved Ba were also measured follow this protocol: fifteen $\mathrm{mL}$ of unfiltered seawater were collected in pre-cleaned polypropylene bottles (rinsed three times with the same seawater sample), acidified with $15 \mu \mathrm{L}$ of $\mathrm{HCl}(10 \mathrm{M}$, Optima grade) and kept at room temperature for later analysis. Dissolved Ba concentrations were measured using an isotope dilution (ID) method (Freydier et al., 1995; Klinkhammer and Chan, 1990) by high resolution -inductively coupled plasma- mass spectrometry (HR-ICP-MS). This method was adapted to a Thermo Finnigan Element XR instrument (MIO, Marseille). The dissolved $\mathrm{Ba}$ measurements presented here are the sum of dissolved $\mathrm{Ba}$ and a very small fraction (generally $<1 \%$ of total $\mathrm{Ba}$ ) that is generated from the particulate $\mathrm{Ba}$ pool as a result of the acidification. For the sake of simplicity, we use the term of dissolved Ba. Samples $(0.5$ $\mathrm{mL}$ ) were spiked with $300 \mu \mathrm{L}$ of a 135Ba-enriched solution (93\% 135Ba; $95 \mathrm{nmol} . \mathrm{kg}^{-1}$ ) and diluted with $15 \mathrm{~mL}$ of acidified ( $2 \% \mathrm{HNO}, 14 \mathrm{M}$, Optima grade) Milli-Q grade water (Millipore). The amounts of sample, spike and dilution water were assessed by weighing. Reproducibility of this method is $1.5 \%$ (1 RSD) as tested on repeated preparations of the reference solution SLRS-5 (NRC-CNRC river water reference material for trace metals; $101.9 \pm$ $3.6 \mathrm{nmol} \mathrm{kg}{ }^{-1}$ ). The limit of detection, calculated as three times the standard deviation of the procedural blank, is $0.09 \mathrm{nmol} . \mathrm{kg}^{-1}$. 


\section{Hydrological context}

[15] Coral and Solomon sea hydrological properties have been the subject of serveral surveys since the 60s. Water mass properties were discussed in miscellaneous works since then (e.g. Tsuchiya, 1981; Tsuchiya et al., 1989; Qu and Lindstrom, 2002; Grenier et al., 2013; Kessler and Cravatte, 2013; Ganachaud et al., 2014). Recently, Germineaud et al. (2016) presented a detailed description of the currents and water masses in the Solomon Sea based on the PANDORA (2012) and MoorSPICE (2014) cruise data. The description proposed here is mostly based on this last work together with the thorough description of the Southwest Pacific currents conducted by Grenier et al. (2011; 2013, 2014). The water mass nomenclatures are varying among authors; the names used in this study are following those proposed by Grenier et al. (2013), Tomczak and Godfrey (2003), and Tomczak and Hao (1989) in order to avoid any confusion when describing the water masses, especially in the layers characterizing the thermocline.

[16] The general circulation scheme, current names and sampling details of the different stations used in this study are given in Figure 1. Figure 2 proposes a compilation of the property plots observed at the different stations, together with the identification of the main water masses sampled during the cruise. The last column of Table 1 also recalls the water masses corresponding to the collected seawater samples.

[17] Water properties in the Southwest Pacific can be traced from the Coral Sea to the Solomon Sea, in part through the Low Latitude Western Boundary Currents (LLWBCs) flowing toward the Equator (Figure 1). The LLWBCs are initially fed by the westward South Equatorial Current (SEC) (Qu and Lindstrom, 2002; Tsuchiya et al., 1989), dividing into several zonal currents when encountering islands in the Coral Sea. These zonal currents, some of them extending deep, transport several water masses that we choose to present here following increasing density.

\subsection{Thermocline Waters}

\subsubsection{Upper thermocline: Tropical and Equatorial Waters}

[18] In the Coral and Solomon Seas, the salty South Pacific Tropical Waters (SPTW) are flowing in the upper thermocline $(\sim \sigma \theta=24.3-25.3 \mathrm{~kg} \cdot \mathrm{m}-3)$. This tropical water can be divided in two main branches.

[19] The northern branch of the SPTW is called the South Pacific Equatorial Water (SPEW) and enters the Coral Sea north of the Vanuatu Archipelago, transported by the North Vanuatu Jet (NVJ) (Kessler and Cravatte, 2013; Tomczak and Godfrey, 2003; Tomczak and Hao, 1989; Tsuchiya et al., 1989). The SPEW originates from the subtropical central South Pacific ( $200 \mathrm{~S}, 110^{\circ} \mathrm{W}$ ), subductes in the high surface evaporation zone (HSEA), characterized by a maximum in sea surface salinity (see Figure 1 of Grenier et al., 2013). The SPEW is thus marked by a maximum in salinity $(\sim S=36.0)$ at $\sim \sigma_{\theta}=24.5 \mathrm{~kg} \cdot \mathrm{m}^{-3}$ (Kessler, 1999; Qu and Lindstrom, 2002) and relative high oxygen ( 135 $\mu \mathrm{mol} . \mathrm{kg}^{-1}$; Grenier et al., 2013). After entering in the Coral Sea, the SPEW follows two pathways to reach the Solomon Sea: the first one is directly entering by the southern entrance of the Solomon Sea while the second is 
conveyed by the Gulf of Papua Current (GPC) before entering the Solomon Sea at its southwestern end (see Figure 3 and Figure 5 of Cravatte et al., 2011; Ganachaud et al., 2014). During Pandora, SPEW was well identified at station 10 (Figure 2).

[20] The southern branch of the SPTW enters the Coral Sea mainly south of the Vanuatu Archipelago, conveyed by the North Caledonian Jet (NCJ) (Ganachaud et al., 2014; Gasparin et al., 2011; Germineaud et al., 2016; Grenier et al., 2013). This tropical water is then transported westward to the Australian coast where it bifurcates equatorward and poleward. The equatorward branch is carried by the GPC, and enters the Solomon Sea where it mixes with the SPEW described above to form the New Guinea Coastal Undercurrent (NGCU) flowing equatorward (Cravatte et al., 2011). At the entrance of the Coral Sea, this water mass is slightly denser $\left(\sim \sigma_{\theta}=24.8 \mathrm{~kg} . \mathrm{m}^{-3}\right)$, less saline (S 35.6) and richer in oxygen $\left(\sim 165 \mu \mathrm{mol} . \mathrm{kg}^{-1}\right)$ than those of the northern branch (see station 4, Figure 2).

[21] Inside the Solomon Sea, the NGCU splits south of Woodlark Island and then remerges at its northern side, to finally bifurcate again into two branches south of New Britain Island. The first branch flows westward towards the Bismarck Sea through the Vitiaz Strait while the second one is conveyed eastward by the New Britain Coastal Undercurrent. It exits the Solomon Sea northward by the St George's Undercurrent (SGU) and the New Ireland Coastal Undercurrent (NICU) through St George's Channel and Solomon Strait, respectively (Cravatte et al., 2011; Ganachaud et al., 2014; Ganachaud et al., 2017; Germineaud et al., 2016). Since the SPTW in the Solomon Sea results from the mixing between two water masses of minor differences which are referred above, its characteristics are fairly high oxygen content (140$\left.145 \mu \mathrm{mol} . \mathrm{kg}^{-1}\right)$, and high salinity $(\sim S=35.7$, see station $34,36,42,43,57,60,71,73$ and 77 in figure 2).

\subsubsection{Lower thermocline: Central Water and Mode Water}

[22] Lying just underneath the upper thermocline water and considered as the lower thermocline water, the Western South Pacific Central Water (WSPCW) is identified in our research area, displaying thermostad characteristics (Grenier et al., 2014; Qu et al., 2008; Tsuchiya, 1981) and a very loose stratification at about $300 \mathrm{~m}$ depth. WSPCW is described by potential density centered at $26.4 \mathrm{~kg} \cdot \mathrm{m}-3$ and high salinity due to its origin, north of New Zealand (Tomczak and Hao, 1989). High oxygen content WSPCW (mean $\mathrm{O}_{2}=160 \mathrm{~kg} \cdot \mathrm{m}^{-3}$ ) is conveyed into the Coral Sea in its southern part, through the deep NCJ (Sokolov and Rintoul, 2000; Tomczak and Godfrey, 2003; Tsuchiya et al., 1989). During its transportation through the Coral Sea, the Gulf of Papua and inside the Solomon Sea (Kessler and Cravatte, 2013), this water mass loses its oxygen as a result of mixing. Near the straits, it mixes with older, deoxygenated water originating from the southeastern Pacific Ocean and entering the Solomon Sea through Solomon Strait. A drop of dissolved oxygen values from $160 \mathrm{~kg} \cdot \mathrm{m}^{-3}$ at the southern entrance of the Solomon Sea to $130 \mathrm{~kg} \cdot \mathrm{m}^{-3}$ in its northeastern part is observed.

[23] Below the WSPCW, another mode water, with no salinity or oxygen extremum, is identified. It is named the Subantarctic Mode Water SAMW $\left(\sim \sigma_{\theta}=26.5-27 \mathrm{~kg} \cdot \mathrm{m}^{-3}\right)$ and enters the Coral and Solomon Seas from the south, (Grenier et al., 2013; McCartney, 1977). It originates from the southeastern Southern Ocean by subduction north of the Antarctic 
Circumpolar Current (Hanawa, 2001). This water mass is centered on $\sim \sigma_{\theta}=27 \mathrm{~kg} \cdot \mathrm{m}^{-3}$ and is characterized by a low salinity ( 34.5) and high oxygen content $\left(\sim 175 \mathrm{~kg} . \mathrm{m}^{-3}\right)$ because of its origin (Qu et al., 2009). In the Coral and Solomon Seas, SAMW keeps its original characteristics and contributes to the formation of $13^{\circ} \mathrm{C}$ Water (Qu et al., 2009).

\subsection{Intermediate Waters}

[24] The Antarctic Intermediate Water (AAIW; $\sigma^{\theta} \sim 27.2 \mathrm{~kg} \cdot \mathrm{m}^{-3}$ ) is identified in the southern 289 part of the studied region by a salinity minimum ( $\mathrm{S}=34.3-34.5)$ and an oxygen maximum $\left(\sim \mathrm{O}_{2}=200-300 \mu \mathrm{mol} . \mathrm{kg}^{-1}, \mathrm{Qu}\right.$ and Lindstrom, 2004). The AAIW circulation in the South Pacific follows the wind-driven subtropical gyre circulation and flows equatorward through the Coral Sea. It enters the Solomon Sea through the LLWBCs (Bostock et al., 2010; Germineaud et al., 2016; Qu and Lindstrom, 2004; Tomczak and Godfrey, 2003). From the Coral Sea to the equator, the AAIW becomes slightly denser and less oxygenated $\left(\sim \sigma_{\theta}=27.26 \mathrm{~kg} \cdot \mathrm{m}^{-3} ; \mathrm{O}_{2}=160\right.$ $190 \mu \mathrm{mol} . \mathrm{kg}^{-1}$ ) due to remineralization of organic material setling from the surface and diapycnal mixing with lower oxygenated waters.

[25] Another intermediate water identified in our study area is the Equatorial Pacific Intermediate Water (EqPIW; $\sigma_{\theta}=27.3 \mathrm{~kg} \cdot \mathrm{m}^{-3}$ ), which is originally formed from a combination of AAIW and upwelled Pacific Deep Water (Bostock et al., 2010). In our study, it is suggested that part of this water mass enters the Solomon Sea from the north-east through Solomon Strait (Germineaud et al., 2016) and mixes then with AAIW as proposed in Figure 1 of Bostock et al. (2010). The distinct characteristics of this water mass is a salinity higher than that of AAIW ( S $=34.5-34.6)$ and a significantly lower oxygen concentration $\left(\sim \mathrm{O}_{2}=75-125 \mu \mathrm{mol} . \mathrm{kg}^{-1}\right)$. It is found at a density of $27 \mathrm{~kg} \cdot \mathrm{m}^{-3}$ at station 43 and 46 . Moreover, the oxygen plot of station 43 show that EqpIW and AAIW are interleaving near $700 \mathrm{~m}$ depth.

\subsection{Deep and Bottom Waters}

[26] The deep and bottom waters within the Coral and Solomon Seas have been poorly documented since the first observations summarized in Reid $(1986,1997)$ and their pathways and fates are not clearly understood. They are strongly constrained by the topography (Johnson and Toole, 1993; Kawabe and Fujio, 2010; Roemmich et al., 1996; Tsimplis et al., 1998). Their pathways, origins and properties are described in Germineaud et al. (in preparation).

[27] The Upper Circumpolar Deep Water (UCDW) is observed between $1000 \mathrm{~m}$ and 3500 $\mathrm{m}$ in the studied area. This water mass has been depleted in oxygen since its origin in the Antarctic Circumpolar Current (ACC) (Reid, 1986; Talley, 2007; Wijffels et al., 2001). In this study, UCDW is characterized by relatively high salinity and low oxygen content with a pronounced minimum $\left(\sim \mathrm{S}=34.6, \sim \mathrm{O}_{2}=140 \mu \mathrm{mol} . \mathrm{kg}^{-1}\right)$ at $\sim \sigma_{\theta}=27.65 \mathrm{~kg} \cdot \mathrm{m}^{-3}$ at almost all of our stations (Figure 2). Germineaud et al. (2016) suggests that the UCDW can be divided into two sublayers which are the upper extent and lower extent UCDW, with potential density anomaly $\left(\sigma_{\theta}\right)$ ranges of $27.4-27.65$ and $27.65-27.76$, respectively.

[28] Just beneath the UCDW, the Lower Circumpolar Deep Water (LCDW; Kawabe and Fujio, 2010; Reid, 1997; Tsimplis et al., 1998) is identified by a salinity maximum reaching 34.72-34.73 and a decrease of its silicate content when compared to the UCDW (Orsi et al., 
1999). The LCDW transport is supposed to be limited from the Tasman Sea to the Coral and Solomon Seas because this last one is so far considered as a sealed area below $3500 \mathrm{~m}$, separated from the outer world by islands and sills (Germineaud, 2016; Sokolov and Rintoul, 2000). Curiously, we clearly identified the LCDW imprint in our profiles, and an unexpected oxygen concentration increase with depth, which underlines that the topography, and the possible pathways and fate of this water mass are still unclear (Germineaud et al., in preparation).

\section{Results}

\subsection{Dissolved REE concentrations}

[29] The dissolved concentrations measured for the 14 REEs at the different stations are compiled in Table 2. For simplicity, only the vertical distributions of dissolved Lanthanum (dLa), Neodymium (dNd), Europium (dEu) and Ytterbium (dYb) are shown in Figure 3. dLa and $\mathrm{dNd}$ represent the dissolved LREE while $\mathrm{dEu}$ and $\mathrm{dYb}$ represent the dMREE and dHREE, respectively.

[30] The dREE concentrations display low values at the surface and increase with depth, showing a vertical profile shape similar to that of nutrients although not completely depleted in the surface waters (Figure 3). The dLa concentrations are increasing from $\sim 4 \mathrm{pmol} . \mathrm{kg}^{-1}$ in the surface water to $\sim 15$ pmol. $\mathrm{kg}^{-1}$ at $\sim 1000 \mathrm{~m}$; dNd profiles are varying from $\sim 5 \mathrm{pmol} . \mathrm{kg}^{-1}$ in the euphotic zone to $\sim 10 \mathrm{pmol} . \mathrm{kg}^{-1}$ at intermediate layer followed by an $\sim 2.5$-fold increase towards the bottom. Typical dEu and dYb profiles show the same kind of gradients as dLa and $\mathrm{dNd}$ but with lower concentrations ( $<1 \mathrm{pmol} . \mathrm{kg}^{-1}$ for $\mathrm{dEu}$ and $<10$ pmol. $\mathrm{kg}^{-1}$ for $\mathrm{dYb}$ ).

[31] The surface depletion and enrichment at depth are consistent with the surfacescavenging and depth-dissolution hypothesis characterizing the fate of these trivalent elements onto particulate carrier phases (oxides, hydroxides, organic matter) along the water column (De Baar et al., 1985a; Elderfield, 1988; Garcia-Solsona et al., 2014; Sholkovitz et al., 1994; Takebe, 2005). The concentration ratio between the deepest samples (deeper than $3000 \mathrm{~m}$ ) and shallowest samples is larger than 4, indicating a significant release of the REE from the particles in the deepest layers. Beyond the observed general concentration increase, the vertical shape of the profiles show subtle but interesting variations:

- Down to $3000 \mathrm{~m}$, all the concentrations linearly increase, although the dYb profile is always slightly more convex than the 3 other dREE ones.

- In the southern part of our study (Coral Sea and Solomon Sea entrance, Figure 3a), a break is observed in the linearity at $3000 \mathrm{~m}$, with dREE concentration values slightly lower between 3000 and $4000 \mathrm{~m}$.

- Station 60 profiles, in the northern part of the Solomon Sea, show a local maximum between 4000 and $5000 \mathrm{~m}$, dREE concentrations being maximal in this layer and then decreasing toward the bottom. The convex shape of $\mathrm{dYb}$ is the most pronounced at this station (Figure 3c).

- On the average, dREE concentrations are slightly enriched within the Solomon Sea compared with the sites located outside of it. For example, dNd average value is of 3.5 pmol. $\mathrm{kg}^{-1}$ in the Solomon Sea for the isopycnal layer $24 \mathrm{~kg} \cdot \mathrm{m}^{-3}<\sigma_{\theta}<26 \mathrm{~kg} \cdot \mathrm{m}^{-3}$ 
while of $2.5 \mathrm{pmol} . \mathrm{kg}^{-1}$ for the same density layer in the Coral Sea and in the east of the Solomon archipelago (see station 04, 10, 34 and 71, Figure 3).

- Figure 3e shows a slight maximum at station 21, suggesting an input of Solomon Archipelago material into seawater passing through Indispensable strait

[32] In addition to these features affecting the profiles, local enrichments are observed at specific stations and depths as at the surface of stations 36, 57 and 77, very likely reflecting the proximity between these stations and the coast. Within the thermocline some layers show enriched dREE concentrations [e.g: around $500 \mathrm{~m}$ at station 42, 46, 57, 77, in the intermediate waters ( 700 $\mathrm{m}$ ) at station 13, 21, 34 and at $980 \mathrm{~m}$ at station 29].

[33] Dissolved cerium ( $\mathrm{dCe}$ ) concentrations are reported in Table 1 and some data will be shown later as part of the discussion. As often observed in seawater where the oxidized $\mathrm{Ce}(\mathrm{IV})$ is poorly soluble and then behaves differently to the remaining trivalent REEs, $d C e$ shows a reverse behavior compared to the other dREEs, with high concentrations at the top of the water column, which decreasing at intermediate levels before increasing again in the deep and bottom waters due to its preference for scavenging (see station 29, 42, 71 and 73, Table 1) (De Baar et al., 1983; De Baar et al., 1985a; Elderfield, 1988; Goldberg et al., 1963; Liu et al., 1988; Piepgras and Jacobsen, 1992; Sholkovitz et al., 1994; Tachikawa et al., 1999). However, consistently with the other dREEs, dCe maxima are observed at some specific locations: surface layers at station 36 and 77, close to the surface and at $735 \mathrm{~m}$ at station 34 and slightly deeper (934 m) at station 29 (Table 1).

\subsection{Comparison with previous studies}

[34] Two previous studies analyzed samples at the entrance of the Solomon Sea and in the Coral Sea (Grenier et al., 2013; Zhang and Nozaki, 1996), allowing us to compare our data with published values. Figure 4 shows the locations of these stations and the dissolved REE concentrations as a function of potential density in order to compare the dREE values in the same isopycnal layers. This figure also highlights the excellent agreement between our data and these previous results. The minor difference observed between the surface dLa concentrations at SA-7 and at station 82 of our study likely reflects the dissimilarity in our sampling locations and times of the year, in this region of high eddy variability (Keppler et al., 2018).

[35] In Vitiaz strait, a striking similarity between our results (station 077) and Grenier et al. (2013) one (EUC-30) is also observed, despite the difference in sampling times (Figure 4) in this highly variable and turbulent region. Station 077 is located in Vitiaz strait which is narrow and relatively shallow (1200 m deep) in comparison with Solomon Sea average depth. The continental influence is therefore suggested to be high and dominant over the influence on dissolve concentration of internal oceanic processes variability. This suggests that the REEs concentrations are "buffered" by interplay of different processes.

\subsection{Dissolved REE patterns}

[36] Fractionation of the dREE from each other while submitted to oceanic processes (uptake, remineralization, freshly weathered from the continent or not...) could be identified using the normalization of dREE concentrations in seawater to those contained in shale, a material representing the average crustal geochemical composition. Here we used the Post- 

are presented in Figure 5.

[37] The main characteristics of the dREE patterns observed in the Coral and Solomon Seas are consistent with those found in the literature: the obvious negative dCe anomalies reflect the impact of the poor solubility and preferential scavenging of this element. The $\left(d N d_{n} / d Y b_{n}\right)$ ratio, which gives information about the dLREE versus dHREE slope evolution, is maximum in surface, decreasing from 0.3 to approximately 0.1 at intermediate level ( 1000 m), from where it increases again in the deep and bottom waters. These observations agree with previously published results (Bertram and Elderfield, 1993; De Baar et al., 1985a; Tachikawa et al., 1999; Garcia-Solsona et al., 2014; Grenier et al., submitted; Grenier et al., 2013; Zhang and Nozaki, 1996).

[38] dREE patterns are relatively flat in surface waters, which seems to indicate that recent lithogenic inputs are affecting these upper layers. The evolution of the pattern shape with depth reflects the differential scavenging along the water column. A slight local maximum is often observed for the dMREE, as already noticed by Grenier (Grenier et al., 2013) in the same area.

\section{Discussion}

\subsection{Nd and dREE enrichments within the Solomon Sea}

[39] A simple box model was built for the Solomon Sea, allowing us to estimate the dREE budget for different isopycnal layers between its southern entrance (southern section) and its northern exits (Vitiaz Strait, St George's Channel and Solomon Strait). The box model proposed here aims at identifying whether dREE (but more specifically dNd) concentrations get enriched, depleted, or stay constant while crossing the Solomon Sea and determining the related input (or output) net fluxes. This is a preliminary step to further developments that will include the on-going measurements of $\mathrm{Nd}$ isotopic compositions, allowing us a better quantification of exchange processes, if any. The scheme of the box model is proposed in Figure 6. This box model is applied to the upper thermocline layer (sigma 24-25.3 kg. $\mathrm{m}^{-3}$ ), the lower thermocline layer (sigma 25.3-26.9 $\mathrm{kg} . \mathrm{m}^{-3}$ ), the intermediate waters (sigma 26.9-27.4 $\mathrm{kg} \cdot \mathrm{m}^{-3}$ ), and the deeper UCWD waters (sigma 27.4-27.65 and 27.65-27.76 kg. $\mathrm{m}^{-3}$ ).

[40] Owing to the complexity of the Solomon Sea currents (see section 3), we hypothesized a slightly simplified circulation scheme. Our box model considers the Solomon Sea as a closed area at steady state and assumes that incoming and exiting water fluxes are balanced (Figure 6a). Two upstream sources (incoming NGCU and direct NVJ) are feeding the Solomon Sea across the southern entrance and three downstream fluxes (SGU, NICU and NGCU) are exiting from it through the different straits (NGCU through Vitiaz Strait, SGU through St George's Channel, NICU through Solomon Strait). The required parameters to achieve the model calculation are the water mass transports and the $\mathrm{Nd}$ concentrations of each layer. Water flowing equatorward into the Solomon Sea includes the transports of the $\operatorname{NGCU}\left(W_{E}\right)$, and of the direct inflow $\left(W_{N}\right)$. Meanwhile, water leaving the Solomon Sea gathers the fluxes exiting at the Solomon Strait $\left(W_{S}\right)$, the St. George's Strait $\left(W_{G}\right)$ and Vitiaz Strait $\left(W_{V}\right)$. Respective dissolved $\mathrm{Nd}$ concentrations considered here $\operatorname{are~}_{\mathrm{Nd}}, \mathrm{Nd}_{\mathrm{N}}$ at the southern 
entrance and $\mathrm{Nd}_{\mathrm{s}}, \mathrm{Nd}_{\mathrm{G}}$ and $\mathrm{Nd} d_{v}$ at the northern exits (Figure $6 \mathrm{a}$ and $\mathrm{b}$ ). Under the hypothesis that diapycnal mixing is weak in this area, we obtain in each density layer the equation:

Where:

$$
W_{E} \cdot[N d]_{E}+W_{N} \cdot[N d]_{N}+F_{\text {tot PANDORA }}=W_{S} \cdot[N d]_{S}+W_{G} \cdot[N d]_{G}+W_{V} \cdot[N d]_{V}
$$

$F_{\text {tot PANDORA }}$ is the total net flux into seawater from the surrounding coasts.

452

[41] The transports are computed in each density layer using the PANDORA cruise data (Ganachaud et al., 2016; Germineaud et al., 2016; Germineaud et al., in prep). Currents were recorded along the ship track with Shipboard Acoustic Doppler Current Profilers (S-ADCPS) with a vertical extent of around 1000-1300 m. S-ADCPs were rotated to estimate the current perpendicular to each of the box model section (Germineaud et al., 2016). At depths below $1000 \mathrm{~m}$, they are combined with geostrophic velocities estimated with CTD station pairs, and referenced to $3000 \mathrm{~m}$ depth, or to the deepest common level of the station pairs.

[42] Transports computed across the southern entrance do not balance the summed transports at the exits, as they were estimated during instantaneous transects. For the purpose of this study, relying on a steady state hypothesis, velocities are adjusted with an inverse model to allow the mass, salt and heat conservation (Germineaud et al., 2016; Germineaud et al., in prep). All water transports in distinct layers associated with their uncertainties are given in Table 4.

[43] The calculation is reported in Figure $6 \mathrm{c}$ for $\mathrm{Nd}$ in the lower thermocline layer, and budgets of the other layers are reported in Table 4. The only missing dREE concentration data was for the upper thermocline at station 29. We therefore estimated these values using its neighbor stations due to their similarity in dREE concentrations (stations 04, 34 and 36). The

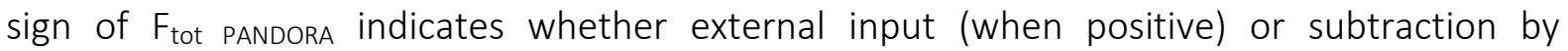
scavenging process (when negative) is dominating the $\mathrm{Nd}$ fate along the pathway of the different water layers. A Monte Carlo statistic method was used to estimate uncertainties of the fluxes.

[44] A significant positive net flux $\left(F_{\text {total PANDORA }}=145.1 \pm 45.8 \mathrm{t}(\mathrm{Nd}) \cdot \mathrm{yr}^{-1}\right.$; Figure $\left.6 \mathrm{c}\right)$ is observed in the Lower Thermocline Layer, suggesting that waters transported equatorward through the Solomon Sea are enriched in dNd. This is consistent with Grenier et al. (2014) who found enrichment in the lower thermocline layer downstream the Solomon Sea and suggested that this enrichment occurred inside the sea itself. Enrichments are also observed in the other layers, except for IW. However, the large uncertainties affecting the calculated fluxes prevent us to draw firm conclusions for these layers (Table 4). Our flux estimations are approximately 50 times those of Grenier et al. (2014). This difference likely reflects that the whole region is considered here whereas Grenier et al. (2014) only focused on inputs into specific current veins.

[45] Surprisingly, in the upper thermocline, our results do not show a clear and strong enrichment in $\mathrm{Nd}$ content. Our hypothesis is that the $\mathrm{dNd}$ (dREE) external inputs, likely weathered from the surrounding islands and discharged into the Solomon Sea, are balanced 
by the dNd ( $d R E E$ ) removal by scavenging, consistent with the productivity of the area (Radenac et al., 2013; Bonnet et al., 2015). This will be confirmed or disproved with the isotopic $\mathrm{Nd}$ signatures.

\subsection{Interesting features in the dREE profiles}

[46] This section discusses more specifically the dREE PAAS-normalized patterns and anomalies. Calculated dREE anomalies allow identifying if, after normalization to the PAAS values, an element is enriched or depleted relatively to its neighbors. Thus, they can bring information about the dominant mechanisms affecting the local marine REE pool. Anomalies are calculated following the equations below (Bau et al., 2004; Bau et al., 1996; Friend et al., 2008; Garcia-Solsona et al., 2014). In the following, we will discuss more specifically the La, $\mathrm{Ce}, \mathrm{Eu}$ and $\mathrm{Yb}$ anomalies.

$$
\begin{aligned}
\frac{\mathrm{La}}{\mathrm{La}^{*}} & =\frac{[\mathrm{La}]_{\mathrm{n}}}{3[\mathrm{Pr}]_{\mathrm{n}}-2[\mathrm{Nd}]_{\mathrm{n}}} \\
\frac{\mathrm{Eu}}{\mathrm{Eu}^{*}} & =\frac{4 \times[\mathrm{Eu}]_{\mathrm{n}}}{3[\mathrm{Sm}]_{\mathrm{n}}+[\mathrm{Dy}]_{\mathrm{n}}}
\end{aligned}
$$$$
\frac{\mathrm{Ce}}{\mathrm{Ce}^{*}}=\frac{[\mathrm{Ce}]_{\mathrm{n}}}{2[\mathrm{Pr}]_{\mathrm{n}}-[\mathrm{Nd}]_{\mathrm{n}}}
$$

$$
\frac{\mathrm{Yb}}{\mathrm{Yb}^{*}}=\frac{[\mathrm{Yb}]_{\mathrm{n}}}{2[\mathrm{Er}]_{\mathrm{n}}+[\mathrm{Dy}]_{\mathrm{n}}}
$$

[47] A complementary parameter to the anomalies is the ratio between normalized LREE and HREE, expressed as $\mathrm{Nd}_{n} / \mathrm{Yb}_{n}$, which provides information about the slope of the normalized dREE pattern. Figure 7 shows the vertical profiles for the La, Eu, Yb anomalies and the $\mathrm{Nd}_{n} / \mathrm{Yb}_{n}$ slope. Normalization of the dREE to PAAS implies that without any fractionation between the dREE within the water column, the dREE pattern would be flat $-\mathrm{Nd}_{n} / \mathrm{Yb}_{n}$ close to 1- and no anomaly would be observed. The full data set is reported in Table 1 . The $\mathrm{REE} / \mathrm{REE}^{*}$ ratio reveals an enrichment relatively to its neighbors when its value is larger than one, and a depletion in the opposite case.

\subsubsection{Dissolved Lanthanum anomaly}

[48] All the dissolved Solomon Sea samples collected during Pandora are characterized by positive La anomalies, with values ranging from 3-6 (Figure 7). Such positive values have been observed elsewhere in the ocean and are believed to result from a differential La behavior due to the lacking electron in the $4 \mathrm{f}$ shell of the La atom, suspected to increase its stability in seawater, so called the "tetrad" or "double-double" effect (Byrne and Kim, 1990; Byrne and Sholkovitz, 1996; De Baar et al., 1985b; Elderfield, 1988; Garcia-Solsona et al., 2014; Grenier et al., submitted; Jong Hyeon and Byrne, 1993; McLennan, 1994). In particular, while dLa is released from riverine particles when freshwaters are discharged into the ocean, more efficient releasing than scavenging rate could cause local positive dLa anomalies (Lawrence and Kamber, 2006). Nevertheless, the positive dLa anomalies in the Solomon Sea are observed at all the monitored stations even that located far from the coastline. Knowing that the oceanic dREE pattern mostly results from dissolved-particle exchange also occurring in the open ocean (Tachikawa et al. 1999), we are seeking if another factor than the "Tetrad effect » only could govern the La behavior in the Coral and Solomon Seas. 
[49] Due to the similar atomic size and close chemical properties of barium and lanthanum, they are suspected to display coupled behavior in seawater (Garcia-Solsona et al., 2014; Haley et al., 2014; Grenier et al., submitted). Bishop (1988) and Dehairs et al. (1980) demonstrated that oceanic dBa distribution is governed by the surface biologically driven formation of barite crystal $\left(\mathrm{BaSO}_{4}\right)$ followed by its dissolution at depth. Coupling between the two elements could therefore occur if dLa is associated to the $\mathrm{dBa} / \mathrm{barite}$ cycle within the water column (Dehairs et al., 1980; Garcia-Solsona et al., 2014; Grenier et al., Submitted in 2017; Guichard et al., 1979).

[50] Figure 8 displays strong correlations between dissolved dLa and dBa measured on the same samples at all the stations, with $R_{\text {coefficient }}^{2} 0.95 \pm 0.04$. These results support the idea that dLa marine behavior is to some extent coupled to the $\mathrm{dBa}$ one. The marked enrichment of dLa over dBa at the " coastal » stations 71, 73 and 77 could reflect the efficient release of dLa from the lithogenic material discussed in Lawrence and Kamber (2006). Nonetheless, the lack of particulate barium data so called as barium excess $\left(\mathrm{Ba}_{\mathrm{xs}}\right)$ prevents us to go farther in discussing the dLa anomaly in the Solomon Sea.

\subsubsection{Dissolved Europium anomaly}

[51] A positive dEu anomaly is characterized for all normalized dREE patterns whatever the water mass type and location of the sample. Such positive dEu anomalies were observed in previous studies (Amakawa et al., 2000; Nozaki et al., 1999) but were not discussed till the work of Zhang et al. (2008) and the more recent observations of Grenier et al. (2013; Submitted in 2017). Either on the Kerguelen plateau (Grenier et al., Submitted in 2017; Zhang et al., 2008) or in the Equatorial Pacific (Grenier et al., 2013) these authors invoke a remaining signature of lithogenic inputs of basaltic origin, local basalts being characterized by a positive Eu anomaly. In our studied area, the conspicuous feature of dEu anomaly shows maxima in the surface water, reach a minimum at intermediate depths $(\sim 500 \mathrm{~m})$ and then slightly increase again toward bottom except in the Coral Sea profiles characterized by fairly constant dEu anomalies at depths below $1000 \mathrm{~m}$ (Figure 7).

[52] The higher dEu anomalies ( 1.3) at the surface likely reflect relatively recent enrichment of lithogenic origin, which could be of coastal or atmospheric source. Indeed, the Solomon Sea is surrounded by volcanic islands whose basaltic material is enriched in Eu (Grenier et al., 2013). Besides, some volcanoes such as Rabaul, Ulawun and Bagana, are still very active (Lefèvre et al., 2008; Slemons et al., 2010).

[53] Deeper than $1000 \mathrm{~m}$, the increase of the positive $\mathrm{dEu}$ anomaly could result from two non-exclusive processes: i) the release of $\mathrm{dREE}$ in intermediate and deep layers caused by the dissolution of basaltic sediments deposited on the margins by submarine weathering followed by the advection of the enriched waters (Grenier et al., 2013; Jeandel et al., 2011; Zhang et al., 2008). As already underlined by Grenier et al. (2013), the preservation of this $\mathrm{dEu}$ anomaly is made possible by the fact that the residence time of dEu (320-820 yrs; Alibo and Nozaki, 1999) is larger than that of the thermocline waters across the studied area (1015 yrs, Fukumori et al., 2004)) ; ii) Grenier et al. (Submitted) suggested that the deep positive dEu anomaly could also result from LREE/MREE preferential scavenging onto surface coating of organic particles in surface water followed by their release at depth (Sholkovitz et al., 
1994). Ongoing measurements of the filtered particles might help to identify the importance of such processes in the Solomon Sea.

\subsubsection{Dissolved Ce anomalies}

[54] Contrastingly to dLa and dEu, the marked depletion of dCe is observed at all the studied stations although less pronounced in the surface and subsurface waters above $500 \mathrm{~m}$ $\left(\mathrm{dCe} / \mathrm{dCe}^{*} \geq 0.4\right)$. Consistent with the higher $\mathrm{dEu}$ anomalies discussed above, these less pronounced dCe anomalies might reflect recent lithogenic inputs, which are more affecting the upper layers. Higher $\mathrm{dCe}$ anomalies $\left(\mathrm{dCe} / \mathrm{dCe}{ }^{*} \geq 0.5\right)$ were found mostly in the surface water of stations located around the Solomon archipelago (e.g. stations 42, 43, 60), indicating more recent inputs. Specifically, one upper thermocline sample at station $71(160 \mathrm{~m})$ shows a significantly high dCe anomaly ( 1.4). However, this station is very close to the coast and was located here to identify any margin input to the waters conveyed by NGCU through the slit between New Britain and Woodlark islands; the existence of strong inputs is thus confirmed by the high positive Ce anomaly observed at this station.

\subsubsection{HREE behavior}

[55] The vertical dHREE profiles show more convex shapes than that of the other dREE (Figure 3). In addition, the $\mathrm{Nd}_{n} / \mathrm{Yb}_{n}$ slopes are increasing below intermediate depths at a rate of two up to the seafloor (Figure 7). Such rapid increase was already observed although not always discussed (Grenier et al., Submitted; Haley et al., 2014; Jeandel et al., 2013; MolinaKescher et al., 2014). Bertram and Elderfield (1993) noticed that coupling between dREE and dSi cycle could be more significant for the dHREE than for the dLREE and recent works of Akagi (2013) and Grenier et al. (Submitted in 2017) seem to confirm this observation. Here we propose to explore the link between dHREE (represented by $d Y b$ ) and the dSi cycle in Figure 9. The high values of the correlation coefficients $\left(\sim R^{2}=0.9\right)$ support this hypothesis again. However, a break of the slope is observed at around $700 \mathrm{~m}$, the $\mathrm{dYb}$ rate of increase diminishing by a factor of 2 below this depth. Although this observation is consistent with that of Grenier et al. (Submitted in 2017), the $\Delta d Y b / \Delta d S i$ slope observed in Figure 9 for $d S i$ concentrations less than $40 \mu \mathrm{mol} . \mathrm{kg}^{-1}$ (samples $<700 \mathrm{~m}, \Delta \mathrm{dYb} / \Delta \mathrm{dSi} \approx 0.09$ ) is larger than that of these authors $(\Delta \mathrm{d} Y \mathrm{~b} / \Delta \mathrm{dSi} \approx 0.01)$. This difference could reflect the impact on both tracer cycles of the different ecosystems characterizing the two areas: the huge diatom bloom on the Kerguelen plateau leads to a dramatic increase of particulate biogenic silica and a subsequent major dSi depletion in the upper layers. Although this scavenging is expected to also deplete $\mathrm{dYb}$, the relative rates of the scavenging processes are likely favoring the $d S i$ subtraction in the Southern Ocean. It is more complex in the Solomon Sea which is known as a hot spot for $\mathrm{N}_{2}$ fixation due to diazotroph blooms (Ganachaud et al., 2017). Interestingly, roughly $10 \%$ of the nitrogen fixed by the diazotroph species was found to be transferred into diatoms leading to a growth of diatom abundance (Bonnet et al., 2016). This moderate diatom growth compared to the Kerguelen diatom bloom is consistent with the higher $\Delta \mathrm{dYb} / \Delta \mathrm{dSi}$ ratio observed here. In the deep layers, the observed slope $\Delta \mathrm{HREE} / \Delta \mathrm{dSi} \approx 0.04$ is consistent with that found in Grenier et al. (submitted) and in the work of Bertram and Elderfield in the intermediate, deep and bottom waters of the Pacific Ocean (See figure 8 of Bertram and Elderfield, 1993). 
[56] The preceding two sections underlined several common features indicating that the dNd (dREE) enrichment calculated with our box model (section 5.1) results from the release of $d N d$ ( $d R E E)$ from the surface and submarine weathering of the surrounding islands. Several complementary parameters allowed us to confirm the nature of this external dNd source and its signature in the dissolved phase. Surface dEu enrichments, larger dCe values are consistent with similar high concentrations observed in the $\mathrm{dAl}$ and $\mathrm{dMn}$ profiles (Michael et al., 2017). In addition, consistent maxima of dREE, dAl and dMn are also observed at some specific points in the thermocline and intermediate layers (i.e: stations $04-1000 \mathrm{~m} ; 10-350 \mathrm{~m}$; 20-700m; 42-700 m; 71-300 m; 77-500 m). Such consistencies underline that submarine weathering took place along the island margins since these enrichments could not result from any surface or bottom external inputs. The Solomon Sea is an area of strong internal wave activity and associated mixing (Alberty et al., 2017). It has been suggested that when the continental slope is close to a critical angle, the strong bottom shear velocities enhance sediment resuspension and potential release of chemical elements (Cacchione et al., 2002). Nepheloid layers might result from these processes and be advected further from the slope, contributing to the observed enrichments. The exact location of such resuspension events could be an interesting investigation for future studies.

\section{Conclusion}

[57] This study presented vertical profiles of dREE concentrations for 143 samples and 21 stations collected in the Coral and Solomon Seas as part of the PANDORA cruise (boreal summer 2012). Although the profile shapes display common dREE features -i.e surface depleted and enriched at depth- the dREE patterns and anomalies could be discussed and lead to interesting results.

[58] A first striking result is that, despite the very high dynamic variability of the Solomon Sea, with strong variables currents and recirculations, eddies, internal waves, the REE concentrations are very close to those previously measured at the same locations, confirming the robustness of this chemical family as tracers of continental/ocean exchanges.

[59] A pronounced dissolved dLa positive anomaly is estimated (dLa*/dLa varying between 3 and 6). The classical interpretation relates to the "tetrad" effect. However, our data show an excellent correlation between $\mathrm{dLa}$ and $\mathrm{dBa}$ which could suggest a coupling between both elements, lanthanum being associated with the dissolved barium/barite cycle. The particulate $\mathrm{La}$ and $\mathrm{Ba}_{\mathrm{xs}}$ data will likely help to dig this hypothesis farther.

[60] An europium positive anomaly is also found in all of our patterns with higher $\mathrm{dEu} / \mathrm{dEu}$ values in the upper layers. This striking feature agrees with previous observations (Grenier et al., submitted; Grenier et al., 2013; Zhang et al., 2008) and suggests that the enrichment calculated with the box model is lithogenic and of basaltic origin, consistent with the geology of the surrounding islands. The lithogenic source is later confirm by dCe anomaly

[61] dHREE behaviour seem to be the most influenced by the Si cycle as suggested by Akagi (2013) and also observed by Grenier et al. (submitted). 
[62] A box model allowed us to establish the net $d N d(d R E E)$ fluxes of the waters flowing

672 673 674 675 676 677 678 679 680 681 682 683 684 685 686 687 688 689 equatorward through the Solomon Sea. Significant enrichment is observed $\left(F_{\text {total }}\right.$ PANDORA $=$ $145.1 \pm 45.8 \mathrm{t}(\mathrm{Nd}) \cdot \mathrm{yr}^{-1}$ ) for the Lower Thermocline Layer (between 200-500 m). This enrichment is of main interest, as these waters will eventually be advected till the equatorial eastern Pacific through the lower part of the EUC (Slemons et al., 2010; Grenier et al., 2013). By contrast, the lack of clear net enrichment in the upper thermocline is surprising in this area bounded by continental margins and with many potential sources. This points to the complexity of boundary exchange processes, and to the need of better understanding the removal processes of the oceanic dissolved material. The ongoing analysis of the associated particles and $\mathrm{Nd}$ isotopic composition will help to refine and conclude about the robustness of these net exchange fluxes.

\section{Acknowledments}

[63] This work is a contribution to the CLIVAR/SPICE and GEOTRACES International programs. We are grateful to the ship crew (RV l'Atalante) who made possible the various in situ measurements, thereby requiring skills and care. The collaboration with SOPAC/SPC, PIGOOS, and University of Papua New Guinea was greatly appreciated. We also acknowledge Dr Benjamin Dupont for his volunteering help during the on-board sampling. The accomplishments were made possible through concurrent contributions of national funding agencies. The Pandora cruise has been co-funded by NSF grant OCE1029487, and by ANR project ANR- 09-BLAN-0233-01 and INSU/LEFE project Solwara (IDAO and CYBER). All the authors whose work contributed to the database GEOTRACES are acknowledged (http://www.geotraces.org; http://www.solomon seaoceanography.org). Besides of that, we would like to thank the research TIM at LEGOS for insightful comment and encouragement. C. Pradoux and F. Candaudap are thanked for their technical support.

\section{References}

Akagi, T., 2013. Rare earth element (REE)-silicic acid complexes in seawater to explain the incorporation of REEs in opal and the "leftover" REEs in surface water: New interpretation of dissolved REE distribution profiles. Geochimica et Cosmochimica Acta, 113: 174-192.

Akagi, T., Fu, F.-f., Hongo, Y., Takahashi, K., 2011. Composition of rare earth elements in settling particles collected in the highly productive North Pacific Ocean and Bering Sea: Implications for siliceous-matter dissolution kinetics and formation of two REE-enriched phases. Geochimica et Cosmochimica Acta, 75(17): 4857-4876.

Alberty, M. S., J. Sprintall, J. MacKinnon, A. Ganachaud, S. Cravatte, G. Eldin, C. Germineaud, and A. Melet (2017), Spatial patterns of mixing in the Solomon Sea, J. Geophys. Res. Oceans, 122, doi:10.1002/2016JC012666.

Alibo, D.S., Nozaki, Y., 1999. Rare earth elements in seawater: particle association, shalenormalization, and Ce oxidation. Geochimica et Cosmochimica Acta, 63(3): 363-372.

Amakawa, H., Alibo, D.S., Nozaki, Y., 2000. Nd isotopic composition and REE pattern in the surface waters of the eastern Indian Ocean and its adjacent seas. Geochimica et Cosmochimica Acta, 64(10): 1715-1727.

Bau, M., Alexander, B., Chesley, J.T., Dulski, P., Brantley, S.L., 2004. Mineral dissolution in the Cape Cod aquifer, Massachusetts, USA: I . Reaction stoichiometry and impact of accessory feldspar and glauconite on strontium isotopes, solute concentrations, and REY 
distribution11Associate Editor: L. M. Walter. Geochimica et Cosmochimica Acta, 68(6): 11991216.

Bau, M., Koschinsky, A., Dulski, P., Hein, J.R., 1996. Comparison of the partitioning behaviours of yttrium, rare earth elements, and titanium between hydrogenetic marine ferromanganese crusts and seawater. Geochimica et Cosmochimica Acta, 60(10): 1709-1725.

Behrens, M. et al., 2016. Rapid and precise analysis of rare earth elements in small volumes of seawater - Method and intercomparison, 186.

Bertram, C.J., Elderfield, H., 1993. The geochemical balance of the rare earth elements and neodymium isotopes in the oceans. Geochimica et Cosmochimica Acta, 57(9): 1957-1986.

Bishop, J.K.B., 1988. The barite-opal-organic carbon association in oceanic particulate matter. Nature, 332: 341.

Bonnet, S. et al., 2016. Diazotroph derived nitrogen supports diatom growth in the South West Pacific: A quantitative study using nanoSIMS. Limnology and Oceanography, 61(5): 15491562.

Bostock, H.C., Opdyke, B.N., Williams, M.J.M., 2010. Characterising the intermediate depth waters of the Pacific Ocean using $\delta 13 \mathrm{C}$ and other geochemical tracers. Deep Sea Research Part I: Oceanographic Research Papers, 57(7): 847-859.

Byrne, R.H., Kim, K.-H., 1990. Rare earth element scavenging in seawater. Geochimica et Cosmochimica Acta, 54(10): 2645-2656.

Byrne, R.H., Sholkovitz, E.R., 1996. Chapter 158 Marine chemistry and geochemistry of the lanthanides, Handbook on the Physics and Chemistry of Rare Earths. Elsevier, pp. 497-593.

Cacchione, D. A., L. F. Pratson, and A. S. Ogston, 2002: The Shaping of Continental Slopes by Internal Tides. Science, 296, 724, doi:10.1126/science.1069803.

Chung, C.-H., Brenner, I., You, C.-F., 2009. Comparison of microconcentric and membranedesolvation sample introduction systems for determination of low rare earth element concentrations in surface and subsurface waters using sector field inductively coupled plasma mass spectrometry. Spectrochimica Acta Part B: Atomic Spectroscopy, 64(9): 849856.

Cravatte, S. et al., 2011. Observed circulation in the Solomon Sea from SADCP data. Progress in Oceanography, 88(1): 116-130.

Cravatte, S., S. Kessler, W., Marin, F., 2012. Intermediate Zonal Jets in the Tropical Pacific Ocean Observed by Argo Floats, 42, 1475-1485 pp.

Crusius, J., Calvert, S., Pedersen, T., Sage, D., 1996. Rhenium and molybdenum enrichments in sediments as indicators of oxic, suboxic and sulfidic conditions of deposition. Earth and Planetary Science Letters, 145(1): 65-78.

Davis, R. E., W. S. Kessler and J. T. Sherman, 2012: Gliders measure western boundary current transport from the South Pacific to the equator. J. Phys. Oceanogr., 42, 2001-2013. doi:10.1175/JPO-D-12-022.1.

De Baar, H.J.W., Bacon, M.P., Brewer, P.G., 1983. Rare-earth distributions with a positive Ce anomaly in the Western North Atlantic Ocean. Nature, 301: 324.

De Baar, H.J.W., Bacon, M.P., Brewer, P.G., Bruland, K.W., 1985a. Rare earth elements in the Pacific and Atlantic Oceans. Geochimica et Cosmochimica Acta, 49(9): 1943-1959.

De Baar, H.J.W., Brewer, P.G., Bacon, M.P., 1985b. Anomalies in rare earth distributions in seawater: Gd and Tb. Geochimica et Cosmochimica Acta, 49(9): 1961-1969.

Deacon, G.E.R., 1937. The hydrology of the southern ocean. Discovery Reports, 1-124 pp.

Dehairs, F., Chesselet, R., Jedwab, J., 1980. Discrete suspended particles of barite and the barium cycle in the open ocean. Earth and Planetary Science Letters, 49(2): 528-550.

Elderfield, H., 1988. The oceanic chemistry of the rare-earth elements. Philosophical Transactions of the Royal Society of London. Series A, Sciences, 325(1583): 105. Mathematical and Physical 
Elrod Virginia, A., Berelson William, M., Coale Kenneth, H., Johnson Kenneth, S., 2004. The flux of iron from continental shelf sediments: A missing source for global budgets. Geophysical Research Letters, 31(12).

Fine, R.A., Lukas, R., Bingham, F.M., Warner, M.J., Gammon, R.H., 1994. The western equatorial Pacific: A water mass crossroads. Journal of Geophysical Research: Oceans, 99(C12): 2506325080.

Friend, C.R.L., Nutman, A.P., Bennett, V.C., Norman, M.D., 2008. Seawater-like trace element signatures $(\mathrm{REE}+\mathrm{Y})$ of Eoarchaean chemical sedimentary rocks from southern West Greenland, and their corruption during high-grade metamorphism. Contributions to Mineralogy and Petrology, 155(2): 229-246.

Freydier, R., Dupré, B., Polve, M., 1995. Analyses by inductively coupled plasma mass spectrometry of Ba concentrations in water and rock samples. Comparison between isotope dilution and external calibration with or without internal standard, 1.

Fukumori, I., Lee, T., Cheng, B., Menemenlis, D., 2004. The Origin, Pathway, and Destination of Niño3 Water Estimated by a Simulated Passive Tracer and Its Adjoint. Journal of Physical Oceanography, 34(3): 582-604.

Ganachaud, A. et al., 2014. The Southwest Pacific Ocean circulation and climate experiment (SPICE). Journal of Geophysical Research: Oceans, 119(11): 7660-7686.

Ganachaud, A. et al., 2017. The Solomon Sea: its circulation, chemistry, geochemistry and biology explored during two oceanographic cruises. Elem Sci Anth, 5:33.

Garcia-Solsona, E. et al., 2014. Rare earth elements and Nd isotopes tracing water mass mixing and particle-seawater interactions in the SE Atlantic. Geochimica et Cosmochimica Acta, 125: 351-372.

Gasparin, F., Ganachaud, A., Maes, C., 2011. A western boundary current east of New Caledonia: Observed characteristics. Deep Sea Research Part I: Oceanographic Research Papers, 58(9): 956-969.

Germineau, C., 2016. Circulation Océanique et Variabilité en Mer des Salomon, Université Toulouse 3 Paul Sabatier (UT3 Paul Sabatier), 240 pp.

Germineaud, C. et al., 2016. Pathways and water mass properties of the thermocline and intermediate waters in the Solomon Sea, 46.

Goldberg, E.D., Koide, M., Schmitt, R.A., Smith, R.H., 1963. Rare-Earth distributions in the marine environment. Journal of Geophysical Research, 68(14): 4209-4217.

Goldstein, S., Hemming, S.R., 2003. Long-lived Isotopic Tracers in Oceanography, Paleoceanography, and Ice-sheet Dynamics, 6, 453-489 pp.

Grenier, M. et al., 2011. From the western boundary currents to the Pacific Equatorial Undercurrent: Modeled pathways and water mass evolutions. Journal of Geophysical Research: Oceans, 116(C12): n/a-n/a.

Grenier, M. et al., Submitted in 2017. Differentiating lithogenic supplies, water mass transport and biological processes on and off the Kerguelen Plateau using rare earth element concentrations and neodymium isotopic compositions, Frontiers in Marine Science.

Grenier, M., Jeandel, C., Cravatte, S., 2014. From the subtropics to the equator in the Southwest Pacific: Continental material fluxes quantified using neodymium data along modeled thermocline water pathways. Journal of Geophysical Research: Oceans, 119(6): 3948-3966.

Grenier, M. et al., 2013. From the subtropics to the central equatorial Pacific Ocean: Neodymium isotopic composition and rare earth element concentration variations. Journal of Geophysical Research: Oceans, 118(2): 592-618.

Guichard, F., Church, T.M., Treuil, M., Jaffrezic, H., 1979. Rare earths in barites: distribution and effects on aqueous partitioning. Geochimica et Cosmochimica Acta, 43(7): 983-997.

Haley, B.A., Frank, M., Hathorne, E., Pisias, N., 2014. Biogeochemical implications from dissolved rare earth element and $\mathrm{Nd}$ isotope distributions in the Gulf of Alaska. Geochimica et Cosmochimica Acta, 126: 455-474. 
Haley, B.A., Klinkhammer, G.P., McManus, J., 2004. Rare earth elements in pore waters of marine sediments. Geochimica et Cosmochimica Acta, 68(6): 1265-1279.

Hanawa, K.a.L.D.T., 2001. Mode Waters. Ocean Circulation and Climate. In: Church, G.S.a.J. (Editor). International Geophysics Series, pp. 373-386.

Jeandel, C., Delattre, H., Grenier, M., Pradoux, C., Lacan, F., 2013. Rare Earth Concentrations and Nd isotopes reveal exchange processes along the East Pacific Rise, South East Pacific Ocean. Geochemistry, Geophysics, Geosystems, 14(2): 328-341.

Jeandel, C. et al., 2011. Ocean margins: The missing term in oceanic element budgets? Eos, Transactions American Geophysical Union, 92(26): 217-218.

Johnson, G.C., McPhaden, M.J., 1999. Interior Pycnocline Flow from the Subtropical to the Equatorial Pacific Ocean. Journal of Physical Oceanography, 29(12): 3073-3089.

Johnson, G.C., Toole, J.M., 1993. Flow of deep and bottom waters in the Pacific at $10^{\circ} \mathrm{N}$. Deep Sea Research Part I: Oceanographic Research Papers, 40(2): 371-394.

Johnson Kenneth, S. et al., 2003. Surface ocean-lower atmosphere interactions in the Northeast Pacific Ocean Gyre: Aerosols, iron, and the ecosystem response. Global Biogeochemical Cycles, 17(2).

Jong Hyeon, L., Byrne, R.H., 1993. Complexation of trivalent rare earth elements (Ce, Eu, Gd, Tb, Yb) by carbonate ions. Geochimica et Cosmochimica Acta, 57(2): 295-302.

Kawabe, M., Fujio, S., 2010. Pacific ocean circulation based on observation. Journal of Oceanography, 66(3): 389-403.

Keppler, L., Cravatte, S., Chaigneau, A., Pegliasco, C., Gourdeau, L., \& Singh, A. (2018). Observed characteristics and vertical structure of mesoscale eddies in the southwest tropical Pacific. Journal of Geophysical Research: Oceans, 123. https://doi.org/10.1002/ 2017JC013712

Kessler, W.S., 1999. Interannual Variability of the Subsurface High Salinity Tongue South of the Equator at $165^{\circ} \mathrm{E}$. Journal of Physical Oceanography, 29(8): 2038-2049.

Kessler, W.S., Cravatte, S., 2013. Mean circulation of the Coral Sea. Journal of Geophysical Research: Oceans, 118(12): 6385-6410.

Klinkhammer, G.P., Chan, L.H., 1990. Determination of barium in marine waters by isotope dilution inductively coupled plasma mass spectrometry. Analytica Chimica Acta, 232: 323-329

Lacan, F., Jeandel, C., 2001. Tracing Papua New Guinea imprint on the central Equatorial Pacific Ocean using neodymium isotopic compositions and Rare Earth Element patterns. Earth and Planetary Science Letters, 186(3): 497-512.

Lawrence, M.G., Kamber, B.S., 2006. The behaviour of the rare earth elements during estuarine mixing-revisited. Marine Chemistry, 100(1): 147-161.

Lefèvre, D., Guigue, C., Obernosterer, I., 2008. The metabolic balance at two contrasting sites in the Southern Ocean: The iron-fertilized Kerguelen area and HNLC waters. Deep Sea Research Part II: Topical Studies in Oceanography, 55(5): 766-776.

Liu, Y.G., Miah, M.R.U., Schmitt, R.A., 1988. Cerium: A chemical tracer for paleo-oceanic redox conditions. Geochimica et Cosmochimica Acta, 52(6): 1361-1371.

Mackey, D.J., O'Sullivan, J.E.O., Watson, R.J., 2002. Iron in the western Pacific: a riverine or hydrothermal source for iron in the Equatorial Undercurrent?, 49, 877-893 pp.

McCartney, M.S., 1977. Subantartic Mode Water, Geogre Deacon 70th anniversary Volume. A Voyage of Discovery, 103-119 pp.

McLennan, 1989. Rare earth elements in sedimentary rocks; influence of provenance and sedimentary processes. Reviews in Mineralogy and Geochemistry, 21(1): 169-200.

McLennan, S.M., 1994. Rare earth element geochemistry and the "tetrad" effect. Geochimica et Cosmochimica Acta, 58(9): 2025-2033.

Michael, S., Resing, J., Lacan, F., Pradoux, C., Jeandel, C., 2017. Using Aluminum and Manganese to Constrain the Contribution of the Solomon Sea to the Equatorial Undercurrent Trace Metal Pool, Goldschmidt, Paris. 
Molina-Kescher, M., Frank, M., Hathorne, E., 2014. South Pacific dissolved Nd isotope compositions and rare earth element distributions: Water mass mixing versus biogeochemical cycling. Geochimica et Cosmochimica Acta, 127: 171-189.

Nozaki, Y., 1986. 226Ra222Rn210Pb systematics in seawater near the bottom of the ocean. Earth and Planetary Science Letters, 80(1): 36-40.

Nozaki, Y., Alibo, D.-S., Amakawa, H., Gamo, T., Hasumoto, H., 1999. Dissolved rare earth elements and hydrography in the Sulu Sea. Geochimica et Cosmochimica Acta, 63(15): 2171-2181.

Nozaki, Y., Alibo, D.S., 2003a. Dissolved rare earth elements in the Southern Ocean, southwest of Australia: Unique patterns compared to the South Atlantic data. GEOCHEMICAL JOURNAL, 37(1): 47-62.

Nozaki, Y., Alibo, D.S., 2003b. Importance of vertical geochemical processes in controlling the oceanic profiles of dissolved rare earth elements in the northeastern Indian Ocean. Earth and Planetary Science Letters, 205(3): 155-172.

Orsi, A.H., Johnson, G.C., Bullister, J.L., 1999. Circulation, mixing, and production of Antarctic Bottom Water. Progress in Oceanography, 43(1): 55-109.

Orsi, A.H., Whitworth, T., Nowlin, W.D., 1995. On the meridional extent and fronts of the Antarctic Circumpolar Current. Deep Sea Research Part I: Oceanographic Research Papers, 42(5): 641673.

Pahnke, K. et al., 2012. GEOTRACES intercalibration of neodymium isotopes and rare earth element concentrations in seawater and suspended particles. Part 2: Systematic tests and baseline profiles. Limnology and Oceanography: Methods, 10(4): 252-269.

Piepgras, D.J., Jacobsen, S.B., 1992. The behavior of rare earth elements in seawater: Precise determination of variations in the North Pacific water column. Geochimica et Cosmochimica Acta, 56(5): 1851-1862.

Qu, T., Gao, S., Fukumori, I., Fine, R.A., Lindstrom, E.J., 2008. Subduction of South Pacific waters. Geophysical Research Letters, 35(2): n/a-n/a.

Qu, T., Gao, S., Fukumori, I., Fine, R.A., Lindstrom, E.J., 2009. Origin and Pathway of Equatorial $13^{\circ} \mathrm{C}$ Water in the Pacific Identified by a Simulated Passive Tracer and Its Adjoint. Journal of Physical Oceanography, 39(8): 1836-1853.

Qu, T., Lindstrom, E.J., 2002. A Climatological Interpretation of the Circulation in the Western South Pacific. Journal of Physical Oceanography, 32(9): 2492-2508.

Qu, T., Lindstrom, E.J., 2004. Northward Intrusion of Antarctic Intermediate Water in the Western Pacific. Journal of Physical Oceanography, 34(9): 2104-2118.

Radenac, M.-H., Messié, M., Léger, F., Bosc, C., 2013. A very oligotrophic zone observed from space in the equatorial Pacific warm pool. Remote Sensing of Environment, 134: 224-233.

Reid, J.L., 1986. On the total geostrophic circulation of the South Pacific Ocean: Flow patterns, tracers and transports. Progress in Oceanography, 16(1): 1-61.

Reid, J.L., 1997. On the total geostrophic circulation of the pacific ocean: flow patterns, tracers, and transports. Progress in Oceanography, 39(4): 263-352.

Roemmich, D., Hautala, S., Rudnick, D., 1996. Northward abyssal transport through the Samoan passage and adjacent regions. Journal of Geophysical Research: Oceans, 101(C6): 1403914055.

Rousseau, T.C.C. et al., 2013. Rare earth element analysis in natural waters by multiple isotope dilution - sector field ICP-MS. Journal of Analytical Atomic Spectrometry, 28(4): 573-584.

Rousseau, T.C.C. et al., 2015. Rapid neodymium release to marine waters from lithogenic sediments in the Amazon estuary. Nature Communications, 6: 7592.

Sholkovitz, E.R., Landing, W.M., Lewis, B.L., 1994. Ocean particle chemistry: The fractionation of rare earth elements between suspended particles and seawater. Geochimica et Cosmochimica Acta, 58(6): 1567-1579. 
Slemons, L.O., Murray, J.W., Resing, J., Paul, B., Dutrieux, P., 2010. Western Pacific coastal sources of iron, manganese, and aluminum to the Equatorial Undercurrent. Global Biogeochemical Cycles, 24(3): n/a-n/a.

Sokolov, S., Rintoul, S., 2000. Circulation and water masses of the southwest Pacific: WOCE Section P11, Papua New Guinea to Tasmania. Journal of Marine Research, 58(2): 223-268.

Tachikawa, K., Athias, V., Jeandel, C., 2003. Neodymium budget in the modern ocean and paleo-oceanographic implications. Journal of Geophysical Research: Oceans, 108(C8).

Tachikawa, K., Jeandel, C., Roy-Barman, M., 1999. A new approach to the Nd residence time in the ocean: the role of atmospheric inputs. Earth and Planetary Science Letters, 170(4): 433-446.

Takebe, M., 2005. Carriers of Rare Earth Elements in Pacific Deep-Sea Sediments. The Journal of Geology, 113(2): 201-215.

Talley, L.D., 1996. Antarctic Intermediate Water in the South Atlantic. In: The South Atlantic. Springer, Berlin.

Talley, L.D., 2007. Hydrographic Atlas of the World Ocean Circulation Experiment (WOCE) Volume 2: Pacific Ocean. WOCE International Project Office.

Tomczak, M., Godfrey, J.S., 2003. Hydrology of the Pacific Ocean, Regional Oceanography: An Introduction, 2nd Improved Edition. Daya Publishing House, Delhi: 137-174.

Tomczak, M., Hao, D., 1989. Water masses in the thermocline of the coral sea. Deep Sea Research Part A. Oceanographic Research Papers, 36(10): 1503-1514.

Tsimplis, M.N., Bacon, S., Bryden, H.L., 1998. The circulation of the subtropical South Pacific derived from hydrographic data. Journal of Geophysical Research: Oceans, 103(C10): 21443-21468.

Tsuchiya, M., 1981. The Origin of the Pacific Equatorial $13^{\circ} \mathrm{C}$ Water. Journal of Physical Oceanography, 11(6): 794-812.

Tsuchiya, M., Lukas, R., Fine, R.A., Firing, E., Lindstrom, E., 1989. Source waters of the Pacific Equatorial Undercurrent. Progress in Oceanography, 23(2): 101-147.

Tsuchiya, M., Talley, L., 1998. A Pacific hydrographic section at $88^{\circ} \mathrm{W}$ : Water-property distribution, $1031,12899-12918 \mathrm{pp}$.

van de Flierdt, T. et al., 2012. GEOTRACES intercalibration of neodymium isotopes and rare earth element concentrations in seawater and suspended particles. Part 1: reproducibility of results for the international intercomparison. Limnology and Oceanography: Methods, 10(4): 234-251.

Wang, Z.-L., Yamada, M., 2007. Geochemistry of dissolved rare earth elements in the Equatorial Pacific Ocean. Environmental Geology, 52(4): 779-787.

Wijffels, S.E., Toole, J.M., Davis, R., 2001. Revisiting the South Pacific subtropical circulation: A synthesis of World Ocean Circulation Experiment observations along $32^{\circ} \mathrm{S}$. Journal of Geophysical Research: Oceans, 106(C9): 19481-19513.

Zhang, J., Nozaki, Y., 1996. Rare earth elements and yttrium in seawater: ICP-MS determinations in the East Caroline, Coral Sea, and South Fiji basins of the western South Pacific Ocean. Geochimica et Cosmochimica Acta, 60(23): 4631-4644.

Zhang, Y., Lacan, F., Jeandel, C., 2008. Dissolved rare earth elements tracing lithogenic inputs over the Kerguelen Plateau (Southern Ocean). Deep Sea Research Part II: Topical Studies in Oceanography, 55(5): 638-652.

\section{Tables and Figures}

\section{Table Captions}

Table 1: Location, Depths, Hydrological properties, Ce anomalies, $\mathrm{Nd}$ concentration of the analyzed sample in this study and the corresponding water masses identified.

936 Table 2: Dissolved REE concentrations $\left(\mathrm{pmol} . \mathrm{kg}^{-1}\right)$. Data are reported with daily confidence 937 interval $(2 \sigma)$. 
Table 3 Average dNd concentrations in the different layers of the box model

Table 4: Water masses and associated volume transport (Sv) at different layer during Pandora (July-August 2012). The water transports were calculated based on S-ADCPs data couple with geostrophic velocities database

\section{Figure Captions}

Figure 1. General map of the studied area (a) and zoom panel in the Coral and Solomon Sea allowing the identification of the sampling locations (b). The sampling locations are represented by circles and different colors associated with distinct regions. The red circles correspond the Coral Sea and Southern entrance of the Solomon Sea. Samples collected in waters flowing through four straits (Indispensable, Vitiaz, St George's and Solomon), are colorized with dark violet, black, green and dark blue, respectively. These color criteria will be kept all along this work. The main currents flowing in the South Western Pacific Ocean are shown by solid arrow (Grenier et al., 2011, 2013). SEC: South Equatorial Current, NVJ: New Vanuatu Jet, NCJ: New Caledonia Jet, GPC: eastward Gulf of Papua Current, NQC: polarward New Queensland Current, NGCU: New Guinea Coastal Undercurrent, NBCU: New Britain Coastal Undercurrent, NICU: New Ireland Coastal Undercurrent, SSCC: South Subsurface Countercurrent, EUC: Equatorial Undercurrent. The main archipelago and islands are also reported in the map. Along with this, straits are identified by a character covered by red circle: Indispensable, Vitiaz, St.George and Solomon Strait also highlighted in the map as V, G and $\mathrm{S}$, correspondingly.

Figure 2. Potential temperature $(\theta)$ versus salinity $(S)$ (right) and potential temperature $(\theta)$ versus dissolved oxygen (O2) (left) plots for the stations. The curve colors correspond to the different locations denoted in figure 1 . The grey curves are representing the same properties at all the hydrographic stations sampled as part of PANDORA. In the left plots, potential density anomaly contours are shown as solid grey lines. Each depth sampled for dissolved REE measurement is identified by a rectangle and its value $(\mathrm{m})$. All the data characterizing the stations represented here are provided in Table 1 . The water masses at the sampling depth are also highlighted by their notation: TSW: Tropical Surface Water, SPTW: South Pacific Tropical Water, SPEW: South Pacific Equatorial Water, WSPCW: Western South Pacific Central Water, SAMW: Subantarctic Mode Water, AAIW: Antarctic Intermediate Water, EqPIW: Equatorial Pacific Intermediate Water, UCDW and LCDW: Upper and Lower Circumpolar Deep Water.

Figure 3. Profiles of dissolved REE concentrations for La, Nd, Eu and Yb. Stations are gathered into five groups with the color codes consistent with their geographical location as proposed in Figure 1.

Figure 4. Comparison of our data with those measured in the framework of preceding studies. Yellow points represent data from station SA-7 (sampled during September-October, 1992) located in the middle of the Coral Sea and measured by Zhang and Nozaki (1996). Aqua square, triangle and dot represent data measured at the entrance of Solomon (FLUSEC 22), Coral sea (FLUSEC 43) and at exiting Vitiaz Strait respectively, measured by Grenier et al. 
(2013). It is noted that all sample using in study of Grenier was sampled in AugustSeptember, 2006. Sampling date of our samples are reported in table 1.

Figure 5. dREE patterns normalized to PAAS $(\times 106)$ at different depths for 8 stations sampled in the Coral Sea and at the entrance of Solomon Sea and for 12 stations located in the Solomon Sea and in the different straits The light colors indicate shallow samples while darker colors represent the deeper ones.

Figure 6. a) Schematic description of the Pandora box (red rectangular). The water layer is defined in the table 4. Yellow arrows signify southern input while red arrows characterize output flow through three straits. Meanwhile, colored letters coupled with number indicate different stations together with their transport. E: NGCU transport, N: direct NVJ transport, V, G and S: Vitiaz Strait, St George's Channel and Solomon Strait transports, respectively. b) Enrichment visualizing by simple Pandora box with 2 southern inputs and 3 northern outputs as presented in figure $6 \mathrm{a}$. The $\mathrm{Nd}$ concentrations were taken into account here are $\mathrm{NdE}, \mathrm{NdN}$ in the south and NdS, NdG and NdV in the north. c) Significant enrichment is observed at Lower Thermocline Water, all fluxes are reported in Table 4.

Figure 7. Vertical profiles of the anomalies of La (La/La*), Eu (Eu/Eu*), $\mathrm{Yb}\left(\mathrm{Yb} / \mathrm{Yb} b^{*}\right)$ and of ratio $(\mathrm{Nd} / \mathrm{Yb})_{n}$, calculated following Bau et al. (2004); Bau et al. (1996); Friend et al. (2008); Garcia-Solsona et al. (2014). The color of markers follow color rule as described in Figure 1. High value was found at the surface water characterize at almost all parameter, except $\mathrm{Yb} / \mathrm{Yb}^{*}$. Profile of ratio $\mathrm{Ndn} / \mathrm{Ybn}$ indicate the recent lilthogenic enrichment at the top of water, then disappear by marine scavenging and later redissolution and or remineralization at depth. Error bars are also plotted together with anomaly value.

Figure 8. Linear correlations between dLa (in pmol. $\mathrm{kg}^{-1}$ ) and $\mathrm{dBa}$ of all Pandora stations. The relationship confirms the hypothesis that a part of La enrichment comes from the barium cycle in oceanic water (Garcia-Solona et al., 2014; Grenier et al. Submitted in 2017). The slope reflects different rates between Barite formation and lilthogenic dissolution in the water column.

Figure 9. Relationship between $\mathrm{dYb}$ (in pmol.kg-1) and $\mathrm{dSi}$ (in $\mu$ mol.kg1). Two linear regression point out the strong relation between HREE and Si cycle as suggested by Akagi et al. $(2011,2013)$ and Grenier et al. (submitted in 2017). The break slope at around $700 \mathrm{~m}$ suggests the strength of different internal and or external oceanic process on REE distribution. 


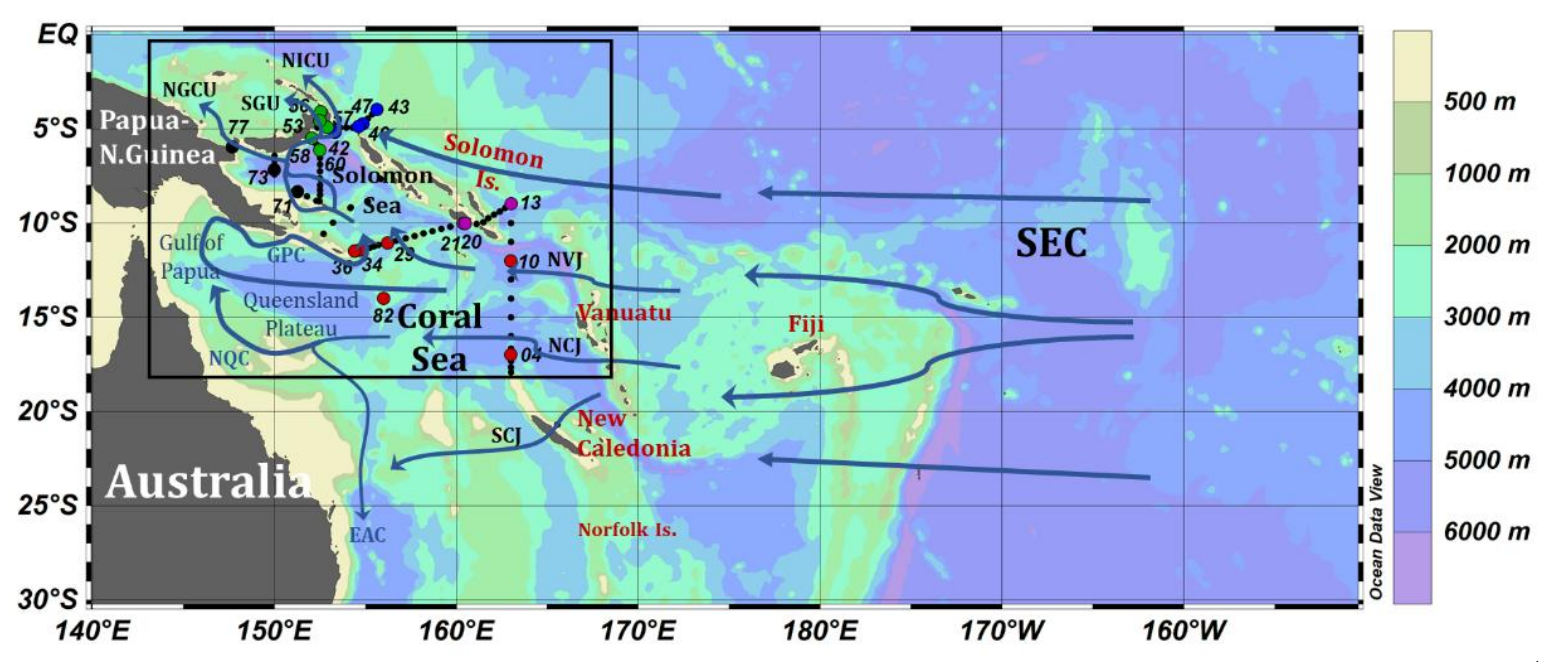

(a)

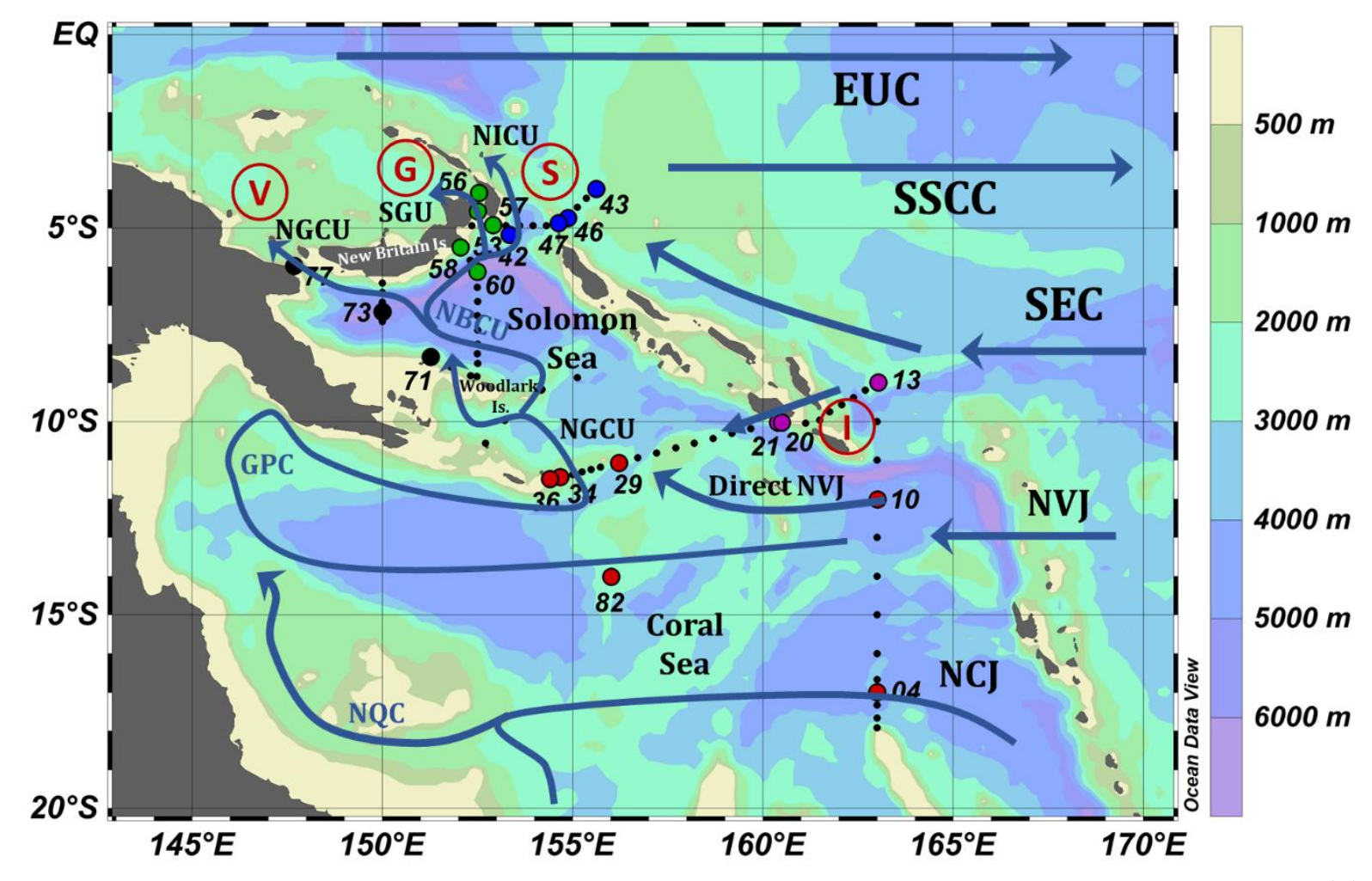

(b)

Figure 1. General map of the studied area (a) and zoom panel in the Coral and Solomon Sea allowing the identification of the sampling locations (b). The sampling locations are represented by circles and different colors associated with distinct regions. The red circles correspond the Coral Sea and Southern entrance of the Solomon Sea. Samples collected in waters flowing through four straits (Indispensable, Vitiaz, St George's and Solomon), are colorized with dark violet, black, green and dark blue, respectively. These color criteria will be kept all along this work. The main currents flowing in the South Western Pacific Ocean are shown by solid arrow (Grenier et al., 2011, 2013). SEC: South Equatorial Current, NVJ: New Vanuatu Jet, NCJ: New Caledonia Jet, GPC: eastward Gulf of Papua Current, NQC: polarward New Queensland Current, NGCU: New Guinea Coastal Undercurrent, NBCU: New Britain Coastal Undercurrent, NICU: New Ireland Coastal Undercurrent, SSCC: South Subsurface Countercurrent, EUC: Equatorial Undercurrent. The main archipelago and islands are also reported in the map. Along with this, straits are identified by a character covered by red circle: Indispensable, Vitiaz, St.George and Solomon Strait also highlighted in the map as V, G and $\mathrm{S}$, correspondingly. 
STATION 04
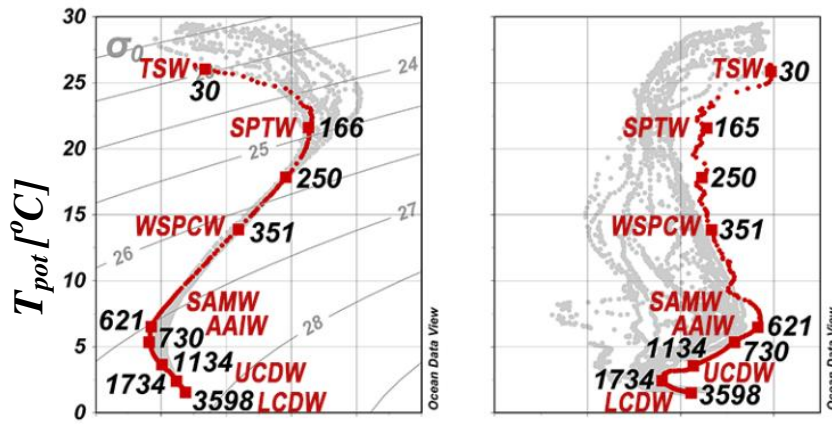

STATION 10
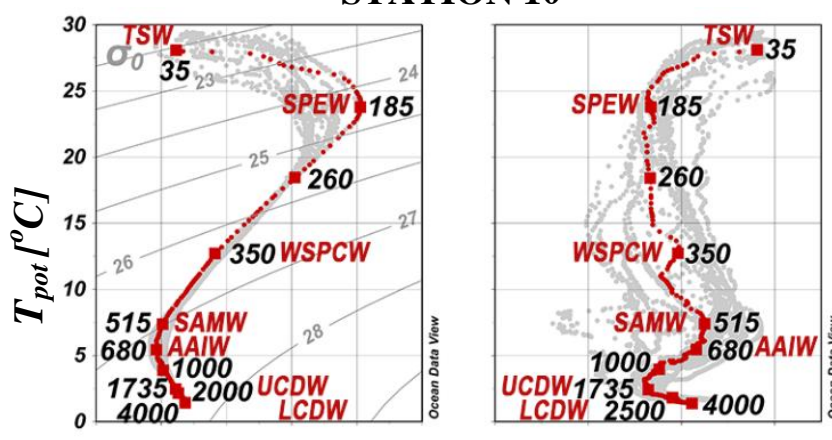

STATION 29
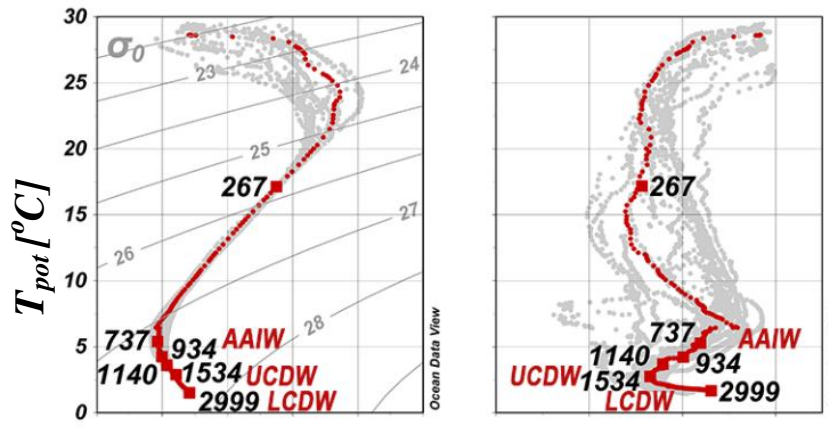

STATION 34

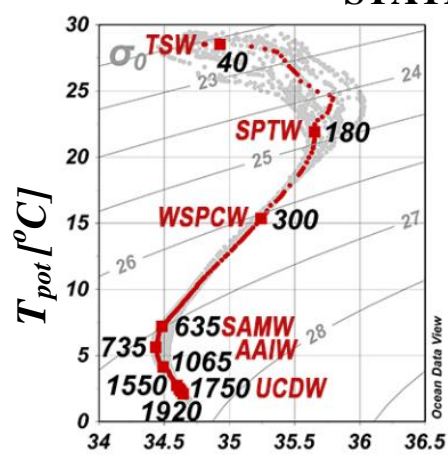

$S$ [PSU]

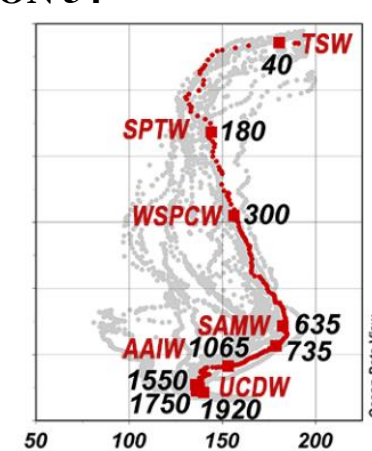

$\mathrm{O}_{2}\left[\mu \mathrm{mol} . \mathrm{kg}^{-1}\right]$

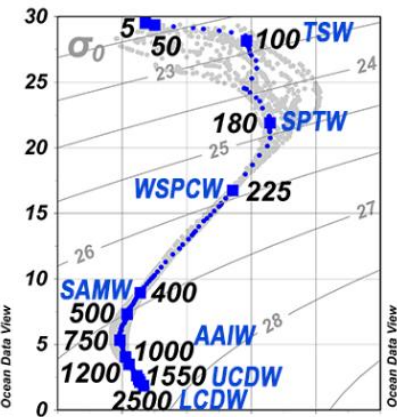

STATION 42

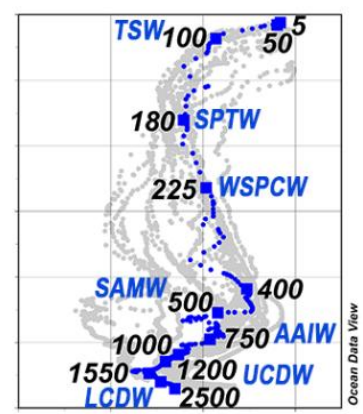

STATION 43
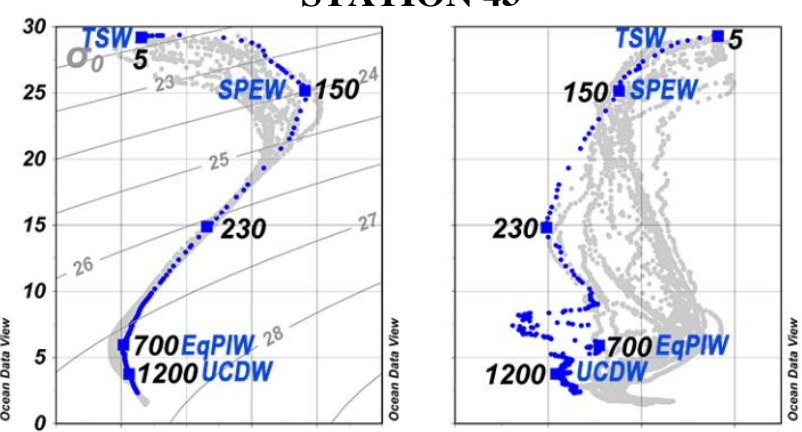

STATION 46
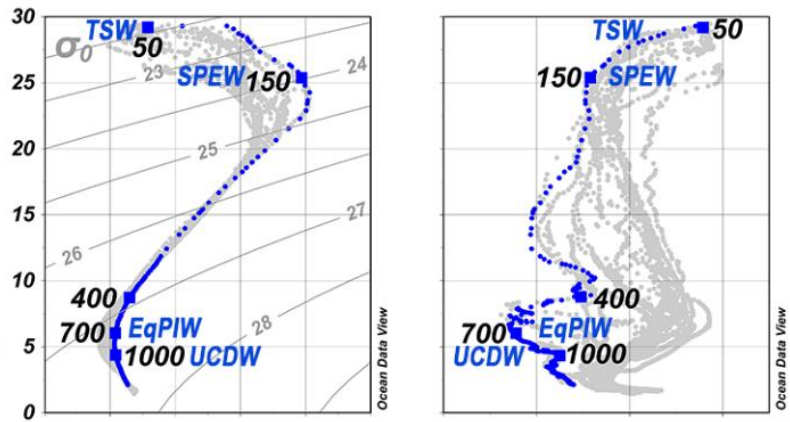

STATION 47
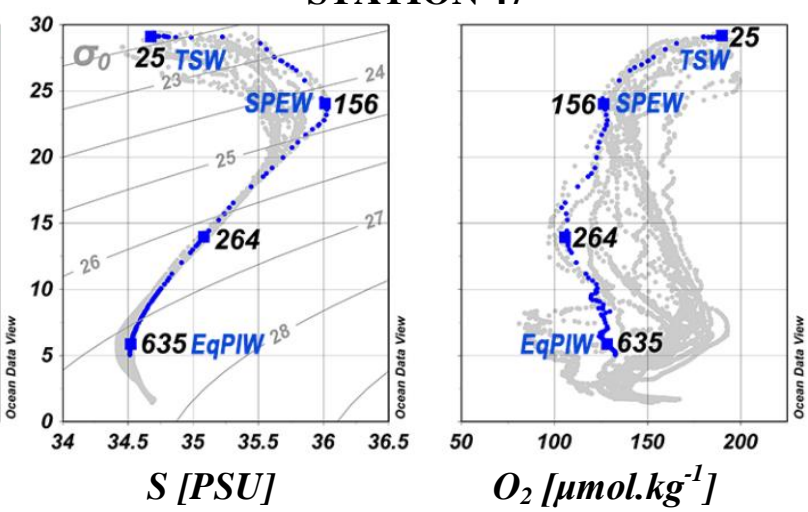

$S$ [PSU]

Figure 2. Potential temperature $(\theta)$ versus salinity (S) (right) and potential temperature $(\theta)$ versus dissolved oxygen $\left(\mathrm{O}_{2}\right)$ (left) plots for the stations. The curve colors correspond to the different locations denoted in figure 1 . The grey curves are representing the same properties at all the hydrographic stations sampled as part of PANDORA. In the left plots, potential density anomaly contours are shown as solid grey lines. Each depth sampled for dissolved REE measurement is identified by a rectangle and its value (m). All the data characterizing the stations represented here are provided in Table 1. The water masses at the sampling depth are also highlighted by their notation: TSW: Tropical Surface Water, SPTW: South Pacific Tropical Water, SPEW: South Pacific Equatorial Water, WSPCW: Western South Pacific Central Water, SAMW: Subantarctic Mode Water, AAIW: Antarctic Intermediate Water, EqPIW: Equatorial Pacific Intermediate Water, UCDW and LCDW: Upper and Lower Circumpolar Deep Water. 
STATION 13
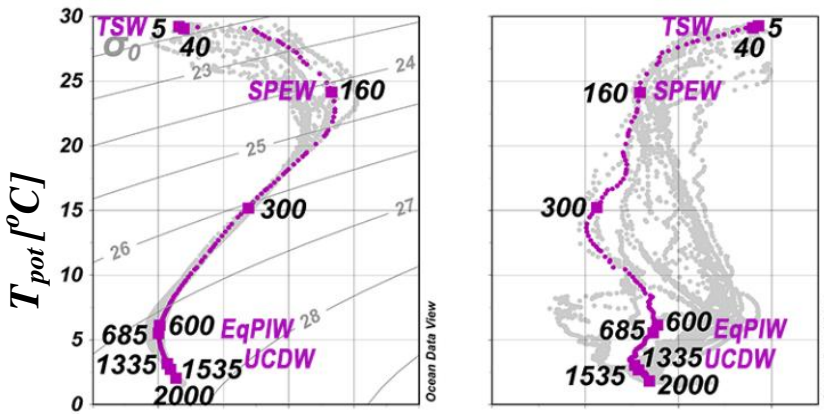

STATION 21
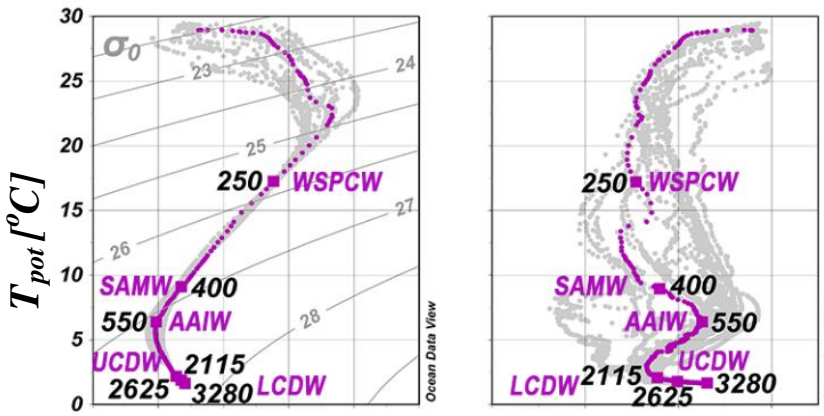

STATION 71
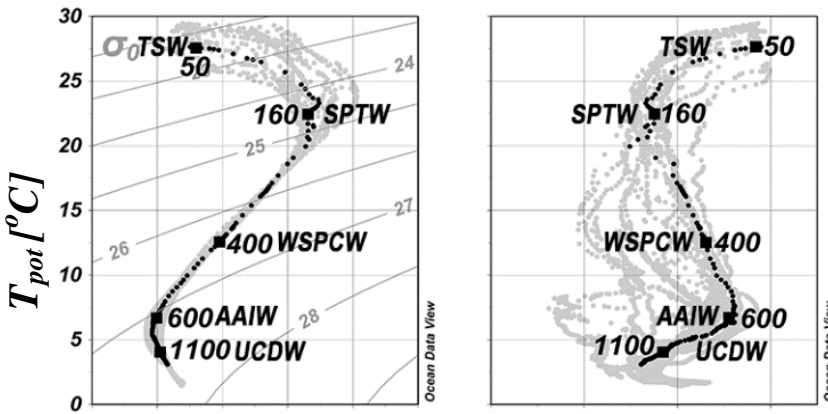

STATION 73
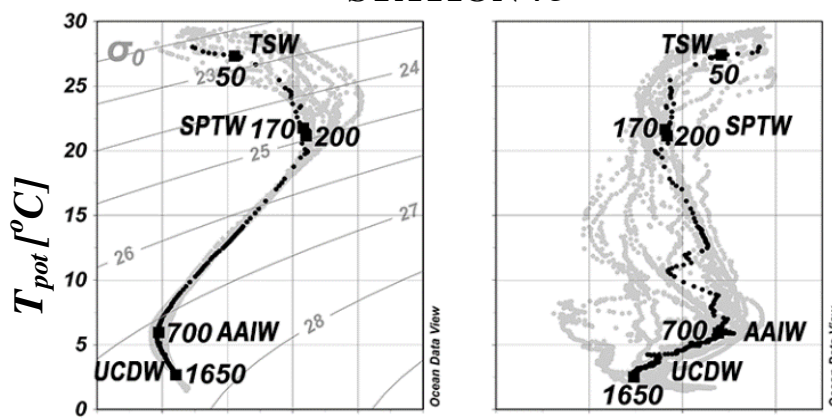

STATION 77
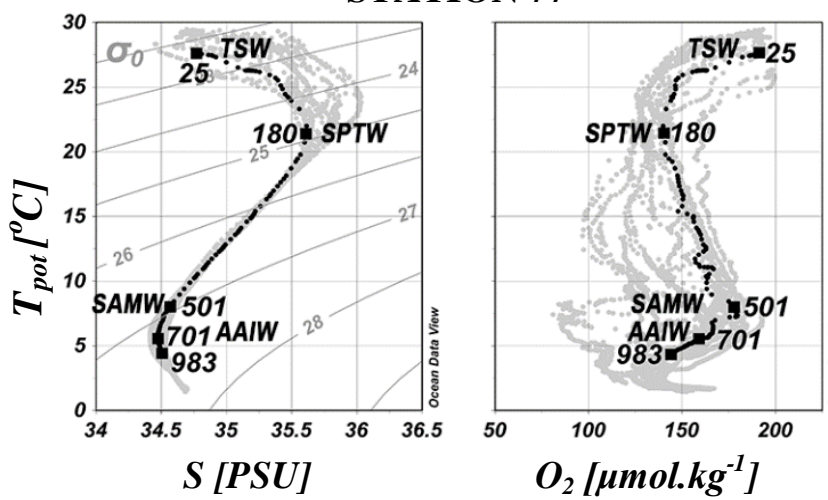

STATION 53
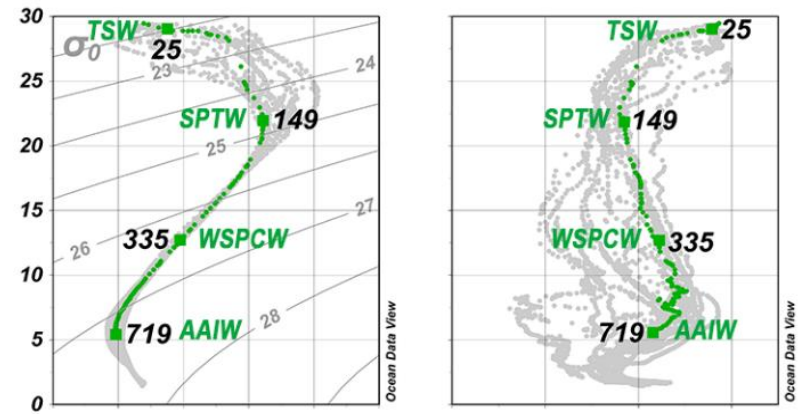

STATION 56
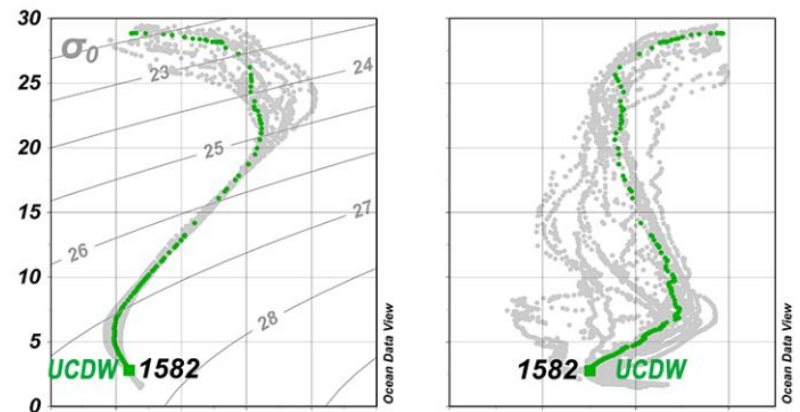

STATION 57

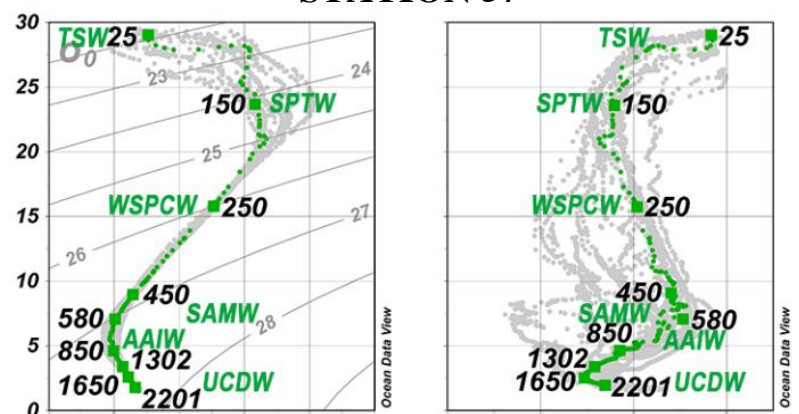

STATION 58
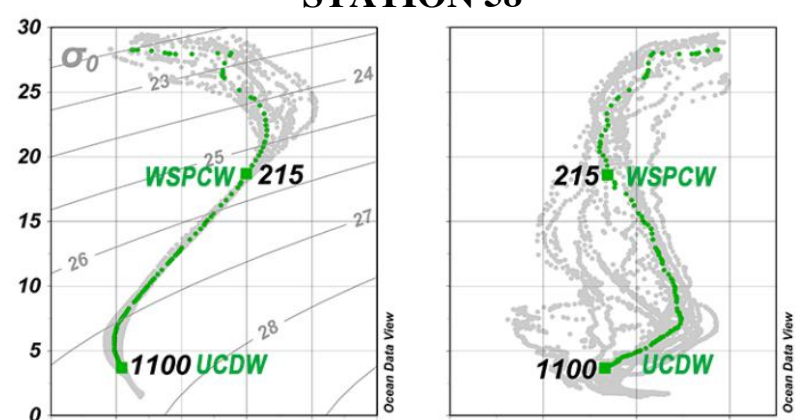

STATION 60
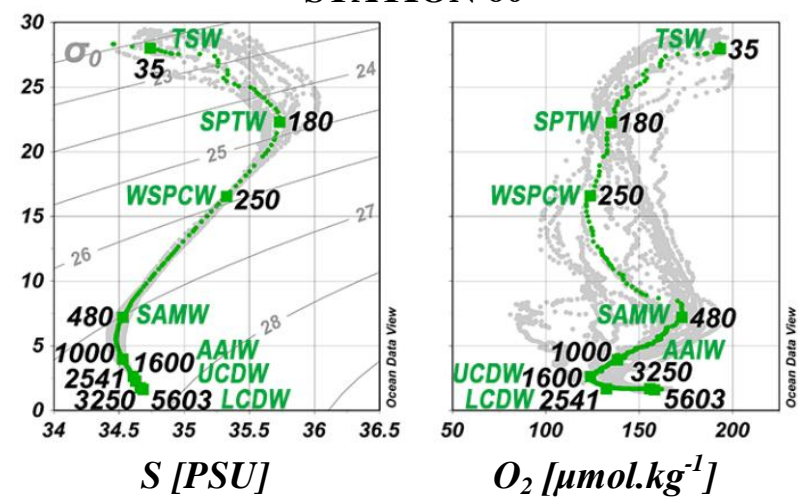

Figure 2. (continued) 
3a) In the Coral Sea, southern entrance of Solomon Sea
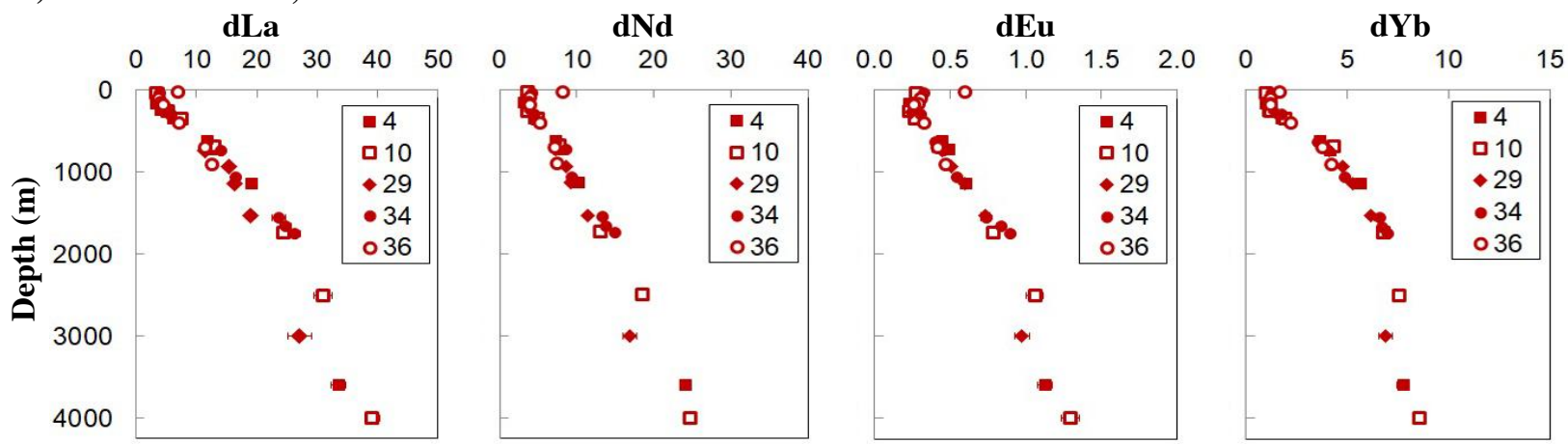

3b) Through Solomon Strait
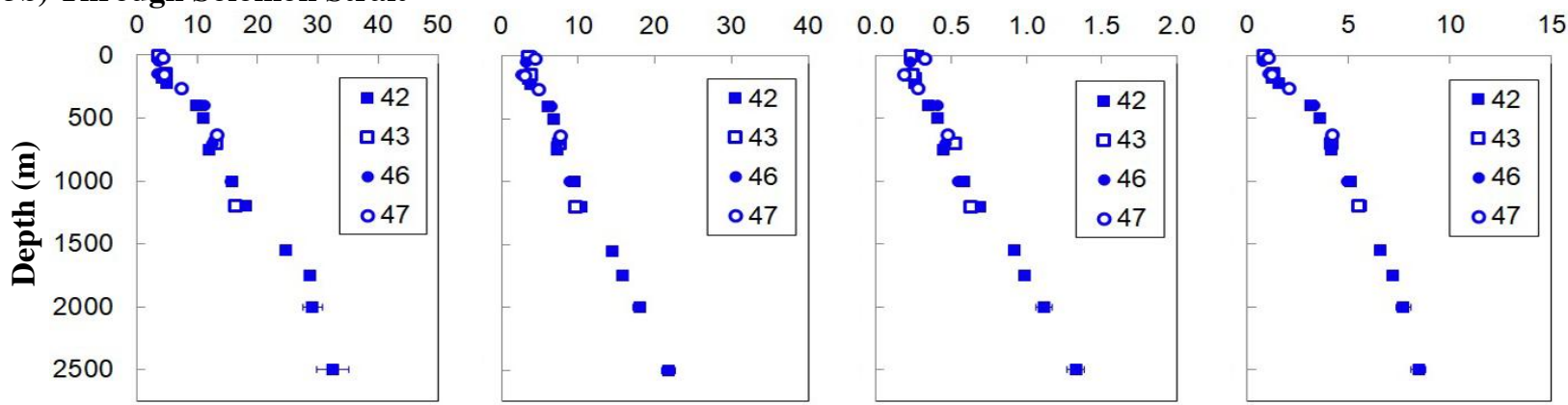

3c) Through St George's Strait
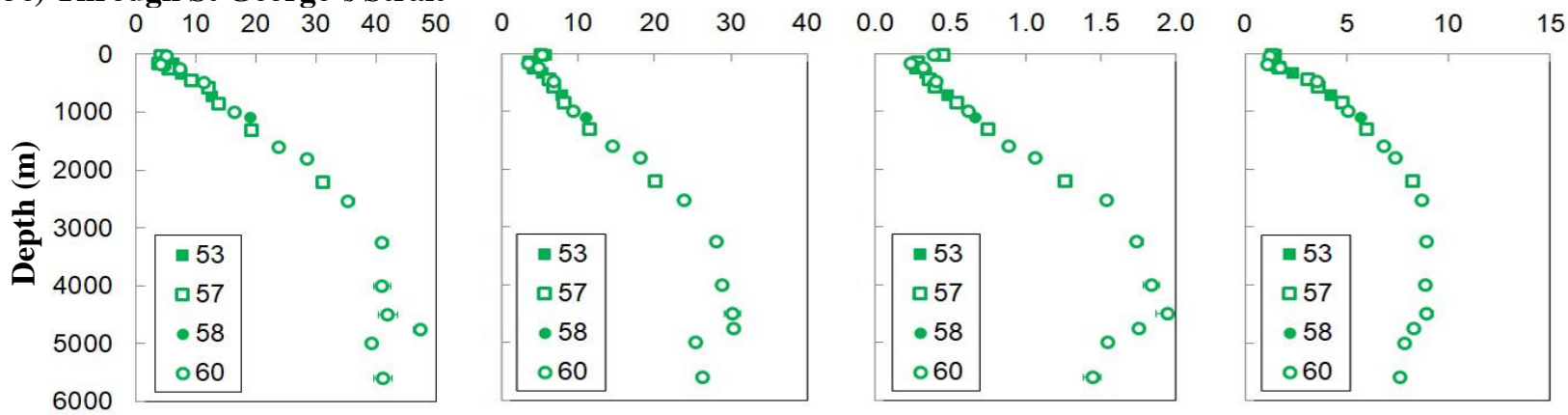

3d) Through Vitiaz Strait
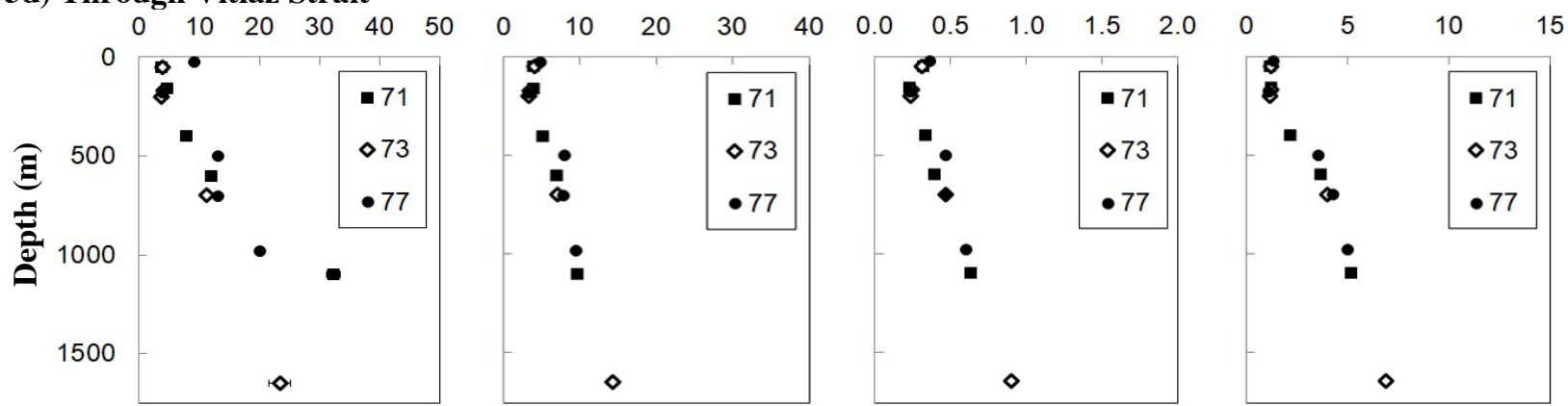

3e) Through Indispensable Strait
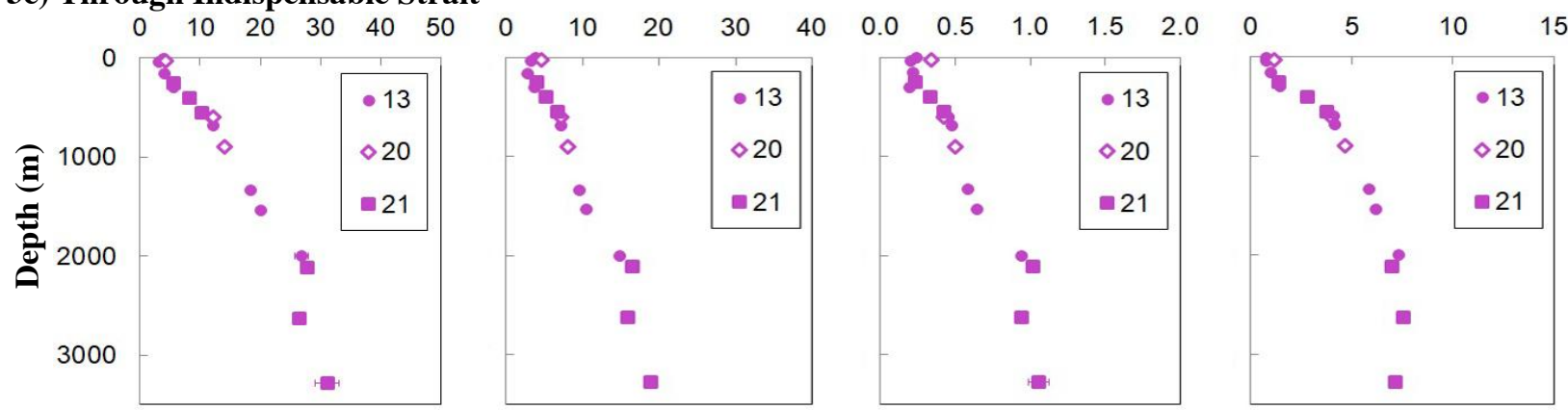

Figure 3. Profiles of dissolved REE concentrations for $\mathrm{La}, \mathrm{Nd}, \mathrm{Eu}$ and $\mathrm{Yb}$. Stations are gathered into five groups with the color codes consistent with their geographical location as proposed in Figure 1. 

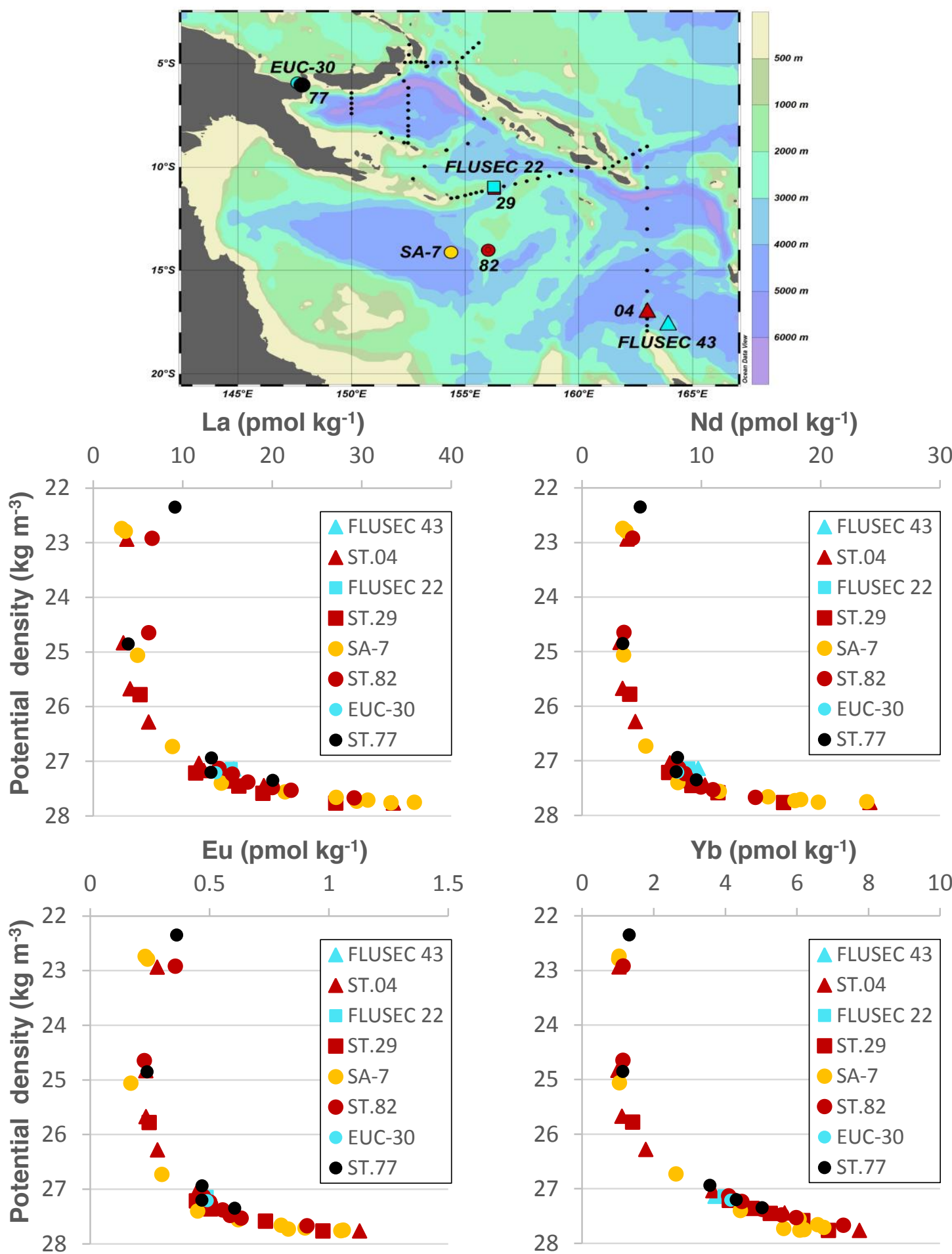

Figure 4. Comparison of our data with those measured in the framework of preceding studies. Yellow points represent data from station SA-7 (sampled during September-October, 1992) located in the middle of the Coral Sea and measured by Zhang and Nozaki (1996). Aqua square, triangle and dot represent data measured at the entrance of Solomon (FLUSEC 22), Coral sea (FLUSEC 43) and at exiting Vitiaz Strait respectively, measured by Grenier et al. (2013). It is noted that all sample using in study of Grenier was sampled in August-September, 2006. Sampling date of our samples are reported in table 

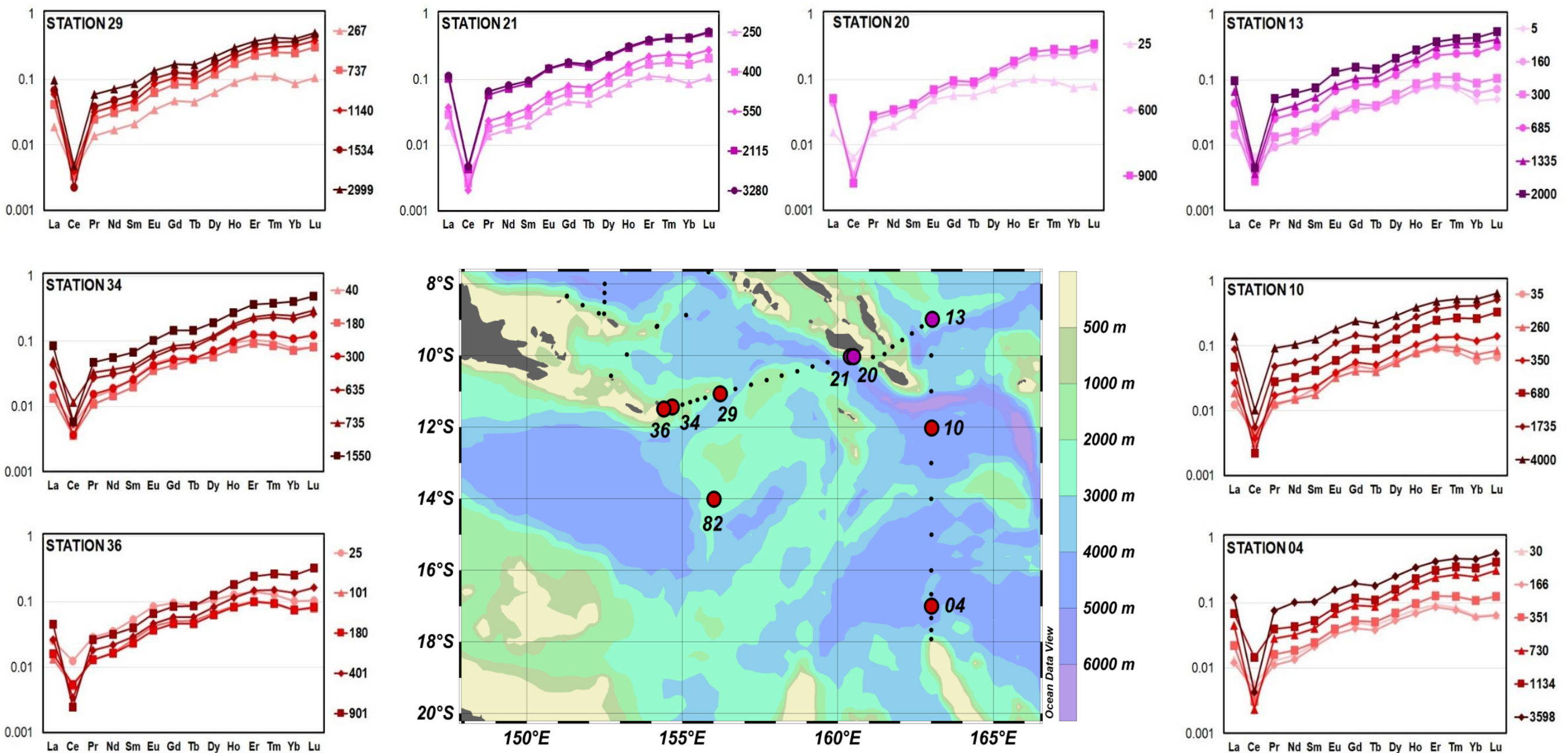

Figure 5. dREE patterns normalized to PAAS $\left(\times 10^{6}\right)$ at different depths for 8 stations sampled in the Coral Sea and at the entrance of Solomon Sea and for 12 stations located in the Solomon Sea and in the different straits The light colors indicate shallow samples while darker colors represent the deeper ones

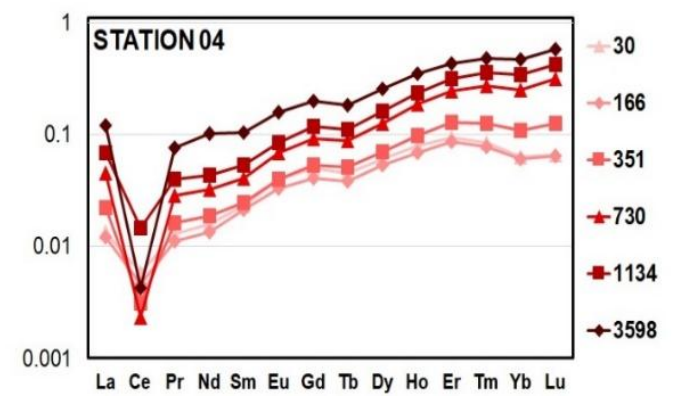



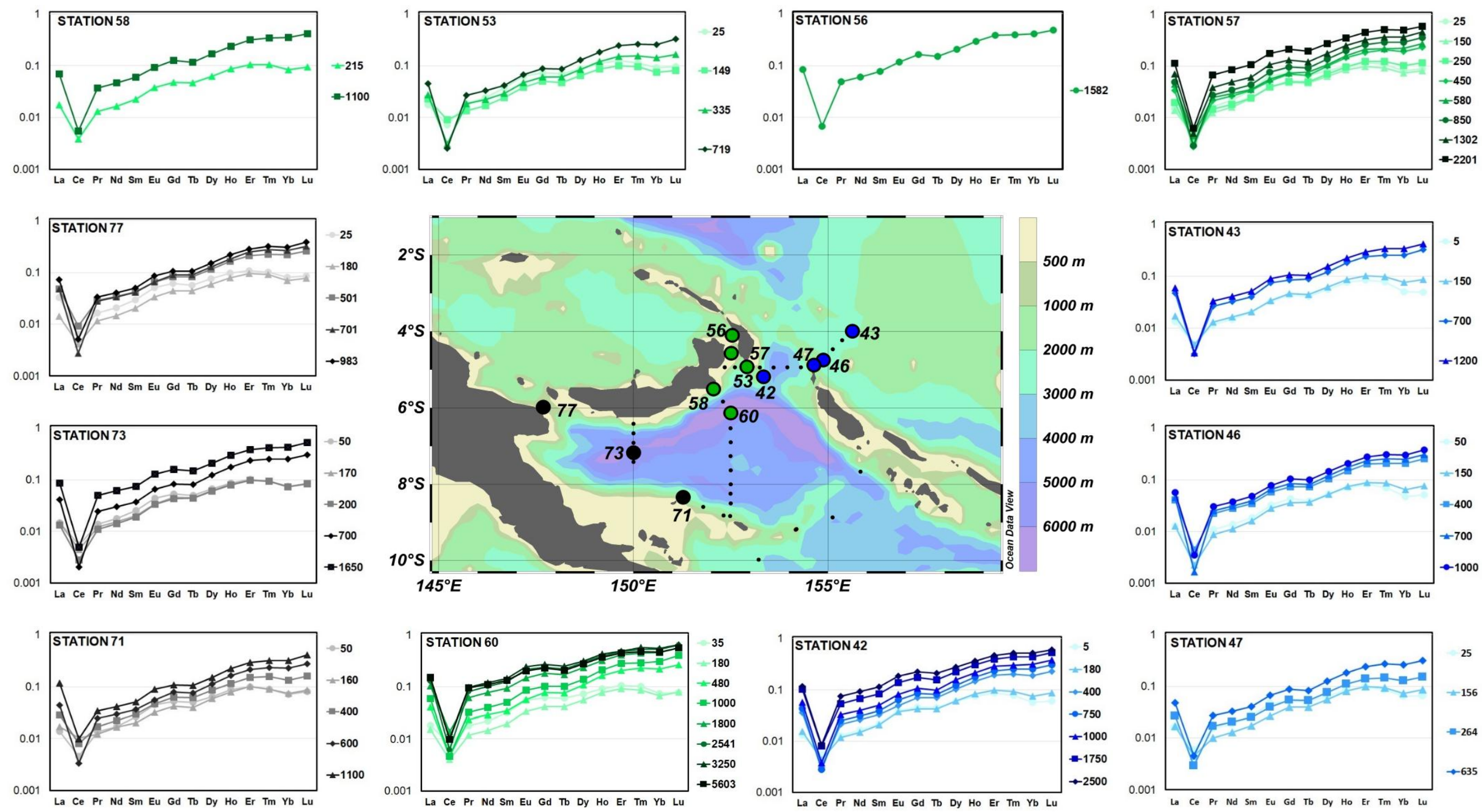

Figure 5. (continued) 
(a)

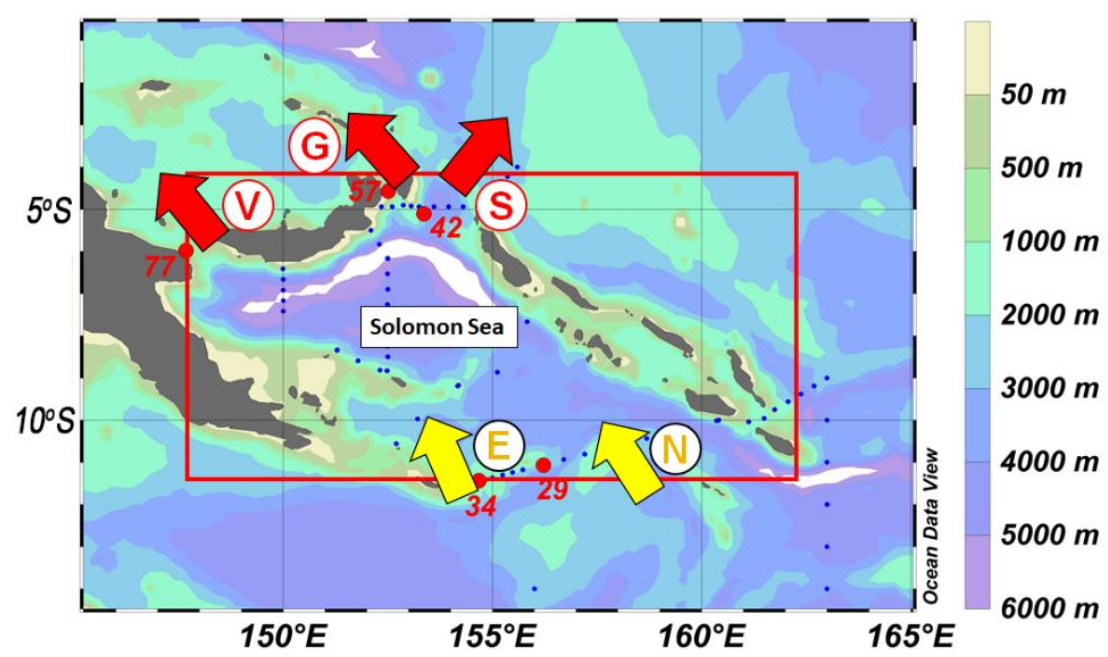

(b)

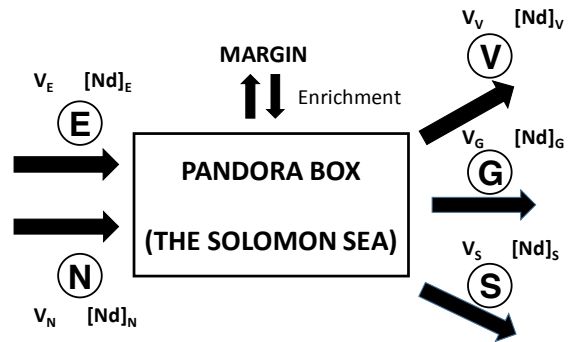

(c)

At Lower Thermocline level $\left(\sigma_{\theta}=25.3-26.9\right)$

$$
\begin{aligned}
& \mathrm{F}_{\text {tot PANDORA }}=145.1 \pm 45.8 \mathrm{t}_{\mathrm{yr}}{ }^{-1} \\
& \mathrm{~W}_{\text {IN. }[\mathrm{Nd}]_{\mathrm{INI}}}=282.8 \pm 12.6 \mathrm{t} . \mathrm{yr}^{-1} \\
& \mathrm{~W}_{\text {OUT. }}[\mathrm{Nd}]_{\mathrm{FIN}}=427.9 \pm 44.1 \mathrm{t} . \mathrm{yr}^{-1}
\end{aligned}
$$

Figure 6. a) Schematic description of the Pandora box (red rectangular). The water layer is defined in the table 3. Yellow arrows signify southern input while red arrows characterize output flow through three straits. Meanwhile, colored letters coupled with number indicate different stations together with their transport. E: NGCU transport, N: direct NVJ transport, V, G and S: Vitiaz Strait, St George's Channel and Solomon Strait transports, respectively. b) Enrichment visualizing by simple Pandora box with 2 southern inputs and 3 northern outputs as presented in figure $6 \mathrm{a}$. The $\mathrm{Nd}$ concentrations were taken into account here are $\mathrm{Nd}_{\mathrm{E}}, \mathrm{Nd}_{\mathrm{N}}$ in the south and $\mathrm{Nd}_{\mathrm{S}}, \mathrm{Nd}_{\mathrm{G}}$ and $\mathrm{Nd}_{\mathrm{V}}$ in the north. c) Significant enrichment is observed at Lower Thermocline Water, all fluxes are reported in Table 3. 


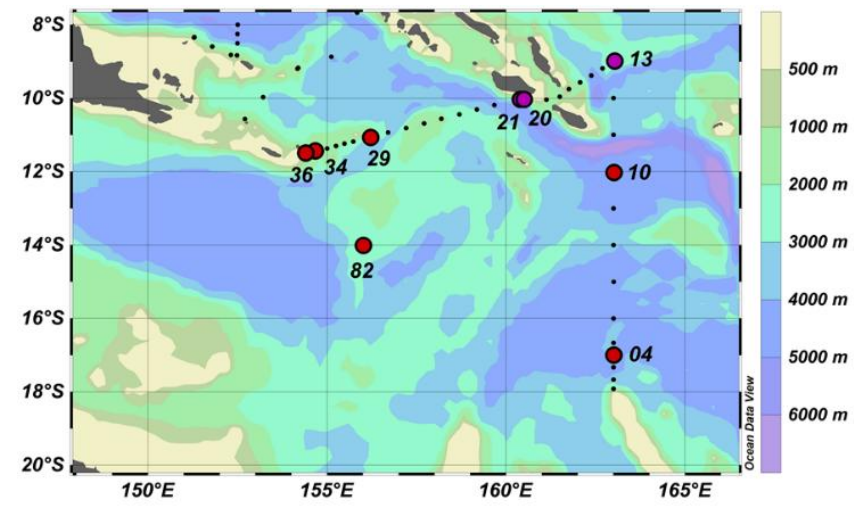

The Coral Sea, southern entrance of Solomon Sea
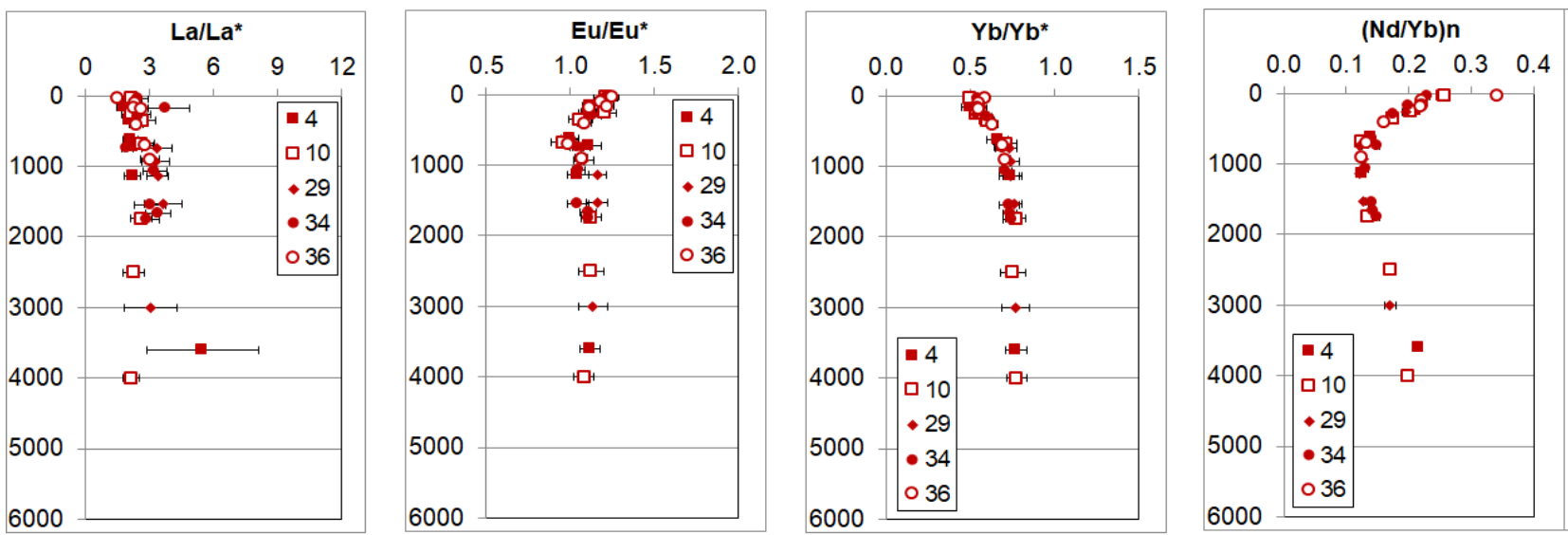

Through Indispensable Strait
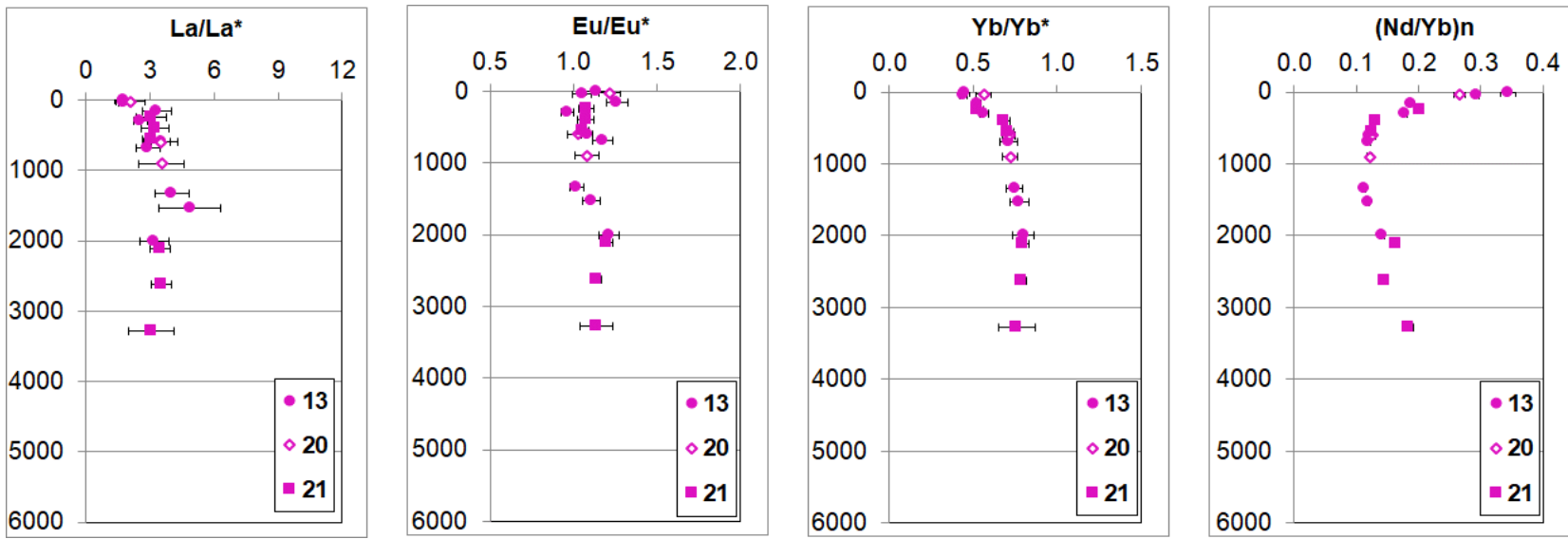

Figure 7. Vertical profiles of the anomalies of $\mathrm{La}\left(\mathrm{La} / \mathrm{La}^{*}\right), \mathrm{Eu}\left(\mathrm{Eu} / \mathrm{Eu}{ }^{*}\right), \mathrm{Yb}\left(\mathrm{Yb} / \mathrm{Yb}^{*}\right)$ and of ratio $(\mathrm{Nd} / \mathrm{Yb})_{\mathrm{n}}$, calculated following Bau et al. (2004); Bau et al. (1996); Friend et al. (2008); Garcia-Solsona et al. (2014). The color of markers follow color rule as described in Figure 1. High value was found the surface water characterize at almost all parameter, except $\mathrm{Yb} / \mathrm{Yb}^{*}$. Profile of ratio $\mathrm{Nd}_{\mathrm{n}}{ }^{\mathrm{Y}} \mathrm{b}_{\mathrm{n}}$ indicate the recent lilthogenic enrichment at the top of water, then disappear by marine scavenging and later redissolution and or remineralization at depth. Error bars are also plotted together with anomaly value. 
Through Solomon Strait

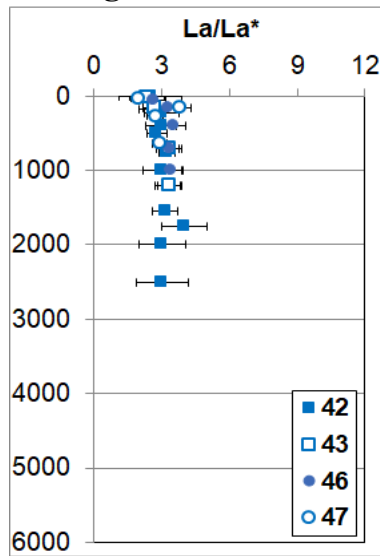

Through St.Geogre Strait

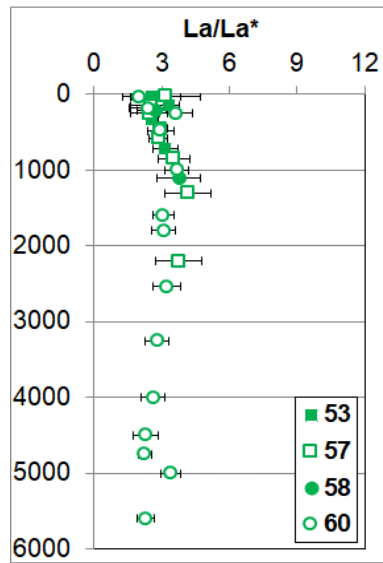

Through Vitiaz Strait

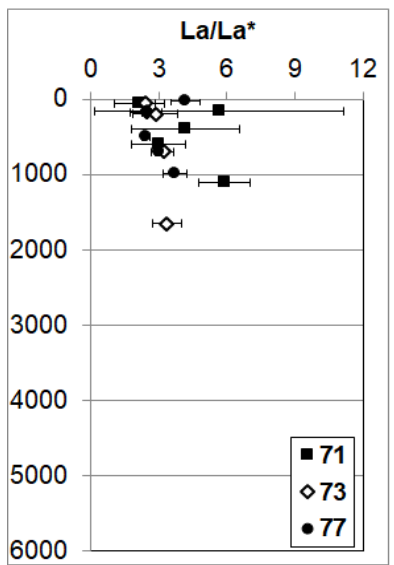

Figure 7 (continued)
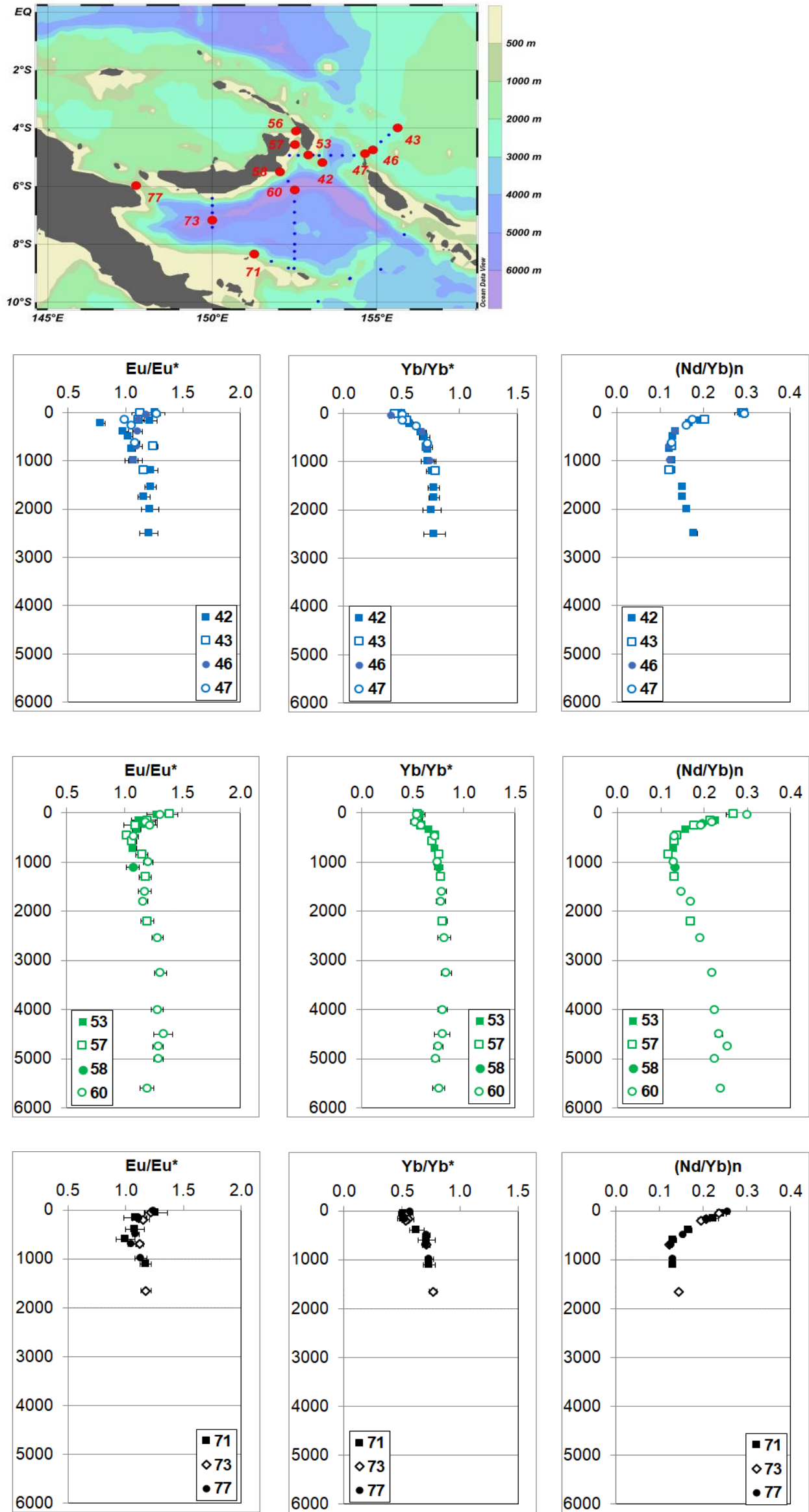


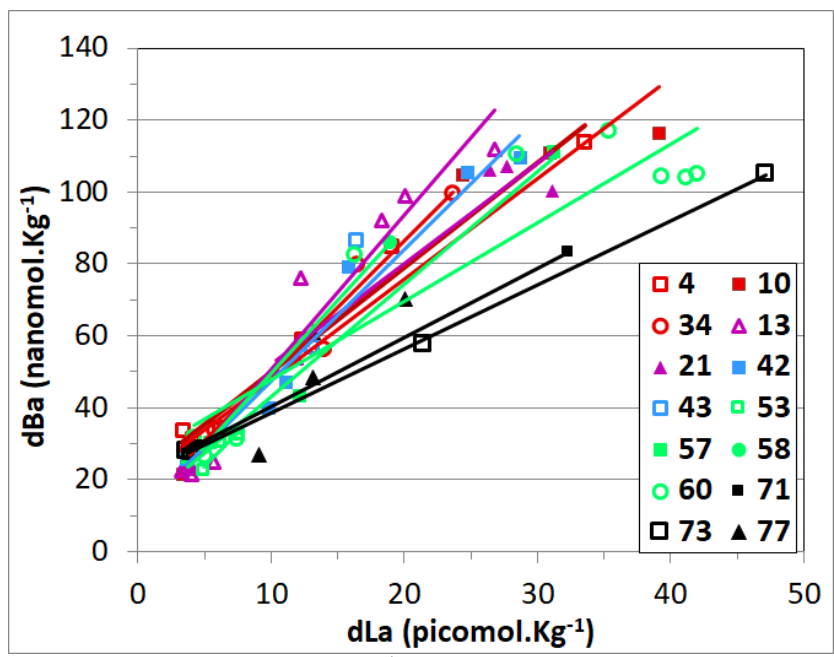

Figure 8. Linear correlations between $\mathrm{dLa}$ (in pmol. $\mathrm{kg}^{-1}$ ) and $\mathrm{dBa}$ of all Pandora stations. The relationship confirms the hypothesis that a part of La enrichment comes from the barium cycle in oceanic water (Garcia-Solona et al ., 2014; Grenier et al. Submitted in 2017). The slope reflects different rates between Barite formation and lilthogenic dissolution in the water column.

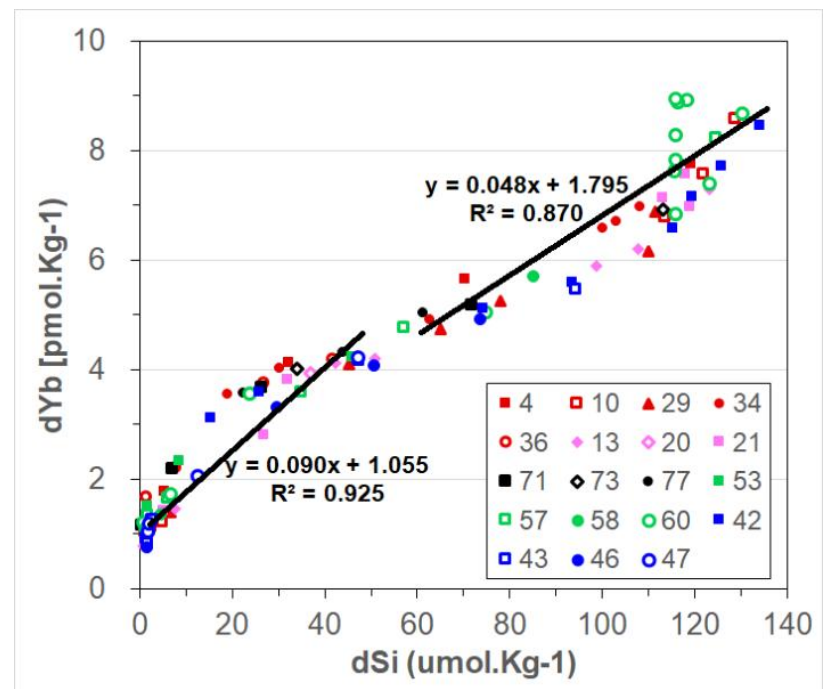

Figure 9. Relationship between $\mathrm{dYb}$ (in pmol. $\mathrm{kg}^{-1}$ ) and $\mathrm{dSi}$ (in $\mu$ mol. $\mathrm{kg}^{1}$ ). Two linear regression point out the strong relation between HREE and Si cycle as suggested by Akagi et al. $(2011,2013)$ and Grenier et al. (submitted in 2017). The break slope at around 700m suggests the strength of different internal and or external oceanic process on REE distribution. 
Table 1. Location, Depths, Hydrological properties, Ce anomalies, Nd concentration of the analyzed sample in this study and the corresponding water masses identified

\begin{tabular}{|c|c|c|c|c|c|c|c|c|c|c|}
\hline $\begin{array}{l}\text { Depth } \\
\text { (m) }\end{array}$ & $\begin{array}{l}\text { Salinity } \\
\text { (PSU) }\end{array}$ & $\begin{array}{c}\text { Pot. Temp } \\
{\left[{ }^{\circ} \mathrm{C}\right]}\end{array}$ & $\begin{array}{c}\mathrm{O}_{2} \\
\left(\mu \mathrm{mol} \mathrm{kg}{ }^{-1}\right)\end{array}$ & $\begin{array}{l}\text { Pot. Dens } \\
\left(\sigma_{\vartheta}\right)\left(\mathrm{kg} \mathrm{m}^{-3}\right)\end{array}$ & $\mathrm{La} / \mathrm{La}^{*}$ & $\mathrm{Ce} / \mathrm{Ce}^{*}$ & $\mathrm{Eu} / \mathrm{Eu}^{*}$ & $\mathrm{Yb} / \mathrm{Yb} *$ & $(\mathrm{Nd} / \mathrm{Yb})_{\mathrm{n}}$ & $\begin{array}{l}\text { Water } \\
\text { Mass }\end{array}$ \\
\hline \multicolumn{11}{|c|}{ Station 004 (July 01, 2012; $17^{\circ} 0^{\prime} 10.8^{\prime \prime}$ S; $162^{\circ} 59^{\prime} 45.6^{\prime \prime} \mathrm{E}$; depth: 4680m) } \\
\hline 30 & 34.840 & 25.931 & 199 & 22.94 & 2.08 & 0.60 & 1.21 & 0.50 & 0.25 & TSW \\
\hline 166 & 35.631 & 21.533 & 164 & 24.83 & 1.81 & 0.51 & 1.12 & 0.50 & 0.22 & \multirow{2}{*}{ SPTW } \\
\hline 250 & 35.462 & 17.831 & 161 & 25.67 & 2.31 & 0.46 & 1.11 & 0.55 & 0.21 & \\
\hline 351 & 35.095 & 13.923 & 167 & 26.28 & 2.04 & 0.23 & 1.09 & 0.59 & 0.17 & WSPCW \\
\hline 621 & 34.426 & 6.496 & 192 & 27.04 & 2.11 & 0.12 & 1.00 & 0.66 & 0.14 & SAMW \\
\hline 730 & 34.415 & 5.375 & 179 & 27.17 & 2.21 & 0.10 & 1.11 & 0.70 & 0.13 & \multirow{2}{*}{ AAIW } \\
\hline 1134 & 34.510 & 3.573 & 157 & 27.44 & 2.20 & 0.41 & 1.05 & 0.74 & 0.13 & \\
\hline 1734 & 34.620 & 2.410 & 140 & 27.64 & - & - & - & - & - & UCDW \\
\hline 3598 & 34.687 & 1.546 & 156 & 27.76 & 5.48 & 0.09 & 1.12 & 0.77 & 0.22 & LCDW \\
\hline \multicolumn{11}{|c|}{ Station 010 (July 03, 2012; 120 0' 0" S; 162º 59' 56.4" E; depth : 5092m) } \\
\hline 35 & 34.616 & 28.053 & 191 & 22.09 & 2.13 & 0.51 & 1.21 & 0.50 & 0.26 & TSW \\
\hline 185 & 36.029 & 24.496 & 134 & 24.50 & - & - & - & - & - & \multirow{2}{*}{ SPEW } \\
\hline 260 & 35.523 & 18.403 & 133 & 25.58 & 2.12 & 0.29 & 1.21 & 0.54 & 0.20 & \\
\hline 350 & 34.918 & 12.675 & 148 & 26.40 & 2.68 & 0.27 & 1.05 & 0.60 & 0.18 & WSPCW \\
\hline 515 & 34.510 & 7.400 & 163 & 26.98 & - & - & - & - & - & SAMW \\
\hline 680 & 34.458 & 5.395 & 158 & 27.20 & 2.61 & 0.10 & 0.95 & 0.72 & 0.12 & \multirow{2}{*}{ AAIW } \\
\hline 1000 & 34.520 & 3.960 & 139 & 27.41 & - & - & - & - & - & \\
\hline 1735 & 34.613 & 2.435 & 133 & 27.63 & 2.62 & 0.14 & 1.12 & 0.77 & 0.13 & UCDW \\
\hline 2500 & 34.669 & 1.777 & 145 & 27.73 & 2.26 & 0.07 & 1.13 & 0.75 & 0.17 & \multirow{2}{*}{ LCDW } \\
\hline 4000 & 34.685 & 1.443 & 153 & 27.77 & 2.14 & 0.13 & 1.08 & 0.77 & 0.20 & \\
\hline \multicolumn{11}{|c|}{ Station 013 (July 04, 2012; 9 0' 10.8" S; 162 59' 56.4" E; depth : 3853m) } \\
\hline 5 & 34.651 & 29.182 & 191 & 21.74 & 1.74 & 0.61 & 1.14 & 0.45 & 0.34 & \multirow{2}{*}{ TSW } \\
\hline 40 & 34.675 & 29.157 & 191 & 21.77 & 1.77 & 0.54 & 1.05 & 0.44 & 0.29 & \\
\hline 160 & 35.830 & 24.121 & 129 & 24.24 & 3.32 & 0.74 & 1.26 & 0.53 & 0.19 & \multirow[t]{2}{*}{ SPEW } \\
\hline 300 & 35.188 & 15.244 & 106 & 26.07 & 2.54 & 0.26 & 0.96 & 0.57 & 0.18 & \\
\hline 600 & 34.515 & 6.128 & 138 & 27.16 & 3.52 & 0.10 & 1.08 & 0.72 & 0.12 & \multirow{3}{*}{ EqPIW } \\
\hline 685 & 34.503 & 5.528 & 138 & 27.22 & 2.89 & 0.14 & 1.18 & 0.71 & 0.12 & \\
\hline 1335 & 34.574 & 3.108 & 126 & 27.54 & 4.01 & 0.15 & 1.02 & 0.75 & 0.11 & \\
\hline 1535 & 34.595 & 2.709 & 129 & 27.60 & 4.86 & 0.10 & 1.11 & 0.78 & 0.12 & \multirow[t]{2}{*}{ UCDW } \\
\hline 2000 & 34.640 & 2.023 & 133 & 27.69 & 3.19 & 0.11 & 1.21 & 0.80 & 0.14 & \\
\hline \multicolumn{11}{|c|}{ Station 020 (July 06, 2012; 9 59' 56.4" S; 160²5' 1.2" E; depth : 2910m) } \\
\hline 25 & 34.832 & 28.896 & 189 & 21.97 & 2.09 & 0.56 & 1.21 & 0.56 & 0.27 & TSW \\
\hline 190 & 35.822 & 22.620 & 127 & 24.67 & - & - & - & - & - & SPEW \\
\hline 600 & 34.485 & 6.223 & 162 & 27.12 & 3.49 & 0.19 & 1.02 & 0.71 & 0.13 & \multirow{2}{*}{ AAIW } \\
\hline 900 & 34.490 & 4.787 & 151 & 27.30 & 3.53 & 0.12 & 1.08 & 0.72 & 0.12 & \\
\hline 1600 & 34.599 & 2.720 & 133 & 27.60 & - & - & - & - & - & UCDW \\
\hline \multicolumn{11}{|c|}{ Station 021 (July 07, 2012; $10^{\circ} 0^{\prime} 46.8^{\prime \prime}$ S; $160^{\circ} 21^{\prime} 25.2^{\prime \prime}$ E; depth : 3342m) } \\
\hline 250 & 35.388 & 17.226 & 127 & 25.76 & 3.05 & 0.35 & 1.08 & 0.53 & 0.20 & WSPCW \\
\hline 400 & 34.675 & 9.036 & 140 & 26.86 & 3.24 & 0.19 & 1.07 & 0.69 & 0.13 & SAMW \\
\hline 550 & 34.491 & 6.382 & 163 & 27.10 & 3.06 & 0.11 & 1.06 & 0.71 & 0.12 & AAIW \\
\hline 2115 & 34.644 & 2.075 & 139 & 27.69 & 3.48 & 0.10 & 1.20 & 0.80 & 0.16 & UCDW \\
\hline 2625 & 34.677 & 1.787 & 150 & 27.74 & 3.52 & 0.09 & 1.14 & 0.79 & 0.15 & \multirow{2}{*}{ LCDW } \\
\hline 3280 & 34.700 & 1.614 & 165 & 27.77 & 3.07 & 0.09 & 1.14 & 0.76 & 0.18 & \\
\hline \multicolumn{11}{|c|}{ Station 029 (July 09, 2012; 11ㅇ 3' 39.6" S; 156 12' 54" E; depth : 3856m) } \\
\hline 267 & 35.378 & 17.122 & 128 & 25.78 & 2.49 & 0.35 & 1.10 & 0.53 & 0.20 & - \\
\hline 737 & 34.465 & 5.346 & 160 & 27.21 & 3.32 & 0.18 & 1.07 & 0.73 & 0.12 & \multirow{3}{*}{ AAIW } \\
\hline 934 & 34.497 & 4.281 & 150 & 27.36 & 3.29 & 0.28 & 1.08 & 0.74 & 0.13 & \\
\hline 1140 & 34.535 & 3.704 & 139 & 27.45 & 3.37 & 0.16 & 1.16 & 0.74 & 0.12 & \\
\hline 1534 & 34.593 & 2.817 & 133 & 27.59 & 3.65 & 0.08 & 1.16 & 0.76 & 0.13 & UCDW \\
\hline 2999 & 34.699 & 1.687 & 166 & 27.77 & 3.02 & 0.10 & 1.14 & 0.77 & 0.17 & LCDW \\
\hline
\end{tabular}

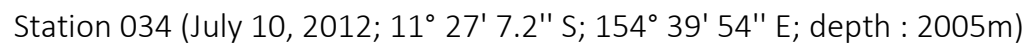




\begin{tabular}{|c|c|c|c|c|c|c|c|c|c|c|}
\hline 40 & 34.932 & 28.522 & 181 & 22.17 & 2.47 & 0.54 & 1.21 & 0.55 & 0.23 & TSW \\
\hline 180 & 35.656 & 21.834 & 144 & 24.77 & 3.76 & 0.50 & 1.21 & 0.57 & 0.20 & SPTW \\
\hline 300 & 35.247 & 15.416 & 156 & 26.08 & 2.46 & 0.30 & 1.14 & 0.60 & 0.18 & WSPCW \\
\hline 635 & 34.485 & 7.121 & 183 & 27.00 & 2.19 & 0.23 & 1.01 & 0.67 & 0.14 & SAMW \\
\hline 735 & 34.439 & 5.649 & 179 & 27.16 & 1.94 & 0.39 & 1.04 & 0.69 & 0.15 & \\
\hline 1065 & 34.493 & 4.140 & 154 & 27.37 & 3.23 & 0.24 & 1.05 & 0.71 & 0.13 & AAIVV \\
\hline 1550 & 34.600 & 2.730 & 136 & 27.60 & 3.02 & 0.15 & 1.05 & 0.73 & 0.14 & \\
\hline 1665 & 34.613 & 2.558 & 137 & 27.62 & 3.42 & 0.09 & 1.11 & 0.74 & 0.14 & UCDW \\
\hline 1750 & 34.625 & 2.385 & 136 & 27.65 & 2.88 & 0.10 & 1.11 & 0.74 & 0.15 & \\
\hline 1920 & 34.645 & 2.140 & 140 & 27.69 & - & - & - & - & - & \\
\hline \multicolumn{11}{|c|}{ Station 036 (July 11, 2012; $11^{\circ} 30^{\prime} 7.2^{\prime \prime} \mathrm{S} ; 154^{\circ} 23^{\prime}$ 24" E; depth : 1168m) } \\
\hline 24 & 34.489 & 27.756 & 195 & 22.09 & 1.52 & 0.54 & 1.25 & 0.59 & 0.34 & \multirow{2}{*}{ TSW } \\
\hline 101 & 35.431 & 24.271 & 163 & 23.89 & 2.31 & 0.56 & 1.18 & 0.55 & 0.22 & \\
\hline 159 & 35.609 & 22.290 & 141 & 24.60 & 2.28 & 0.50 & 1.22 & 0.54 & 0.22 & \multirow{2}{*}{ SPTW } \\
\hline 180 & 35.639 & 21.074 & 144 & 24.96 & 2.60 & 0.56 & 1.11 & 0.55 & 0.22 & \\
\hline 401 & 34.943 & 12.203 & 167 & 26.51 & 2.37 & 0.23 & 1.08 & 0.63 & 0.16 & WSPCW \\
\hline 699 & 34.460 & 6.285 & 182 & 27.09 & 2.75 & 0.12 & 0.98 & 0.69 & 0.13 & \multirow{2}{*}{ AAIW } \\
\hline 901 & 34.458 & 5.126 & 170 & 27.24 & 3.03 & 0.12 & 1.07 & 0.71 & 0.12 & \\
\hline \multicolumn{11}{|c|}{ Station 042 (July 15, 2012; 5 8' 42" S; 153 17' 24" E; depth : 3081m) } \\
\hline 5 & 34.691 & 29.381 & 192 & 21.71 & 2.50 & 0.61 & 1.26 & 0.50 & 0.29 & \multirow{3}{*}{ TSW } \\
\hline 50 & 34.753 & 29.380 & 192 & 21.75 & - & - & - & - & - & \\
\hline 100 & 35.464 & 28.210 & 157 & 22.68 & - & - & - & - & - & \\
\hline 180 & 35.648 & 21.971 & 140 & 24.72 & 2.62 & 0.50 & 1.21 & 0.55 & 0.20 & SPTW \\
\hline 225 & 35.353 & 16.762 & 152 & 25.85 & 2.99 & 0.26 & 0.79 & 0.57 & 0.17 & WSPCW \\
\hline 400 & 34.644 & 9.024 & 174 & 26.84 & 2.99 & 0.19 & 0.98 & 0.67 & 0.14 & \multirow{3}{*}{ SAMW } \\
\hline 500 & 34.538 & 7.266 & 158 & 27.02 & 2.79 & 0.16 & 1.03 & 0.70 & 0.13 & \\
\hline 750 & 34.484 & 5.316 & 154 & 27.23 & 3.24 & 0.15 & 1.06 & 0.73 & 0.12 & \\
\hline 1000 & 34.526 & 4.032 & 137 & 27.41 & 3.01 & 0.14 & 1.07 & 0.73 & 0.13 & \multirow[t]{3}{*}{ AAIW } \\
\hline 1200 & 34.557 & 3.501 & 130 & 27.49 & 3.31 & 0.18 & 1.22 & 0.77 & 0.13 & \\
\hline 1550 & 34.610 & 2.607 & 123 & 27.62 & 3.15 & 0.22 & 1.22 & 0.78 & 0.15 & \\
\hline 1750 & 34.621 & 2.419 & 124 & 27.64 & 3.99 & 0.20 & 1.16 & 0.78 & 0.15 & \multirow[t]{2}{*}{ UCDW } \\
\hline 2000 & 34.639 & 2.132 & 126 & 27.68 & 3.03 & 0.13 & 1.22 & 0.76 & 0.16 & \\
\hline 2500 & 34.660 & 1.782 & 133 & 27.73 & 3.02 & 0.15 & 1.20 & 0.78 & 0.18 & LCDW \\
\hline \multicolumn{11}{|c|}{ Station 043 (July 17, 2012; 3 59' 52.8" S; 155³5' 38.4" E; depth : 1925m) } \\
\hline 5 & 34.659 & 29.274 & 191 & 21.72 & 2.34 & 0.57 & 1.13 & 0.44 & 0.29 & TSW \\
\hline 150 & 35.914 & 25.138 & 138 & 23.99 & 2.65 & 0.49 & 1.12 & 0.55 & 0.20 & SPEW \\
\hline 230 & 35.161 & 14.819 & 99 & 26.14 & [6.85] & [1.32] & [1.19] & [0.64] & [0.17] & - \\
\hline 700 & 34.513 & 5.914 & 128 & 27.18 & 3.35 & 0.16 & 1.24 & 0.72 & 0.13 & EqPIW \\
\hline 1200 & 34.564 & 3.737 & 105 & 27.47 & 3.31 & 0.13 & 1.15 & 0.79 & 0.12 & UCDW \\
\hline \multicolumn{11}{|c|}{ Station 046 (July 18, 2012; 4 42' 0" S; 154 52' 48"' E; depth : 3117m) } \\
\hline 50 & 34.794 & 29.190 & 190 & 21.85 & 2.67 & 0.49 & 1.19 & 0.42 & 0.30 & TSW \\
\hline 150 & 35.974 & 25.365 & 129 & 23.97 & 3.29 & 0.36 & 1.11 & 0.52 & 0.18 & SPEW \\
\hline 400 & 34.649 & 8.724 & 124 & 26.89 & 3.52 & 0.26 & 1.11 & 0.68 & 0.14 & - \\
\hline 700 & 34.542 & 6.028 & 89 & 27.19 & 3.34 & 0.09 & 1.10 & 0.72 & 0.12 & EqPIW \\
\hline 1000 & 34.540 & 4.326 & 112 & 27.39 & 3.43 & 0.15 & 1.07 & 0.75 & 0.13 & UCDW \\
\hline \multicolumn{11}{|c|}{ Station 047 (July 18, 2012; 4 56' 2.4" S; 154 38' 52.8" E; depth : 1004m) } \\
\hline 25 & 34.670 & 29.108 & 190 & 21.78 & 1.99 & 0.50 & 1.27 & 0.51 & 0.30 & TSW \\
\hline 156 & 36.017 & 24.025 & 126 & 24.41 & 3.80 & 0.63 & 0.99 & 0.51 & 0.18 & SPEW \\
\hline 264 & 35.082 & 13.952 & 106 & 26.27 & 2.71 & 0.22 & 1.05 & 0.63 & 0.16 & - \\
\hline 635 & 34.522 & 5.856 & 129 & 27.20 & 2.92 & 0.21 & 1.09 & 0.72 & 0.13 & EqPIW \\
\hline \multicolumn{11}{|c|}{ Station 053 (July 19, 2012; 4 54' 18" S; 152 52' 12" E; depth : 733m) } \\
\hline 25 & 34.879 & 28.959 & 189 & 21.99 & 2.55 & 0.57 & 1.27 & 0.57 & 0.26 & TSW \\
\hline 149 & 35.610 & 21.864 & 142 & 24.72 & 3.30 & 0.89 & 1.12 & 0.55 & 0.23 & SPTW \\
\hline 335 & 34.977 & 12.632 & 161 & 26.45 & 2.57 & 0.21 & 1.10 & 0.65 & 0.16 & WSPCW \\
\hline 719 & 34.480 & 5.424 & 158 & 27.22 & 3.17 & 0.12 & 1.07 & 0.71 & 0.13 & AAIW \\
\hline
\end{tabular}




\begin{tabular}{|c|c|c|c|c|c|c|c|c|c|c|}
\hline 1582 & 34.599 & 2.818 & 125 & 27.59 & 3.20 & 0.18 & 1.08 & 0.72 & 0.15 & UCDW \\
\hline \multicolumn{11}{|c|}{ Station 057 (July 20, 2012; $4^{\circ} 34^{\prime} 12^{\prime \prime} \mathrm{S} ; 152^{\circ} 31^{\prime} 22.8^{\prime \prime} \mathrm{E}$; depth : 2552m) } \\
\hline 25 & 34.767 & 28.952 & 192 & 21.91 & 3.16 & 0.59 & 1.39 & 0.55 & 0.27 & TSW \\
\hline 150 & 35.583 & 23.624 & 139 & 24.20 & 2.52 & 0.52 & 1.19 & 0.55 & 0.21 & SPTW \\
\hline 250 & 35.268 & 15.802 & 152 & 26.00 & 2.45 & 0.32 & 1.09 & 0.58 & 0.18 & \multirow{2}{*}{ WSPCW } \\
\hline 450 & 34.650 & 8.974 & 171 & 26.85 & 2.94 & 0.16 & 1.02 & 0.71 & 0.14 & \\
\hline 580 & 34.509 & 7.083 & 177 & 27.02 & 2.85 & 0.22 & 1.06 & 0.69 & 0.13 & SAMW \\
\hline 850 & 34.503 & 4.623 & 143 & 27.33 & 3.53 & 0.14 & 1.15 & 0.76 & 0.12 & AAIW \\
\hline 1302 & 34.565 & 3.374 & 129 & 27.51 & 4.17 & 0.18 & 1.18 & 0.77 & 0.13 & \\
\hline 1650 & 34.611 & 2.610 & 124 & 27.62 & - & - & - & - & - & ULDV \\
\hline 2201 & 34.654 & 1.992 & 135 & 27.71 & 3.77 & 0.13 & 1.20 & 0.79 & 0.17 & LCDW \\
\hline \multicolumn{11}{|c|}{ Station 058 (July 21, 2012; 5³0' 10.8" S; $152^{\circ} 5^{\prime}$ 52.8' E; depth : 1142m) } \\
\hline 215 & 35.500 & 18.602 & 135 & 25.51 & 2.74 & 0.40 & 1.16 & 0.56 & 0.20 & WSPCW \\
\hline 1100 & 34.547 & 3.675 & 133 & 27.47 & 3.77 & 0.20 & 1.07 & 0.76 & 0.13 & UCDW \\
\hline \multicolumn{11}{|c|}{ Station 060 (July 22, 2012; 6 10' 1.2" S; 152²9' 49.2" E; depth : 5609m) } \\
\hline 35 & 34.737 & 28.022 & 193 & 22.19 & 2.03 & 0.59 & 1.30 & 0.54 & 0.30 & TSW \\
\hline 180 & 35.733 & 22.267 & 135 & 24.70 & 2.40 & 0.44 & 1.18 & 0.52 & 0.22 & SPTW \\
\hline 250 & 35.325 & 16.605 & 124 & 25.86 & 3.65 & 0.55 & 1.22 & 0.58 & 0.19 & WSPCW \\
\hline 480 & 34.531 & 7.193 & 173 & 27.03 & 2.97 & 0.25 & 1.08 & 0.72 & 0.13 & SAMW \\
\hline 1000 & 34.530 & 3.930 & 138 & 27.43 & 3.68 & 0.19 & 1.20 & 0.74 & 0.13 & AAIW \\
\hline 1600 & 34.611 & 2.604 & 124 & 27.62 & 3.08 & 0.22 & 1.18 & 0.79 & 0.15 & \multirow{2}{*}{ UCDW } \\
\hline 1800 & 34.631 & 2.263 & 125 & 27.67 & 3.11 & 0.29 & 1.16 & 0.77 & 0.17 & \\
\hline 2541 & 34.661 & 1.724 & 132 & 27.73 & 3.21 & 0.10 & 1.28 & 0.81 & 0.19 & \\
\hline 3250 & 34.692 & 1.673 & 155 & 27.76 & 2.81 & 0.14 & 1.31 & 0.83 & 0.22 & \\
\hline 4000 & 34.696 & 1.665 & 158 & 27.77 & 2.62 & 0.13 & 1.28 & 0.81 & 0.23 & \\
\hline 4500 & 34.696 & 1.660 & 160 & 27.77 & 2.31 & 0.16 & 1.34 & 0.79 & 0.23 & LCDW \\
\hline 4750 & 34.697 & 1.656 & 160 & 27.77 & 2.26 & 0.27 & 1.29 & 0.75 & 0.25 & \\
\hline 5000 & 34.697 & 1.653 & 161 & 27.77 & 3.43 & 0.15 & 1.29 & 0.72 & 0.22 & \\
\hline 5603 & 34.697 & 1.649 & 162 & 27.77 & 2.30 & 0.12 & 1.19 & 0.75 & 0.24 & \\
\hline \multicolumn{11}{|c|}{ Station 071 (July 25, 2012; 8 19' 55.2" S; 151 17' 27.6" E; depth : 1563m) } \\
\hline 50 & 34.797 & 27.552 & 192 & 22.39 & 2.14 & 0.46 & 1.26 & 0.52 & 0.24 & TSW \\
\hline 160 & 35.659 & 22.424 & 138 & 24.60 & 5.68 & 1.37 & 1.09 & 0.52 & 0.22 & SPTW \\
\hline 400 & 34.977 & 12.552 & 165 & 26.47 & 4.17 & 0.67 & 1.08 & 0.63 & 0.17 & WSPCW \\
\hline 600 & 34.493 & 6.699 & 178 & 27.06 & 3.00 & 0.17 & 1.00 & 0.71 & 0.13 & AAIW \\
\hline 1100 & 34.522 & 4.051 & 143 & 27.41 & 5.89 & 0.36 & 1.17 & 0.74 & 0.13 & UCDW \\
\hline \multicolumn{11}{|c|}{ Station 073 (July 26, 2012; 7 9' 57.6" S; 149 59' 56.4" E; depth : 5253m) } \\
\hline 50 & 35.058 & 27.325 & 171 & 22.66 & 2.40 & 0.55 & 1.22 & 0.55 & 0.24 & TSW \\
\hline 170 & 35.586 & 21.658 & 141 & 24.76 & 2.40 & 0.44 & 1.33 & 0.55 & 0.21 & \multirow{2}{*}{ SPTW } \\
\hline 200 & 35.602 & 21.191 & 140 & 24.90 & 2.85 & 0.36 & 1.15 & 0.53 & 0.19 & \\
\hline 700 & 34.474 & 5.882 & 169 & 27.16 & 3.24 & 0.11 & 1.12 & 0.71 & 0.12 & AAIW \\
\hline 1650 & 34.609 & 2.604 & 123 & 27.62 & 3.35 & 0.13 & 1.18 & 0.77 & 0.14 & UCDW \\
\hline \multicolumn{11}{|c|}{ Station 077 (July 28, 2012; 5 57' 3.6" S; 147³9' 36" E; depth : 1045m) } \\
\hline 25 & 34.767 & 27.606 & 191 & 22.35 & 4.19 & 0.53 & 1.24 & 0.57 & 0.26 & TSW \\
\hline 180 & 35.609 & 21.401 & 140 & 24.85 & 2.52 & 0.48 & 1.12 & 0.53 & 0.21 & SPTW \\
\hline 501 & 34.572 & 8.016 & 178 & 26.94 & 2.43 & 0.37 & 1.09 & 0.71 & 0.16 & SAMW \\
\hline 701 & 34.477 & 5.536 & 159 & 27.20 & 3.00 & 0.13 & 1.05 & 0.71 & 0.13 & \multirow{2}{*}{ AAIW } \\
\hline 983 & 34.505 & 4.473 & 145 & 27.35 & 3.73 & 0.19 & 1.13 & 0.74 & 0.13 & \\
\hline \multicolumn{11}{|c|}{ Station 082- Non-filtrated (August 03, 2012; $13^{\circ} 59^{\prime} 49.2^{\prime \prime} \mathrm{S} ; 156^{\circ} 0^{\prime} 25.2^{\prime \prime}$ E; depth : $2586 \mathrm{~m}$ ) } \\
\hline 25 & 34.927 & 26.195 & 197 & 22.92 & 2.68 & 0.72 & 1.40 & 0.53 & 0.26 & TSW \\
\hline 180 & 35.789 & 22.612 & 129 & 24.65 & 3.06 & 0.82 & 1.04 & 0.53 & 0.21 & SPTW \\
\hline 700 & 34.469 & 6.035 & 165 & 27.13 & 2.55 & 0.32 & 1.00 & 0.67 & 0.14 & \\
\hline 800 & 34.451 & 5.083 & 163 & 27.23 & 2.65 & 0.29 & 1.02 & 0.68 & 0.13 & AAIW \\
\hline 1000 & 34.498 & 4.114 & 151 & 27.38 & 3.14 & 0.92 & 1.04 & 0.71 & 0.13 & \\
\hline 1200 & 34.539 & 3.454 & 145 & 27.48 & 3.60 & 0.44 & 1.05 & 0.74 & 0.12 & \\
\hline 1350 & 34.565 & 3.159 & 140 & 27.53 & 3.45 & 0.17 & 0.98 & 0.73 & 0.13 & UCDW \\
\hline 2000 & 34.636 & 2.226 & 141 & 27.67 & 2.29 & 0.37 & 1.18 & 0.77 & 0.14 & \\
\hline
\end{tabular}


Table 2: Dissolved REE concentrations (pmol.kg-1). Data are reported with daily confidence interval (2б).

\begin{tabular}{|c|c|c|c|c|c|c|c|c|c|c|c|c|c|c|c|c|c|}
\hline Depth & Salinity & $\mathrm{O}_{2}$ & $\sigma_{\theta}$ & La & $\mathrm{Ce}$ & $\operatorname{Pr}$ & $\mathrm{Nd}$ & Sm & $\mathrm{Eu}$ & Gd & $\mathrm{Tb}$ & Dy & Ho & $\mathrm{Er}$ & $\mathrm{Tm}$ & $\mathrm{Yb}$ & Lu \\
\hline (m) & (PSU) & $\left(\mu \mathrm{mol} . \mathrm{kg}^{-1}\right)$ & $\left(\mathrm{kg} \mathrm{m}^{-3}\right)$ & \multicolumn{14}{|c|}{$\left(\mathrm{pmol} . \mathrm{kg}^{-1}\right)$} \\
\hline \multicolumn{18}{|c|}{ Station 004 (July 01, 2012; $17^{\circ} 0^{\prime} 10.8^{\prime \prime}$ S; 162 59' 45.6" E ; depth: 4680m) } \\
\hline 30 & 34.84 & 199 & 22.94 & $3.7 \pm 0.1$ & $3.3 \pm 0.1$ & $0.8 \pm 0$ & $3.8 \pm 0.1$ & $0.9 \pm 0$ & $0.3 \pm 0$ & $1.5 \pm 0.1$ & $0.2 \pm 0$ & $1.8 \pm 0.1$ & $0.5 \pm 0$ & $1.6 \pm 0.1$ & $0.2 \pm 0$ & $1 \pm 0$ & $0.2 \pm 0$ \\
\hline 166 & 35.63 & 164 & 24.83 & $3.3 \pm 0.1$ & $2.6 \pm 0.1$ & $0.7 \pm 0$ & $3.2 \pm 0.1$ & $0.8 \pm 0$ & $0.2 \pm 0$ & $1.2 \pm 0.1$ & $0.2 \pm 0$ & $1.5 \pm 0.1$ & $0.4 \pm 0$ & $1.5 \pm 0.1$ & $0.2 \pm 0$ & $1 \pm 0$ & $0.2 \pm 0$ \\
\hline 250 & 35.46 & 161 & 25.67 & $4.1 \pm 0.2$ & $2.4 \pm 0.1$ & $0.7 \pm 0$ & $3.4 \pm 0.1$ & $0.8 \pm 0$ & $0.2 \pm 0$ & $1.2 \pm 0$ & $0.2 \pm 0$ & $1.6 \pm 0.1$ & $0.4 \pm 0$ & $1.5 \pm 0.1$ & $0.2 \pm 0$ & $1.1 \pm 0$ & $0.2 \pm 0$ \\
\hline 351 & 35.10 & 167 & 26.28 & $6.2 \pm 0.2$ & $1.8 \pm 0$ & $1 \pm 0$ & $4.5 \pm 0.1$ & $0.9 \pm 0$ & $0.3 \pm 0$ & $1.6 \pm 0.1$ & $0.2 \pm 0$ & $2 \pm 0.1$ & $0.6 \pm 0$ & $2.2 \pm 0.1$ & $0.3 \pm 0$ & $1.8 \pm 0$ & $0.3 \pm 0$ \\
\hline 621 & 34.43 & 192 & 27.04 & $11.8 \pm 0.5$ & $1.6 \pm 0.1$ & $1.7 \pm 0.1$ & $7.3 \pm 0.2$ & $1.7 \pm 0.1$ & $0.4 \pm 0$ & $2.5 \pm 0.1$ & $0.4 \pm 0$ & $3.4 \pm 0.1$ & $1 \pm 0$ & $3.9 \pm 0.3$ & $0.6 \pm 0$ & $3.7 \pm 0.1$ & $0.7 \pm 0$ \\
\hline 730 & 34.42 & 179 & 27.17 & $12.3 \pm 0.6$ & $1.3 \pm 0.1$ & $1.8 \pm 0.1$ & $7.7 \pm 0.4$ & $1.5 \pm 0.1$ & $0.5 \pm 0$ & $2.8 \pm 0.1$ & $0.4 \pm 0$ & $3.6 \pm 0.2$ & $1.1 \pm 0.1$ & $4.2 \pm 0.2$ & $0.7 \pm 0$ & $4.1 \pm 0.1$ & $0.8 \pm 0$ \\
\hline 1134 & 34.51 & 157 & 27.44 & $19 \pm 0.7$ & $8.3 \pm 0.3$ & $2.5 \pm 0.1$ & $10.3 \pm 0.3$ & $2 \pm 0.1$ & $0.6 \pm 0$ & $3.5 \pm 0.2$ & $0.5 \pm 0$ & $4.7 \pm 0.3$ & $1.4 \pm 0.1$ & $5.4 \pm 0.3$ & $0.9 \pm 0$ & $5.7 \pm 0.2$ & $1.1 \pm 0$ \\
\hline 1734 & 34.62 & 140 & 27.64 & - & - & - & - & - & - & - & - & - & - & - & - & - & - \\
\hline 3598 & 34.69 & 156 & 27.76 & $33.5 \pm 1.3$ & $2.4 \pm 0.1$ & $4.8 \pm 0.2$ & $24.1 \pm 0.7$ & $3.8 \pm 0.2$ & $1.1 \pm 0$ & $6 \pm 0.3$ & $0.9 \pm 0$ & $7.4 \pm 0.3$ & $2.1 \pm 0.1$ & $7.4 \pm 0.4$ & $1.2 \pm 0.1$ & $7.7 \pm 0.3$ & $1.4 \pm 0.1$ \\
\hline \multicolumn{18}{|c|}{ Station 010 (July 03, 2012; 120' 0" S; 162 59' 56.4" E; depth : 5092m) } \\
\hline 35 & 34.62 & 191 & 22.09 & $3.4 \pm 0.1$ & $2.6 \pm 0.1$ & $0.8 \pm 0$ & $3.6 \pm 0.1$ & $0.8 \pm 0$ & $0.3 \pm 0$ & $1.5 \pm 0.1$ & $0.2 \pm 0$ & $1.7 \pm 0.1$ & $0.5 \pm 0$ & $1.5 \pm 0.1$ & $0.2 \pm 0$ & $1 \pm 0$ & $0.2 \pm 0$ \\
\hline 185 & 36.03 & 134 & 24.50 & - & - & - & - & - & - & - & - & - & - & - & - & - & - \\
\hline 260 & 35.52 & 133 & 25.58 & $5.2 \pm 0.2$ & $1.8 \pm 0.1$ & $0.8 \pm 0$ & $3.6 \pm 0.1$ & $0.7 \pm 0$ & $0.2 \pm 0$ & $1.2 \pm 0.1$ & $0.2 \pm 0$ & $1.6 \pm 0.1$ & $0.5 \pm 0$ & $1.6 \pm 0.1$ & $0.2 \pm 0$ & $1.2 \pm 0$ & $0.2 \pm 0$ \\
\hline 350 & 34.92 & 148 & 26.40 & $7.4 \pm 0.3$ & $2.1 \pm 0.1$ & $1.1 \pm 0$ & $4.9 \pm 0.2$ & $0.9 \pm 0$ & $0.3 \pm 0$ & $1.7 \pm 0.1$ & $0.3 \pm 0$ & $2.2 \pm 0.1$ & $0.6 \pm 0$ & $2.3 \pm 0.1$ & $0.3 \pm 0$ & $1.9 \pm 0.1$ & $0.3 \pm 0$ \\
\hline 515 & 34.51 & 163 & 26.98 & - & - & - & - & - & - & - & - & - & - & - & - & - & - \\
\hline 680 & 34.46 & 158 & 27.20 & $13 \pm 0.5$ & {$[1.3 \pm 0.1]$} & $1.7 \pm 0.1$ & $7.7 \pm 0.2$ & $1.5 \pm 0.1$ & $0.4 \pm 0$ & $2.6 \pm 0.1$ & $0.4 \pm 0$ & $3.7 \pm 0.2$ & $1.1 \pm 0.1$ & $4.2 \pm 0.2$ & $0.7 \pm 0$ & $4.3 \pm 0.1$ & $0.8 \pm 0.1$ \\
\hline 1000 & 34.52 & 139 & 27.41 & - & - & - & - & - & - & - & - & - & - & - & - & - & - \\
\hline 1735 & 34.61 & 133 & 27.63 & $24.4 \pm 1$ & $3.2 \pm 0.1$ & $3 \pm 0.1$ & $13.1 \pm 0.3$ & $2.4 \pm 0.1$ & $0.8 \pm 0$ & $4.3 \pm 0.2$ & $0.7 \pm 0$ & $5.7 \pm 0.3$ & $1.7 \pm 0.1$ & $6.3 \pm 0.3$ & $1 \pm 0$ & $6.8 \pm 0.2$ & $1.3 \pm 0.1$ \\
\hline 2500 & 34.67 & 145 & 27.73 & $31 \pm 1.5$ & $2.2 \pm 0.1$ & $4.3 \pm 0.2$ & $18.5 \pm 0.6$ & $3.5 \pm 0.2$ & $1.1 \pm 0.1$ & $5.6 \pm 0.3$ & $0.9 \pm 0$ & $7.1 \pm 0.4$ & $2.1 \pm 0.1$ & $7.3 \pm 0.4$ & $1.1 \pm 0.1$ & $7.6 \pm 0.3$ & $1.4 \pm 0.1$ \\
\hline 4000 & 34.69 & 153 & 27.77 & $39.1 \pm 1.3$ & $5.9 \pm 0.2$ & $5.8 \pm 0.2$ & $24.6 \pm 0.7$ & $4.7 \pm 0.2$ & $1.3 \pm 0.1$ & $7.2 \pm 0.3$ & $1.1 \pm 0$ & $8.5 \pm 0.4$ & $2.4 \pm 0.1$ & $8.3 \pm 0.4$ & $1.3 \pm 0$ & $8.6 \pm 0.3$ & $1.6 \pm 0.1$ \\
\hline \multicolumn{18}{|c|}{ Station 013 (July 04, 2012; 9 0' 10.8" S; 162 59' 56.4" E; depth : 3853m) } \\
\hline 5 & 34.65 & 191 & 21.74 & $4 \pm 0.1$ & $3.8 \pm 0.1$ & $0.9 \pm 0$ & $3.9 \pm 0.1$ & $0.8 \pm 0.1$ & $0.2 \pm 0$ & $1.3 \pm 0.1$ & $0.2 \pm 0$ & $1.6 \pm 0.1$ & $0.4 \pm 0$ & $1.4 \pm 0$ & $0.2 \pm 0$ & $0.8 \pm 0$ & $0.1 \pm 0$ \\
\hline 40 & 34.68 & 191 & 21.77 & $3.3 \pm 0.1$ & $2.8 \pm 0.1$ & $0.7 \pm 0$ & $3.3 \pm 0$ & $0.7 \pm 0$ & $0.2 \pm 0$ & $1.2 \pm 0$ & $0.2 \pm 0$ & $1.5 \pm 0$ & $0.4 \pm 0$ & $1.4 \pm 0$ & $0.2 \pm 0$ & $0.8 \pm 0$ & $0.1 \pm 0$ \\
\hline 160 & 35.83 & 129 & 24.24 & $4 \pm 0.1$ & $2.9 \pm 0.1$ & $0.6 \pm 0$ & $2.8 \pm 0.1$ & $0.6 \pm 0$ & $0.2 \pm 0$ & $1.1 \pm 0$ & $0.2 \pm 0$ & $1.4 \pm 0.1$ & $0.4 \pm 0$ & $1.4 \pm 0$ & $0.2 \pm 0$ & $1 \pm 0$ & $0.2 \pm 0$ \\
\hline 300 & 35.19 & 106 & 26.07 & $5.6 \pm 0.1$ & {$[1.6 \pm 0]$} & $0.8 \pm 0$ & $3.7 \pm 0.1$ & $0.7 \pm 0$ & $0.2 \pm 0$ & $1.3 \pm 0$ & $0.2 \pm 0$ & $1.7 \pm 0.1$ & $0.5 \pm 0$ & $1.9 \pm 0.1$ & $0.3 \pm 0$ & $1.5 \pm 0$ & $0.3 \pm 0$ \\
\hline 600 & 34.52 & 138 & 27.16 & $11.8 \pm 0.2$ & {$[1 \pm 0]$} & $1.5 \pm 0$ & $7.2 \pm 0.1$ & $1.4 \pm 0$ & $0.5 \pm 0$ & $2.5 \pm 0.1$ & $0.4 \pm 0$ & $3.5 \pm 0.1$ & $1.1 \pm 0$ & $4 \pm 0.1$ & $0.6 \pm 0$ & $4.1 \pm 0.1$ & $0.8 \pm 0$ \\
\hline 685 & 34.50 & 138 & 27.22 & $12.2 \pm 0.5$ & $1.6 \pm 0.1$ & $1.6 \pm 0$ & $7.2 \pm 0.2$ & $1.4 \pm 0.1$ & $0.5 \pm 0$ & $2.4 \pm 0.1$ & $0.4 \pm 0$ & $3.4 \pm 0.2$ & $1.1 \pm 0$ & $4.1 \pm 0.2$ & $0.6 \pm 0$ & $4.2 \pm 0.1$ & $0.8 \pm 0$ \\
\hline 1335 & 34.57 & 126 & 27.54 & $18.3 \pm 0.5$ & $2.1 \pm 0.1$ & $2 \pm 0.1$ & $9.6 \pm 0.2$ & $2 \pm 0.1$ & $0.6 \pm 0$ & $3.1 \pm 0.1$ & $0.5 \pm 0$ & $4.7 \pm 0.2$ & $1.3 \pm 0$ & $5.5 \pm 0.2$ & $0.8 \pm 0$ & $5.9 \pm 0.1$ & $1 \pm 0$ \\
\hline 1535 & 34.60 & 129 & 27.60 & $20 \pm 0.7$ & $1.4 \pm 0.1$ & $2.2 \pm 0.1$ & $10.6 \pm 0.3$ & $1.9 \pm 0.1$ & $0.6 \pm 0$ & $3.5 \pm 0.2$ & $0.5 \pm 0$ & $4.9 \pm 0.2$ & $1.4 \pm 0.1$ & $5.6 \pm 0.2$ & $0.9 \pm 0$ & $6.2 \pm 0.2$ & $1.2 \pm 0.1$ \\
\hline 2000 & 34.64 & 133 & 27.69 & $26.8 \pm 1.1$ & $2.6 \pm 0.1$ & $3.3 \pm 0.1$ & $14.8 \pm 0.4$ & $2.8 \pm 0.1$ & $0.9 \pm 0$ & $4.7 \pm 0.2$ & $0.7 \pm 0$ & $6.1 \pm 0.4$ & $1.7 \pm 0.1$ & $6.6 \pm 0.3$ & $1 \pm 0$ & $7.3 \pm 0.2$ & $1.4 \pm 0.1$ \\
\hline
\end{tabular}




\begin{tabular}{|c|c|c|c|c|c|c|c|c|c|c|c|c|c|c|c|c|c|}
\hline 25 & 34.83 & 189 & 21.97 & $4.3 \pm 0.2$ & $3.7 \pm 0.1$ & $1 \pm 0$ & $4.7 \pm 0.2$ & $1.1 \pm 0.1$ & $0.3 \pm 0$ & $1.7 \pm 0.1$ & $0.3 \pm 0$ & $2.1 \pm 0.1$ & $0.5 \pm 0$ & $1.7 \pm 0.1$ & $0.2 \pm 0$ & $1.2 \pm 0$ & $0.2 \pm 0$ \\
\hline 190 & 35.82 & 127 & 24.67 & - & - & - & - & - & - & - & - & - & - & - & - & - & - \\
\hline 600 & 34.49 & 162 & 27.12 & $0 \pm 0$ & $0 \pm 0$ & $0 \pm 0$ & $0 \pm 0$ & $0 \pm 0$ & $0 \pm 0$ & $0 \pm 0$ & $0 \pm 0$ & $0 \pm 0$ & $0 \pm 0$ & $0 \pm 0$ & $0 \pm 0$ & $0 \pm 0$ & $0 \pm 0$ \\
\hline 900 & 34.49 & 151 & 27.30 & $14.1 \pm 0.6$ & $1.5 \pm 0.1$ & $1.8 \pm 0.1$ & $8.2 \pm 0.3$ & $1.6 \pm 0.1$ & $0.5 \pm 0$ & $2.8 \pm 0.2$ & $0.4 \pm 0$ & $3.8 \pm 0.2$ & $1.2 \pm 0$ & $4.5 \pm 0.2$ & $0.7 \pm 0$ & $4.7 \pm 0.2$ & $0.9 \pm 0$ \\
\hline 1600 & 34.60 & 133 & 27.60 & - & - & - & - & - & - & - & - & - & - & - & - & - & - \\
\hline \multicolumn{18}{|c|}{ Station 021 (July 07, 2012; $10^{\circ} 0^{\prime} 46.8^{\prime \prime} \mathrm{S} ; 160^{\circ} 21^{\prime} 25.2^{\prime \prime} \mathrm{E}$; depth : 3342m) } \\
\hline 250 & 35.39 & 127 & 25.76 & $5.6 \pm 0.2$ & $2 \pm 0.1$ & $0.9 \pm 0$ & $4.1 \pm 0.1$ & $0.7 \pm 0$ & $0.2 \pm 0$ & $1.4 \pm 0.1$ & $0.2 \pm 0$ & $1.8 \pm 0.1$ & $0.5 \pm 0$ & $1.9 \pm 0.1$ & $0.3 \pm 0$ & $1.4 \pm 0$ & $0.3 \pm 0$ \\
\hline 400 & 34.68 & 140 & 26.86 & $8.2 \pm 0.2$ & $1.5 \pm 0$ & $1.1 \pm 0$ & $5.3 \pm 0.1$ & $1.1 \pm 0$ & $0.3 \pm 0$ & $1.8 \pm 0.1$ & $0.3 \pm 0$ & $2.6 \pm 0.1$ & $0.8 \pm 0$ & $2.9 \pm 0.1$ & $0.4 \pm 0$ & $2.8 \pm 0.1$ & $0.5 \pm 0$ \\
\hline 550 & 34.49 & 163 & 27.10 & $10.3 \pm 0.2$ & $1.2 \pm 0$ & $1.5 \pm 0$ & $6.8 \pm 0.1$ & $1.4 \pm 0$ & $0.4 \pm 0$ & $2.4 \pm 0.1$ & $0.4 \pm 0$ & $3.4 \pm 0.1$ & $1 \pm 0$ & $3.8 \pm 0.1$ & $0.6 \pm 0$ & $3.8 \pm 0.1$ & $0.7 \pm 0$ \\
\hline 2115 & 34.64 & 139 & 27.69 & $27.7 \pm 0.6$ & $2.4 \pm 0.1$ & $3.5 \pm 0.1$ & $16.5 \pm 0.3$ & $3.1 \pm 0.1$ & $1 \pm 0$ & $5.1 \pm 0.2$ & $0.8 \pm 0$ & $6.4 \pm 0.2$ & $1.8 \pm 0$ & $6.5 \pm 0.2$ & $1 \pm 0$ & $7 \pm 0.1$ & $1.3 \pm 0$ \\
\hline 2625 & 34.68 & 150 & 27.74 & $26.4 \pm 0.4$ & $2.1 \pm 0.1$ & $3.4 \pm 0.1$ & $15.9 \pm 0.2$ & $2.9 \pm 0.1$ & $0.9 \pm 0$ & $5.1 \pm 0.2$ & $0.8 \pm 0$ & $6.6 \pm 0.2$ & $1.9 \pm 0$ & $6.9 \pm 0.2$ & $1.1 \pm 0$ & $7.6 \pm 0.1$ & $1.4 \pm 0$ \\
\hline 3280 & 34.70 & 165 & 27.77 & $31.1 \pm 2$ & $2.7 \pm 0.2$ & $4.1 \pm 0.2$ & $19 \pm 0.7$ & $3.5 \pm 0.2$ & $1.1 \pm 0.1$ & $5.5 \pm 0.4$ & $0.8 \pm 0.1$ & $6.8 \pm 0.6$ & $1.9 \pm 0.1$ & $6.9 \pm 0.6$ & $1 \pm 0.1$ & $7.1 \pm 0.3$ & $1.3 \pm 0.1$ \\
\hline \multicolumn{18}{|c|}{ 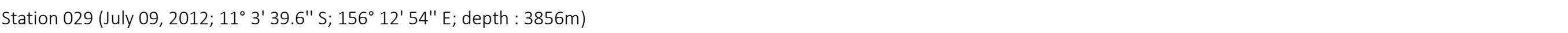 } \\
\hline 267 & 35.38 & 128 & 25.78 & $5.2 \pm 0.2$ & $2.2 \pm 0.1$ & $0.9 \pm 0$ & $4 \pm 0.1$ & $0.8 \pm 0$ & $0.2 \pm 0$ & $1.4 \pm 0.1$ & $0.2 \pm 0$ & $1.8 \pm 0.1$ & $0.5 \pm 0$ & $1.9 \pm 0.1$ & $0.3 \pm 0$ & $1.4 \pm 0$ & $0.3 \pm 0$ \\
\hline 737 & 34.47 & 160 & 27.21 & $11.4 \pm 0.4$ & $1.9 \pm 0.1$ & $1.6 \pm 0$ & $7.2 \pm 0.2$ & $1.4 \pm 0.1$ & $0.4 \pm 0$ & $2.5 \pm 0.1$ & $0.4 \pm 0$ & $3.5 \pm 0.1$ & $1 \pm 0$ & $4 \pm 0.2$ & $0.6 \pm 0$ & $4.1 \pm 0.1$ & $0.8 \pm 0$ \\
\hline 934 & 34.50 & 150 & 27.36 & $15.3 \pm 0.6$ & $3.8 \pm 0.1$ & $1.9 \pm 0.1$ & $8.6 \pm 0.2$ & $1.6 \pm 0.1$ & $0.5 \pm 0$ & $2.8 \pm 0.1$ & $0.5 \pm 0$ & $3.9 \pm 0.2$ & $1.1 \pm 0$ & $4.5 \pm 0.2$ & $0.7 \pm 0$ & $4.7 \pm 0.1$ & $0.9 \pm 0$ \\
\hline 1140 & 34.54 & 139 & 27.45 & $16.2 \pm 0.5$ & $2.2 \pm 0$ & $2 \pm 0$ & $9.2 \pm 0.2$ & $1.8 \pm 0.1$ & $0.6 \pm 0$ & $3.2 \pm 0.1$ & $0.5 \pm 0$ & $4.2 \pm 0.2$ & $1.3 \pm 0$ & $4.9 \pm 0.2$ & $0.8 \pm 0$ & $5.3 \pm 0.1$ & $1 \pm 0$ \\
\hline 1534 & 34.59 & 133 & 27.59 & $18.9 \pm 0.7$ & $1.3 \pm 0.1$ & $2.4 \pm 0.1$ & $11.4 \pm 0.3$ & $2.2 \pm 0.1$ & $0.7 \pm 0$ & $3.8 \pm 0.2$ & $0.6 \pm 0$ & $5.2 \pm 0.3$ & $1.5 \pm 0.1$ & $5.8 \pm 0.2$ & $0.9 \pm 0$ & $6.2 \pm 0.2$ & $1.2 \pm 0.1$ \\
\hline 2999 & 34.70 & 166 & 27.77 & $27.1 \pm 2$ & $2.7 \pm 0.2$ & $3.7 \pm 0.2$ & $16.9 \pm 0.9$ & $3.2 \pm 0.3$ & $1 \pm 0.1$ & $5.1 \pm 0.4$ & $0.8 \pm 0$ & $6.5 \pm 0.4$ & $1.8 \pm 0.1$ & $6.6 \pm 0.4$ & $1 \pm 0.1$ & $6.9 \pm 0.4$ & $1.3 \pm 0.1$ \\
\hline \multicolumn{18}{|c|}{ Station 034 (July 10, 2012; $11^{\circ} 27^{\prime} 7.2^{\prime \prime} \mathrm{S} ; 154^{\circ} 39^{\prime}$ 54" E; depth : $2005 \mathrm{~m}$ ) } \\
\hline 40 & 34.93 & 181 & 22.17 & $4 \pm 0.1$ & $3 \pm 0.1$ & $0.9 \pm 0$ & $4.2 \pm 0.1$ & $1 \pm 0$ & $0.3 \pm 0$ & $1.7 \pm 0$ & $0.3 \pm 0$ & $2 \pm 0$ & $0.6 \pm 0$ & $1.8 \pm 0$ & $0.2 \pm 0$ & $1.3 \pm 0$ & $0.2 \pm 0$ \\
\hline 180 & 35.66 & 144 & 24.77 & $3.7 \pm 0.1$ & $2.1 \pm 0$ & $0.7 \pm 0$ & $3.4 \pm 0$ & $0.7 \pm 0$ & $0.3 \pm 0$ & $1.3 \pm 0$ & $0.3 \pm 0$ & $1.7 \pm 0$ & $0.5 \pm 0$ & $1.6 \pm 0.1$ & $0.2 \pm 0$ & $1.2 \pm 0$ & $0.2 \pm 0$ \\
\hline 300 & 35.25 & 156 & 26.08 & $5.8 \pm 0.1$ & $2.1 \pm 0.1$ & $1 \pm 0$ & $4.5 \pm 0.1$ & $1 \pm 0$ & $0.3 \pm 0$ & $1.6 \pm 0$ & $0.3 \pm 0$ & $2.1 \pm 0.1$ & $0.6 \pm 0$ & $2.2 \pm 0.1$ & $0.3 \pm 0$ & $1.8 \pm 0$ & $0.3 \pm 0$ \\
\hline 635 & 34.49 & 183 & 27.00 & $11.8 \pm 0.5$ & $3.1 \pm 0.1$ & $1.7 \pm 0$ & $7.2 \pm 0.1$ & $1.4 \pm 0.1$ & $0.4 \pm 0$ & $2.3 \pm 0.1$ & $0.4 \pm 0$ & $3.3 \pm 0.1$ & $1 \pm 0$ & $3.7 \pm 0.1$ & $0.6 \pm 0$ & $3.5 \pm 0.1$ & $0.7 \pm 0$ \\
\hline 735 & 34.44 & 179 & 27.16 & $14 \pm 0.6$ & $6.5 \pm 0.2$ & $2.1 \pm 0.1$ & $8.6 \pm 0.2$ & $1.5 \pm 0.1$ & $0.5 \pm 0$ & $2.5 \pm 0.1$ & $0.4 \pm 0$ & $3.5 \pm 0.1$ & $1.1 \pm 0$ & $4.1 \pm 0.1$ & $0.6 \pm 0$ & $4 \pm 0.1$ & $0.7 \pm 0$ \\
\hline 1065 & 34.49 & 154 & 27.37 & $16.5 \pm 0.6$ & $3.5 \pm 0.1$ & $2 \pm 0.1$ & $9.3 \pm 0.2$ & $1.8 \pm 0.1$ & $0.5 \pm 0$ & $3.2 \pm 0.1$ & $0.5 \pm 0$ & $4.3 \pm 0.1$ & $1.3 \pm 0$ & $4.9 \pm 0.2$ & $0.7 \pm 0$ & $4.9 \pm 0.1$ & $0.9 \pm 0$ \\
\hline 1550 & 34.60 & 136 & 27.60 & $23.6 \pm 1.1$ & $3.3 \pm 0.2$ & $3 \pm 0.1$ & $13.3 \pm 0.5$ & $2.5 \pm 0.1$ & $0.7 \pm 0$ & $4.3 \pm 0.2$ & $0.7 \pm 0$ & $5.5 \pm 0.3$ & $1.6 \pm 0.1$ & $6.3 \pm 0.3$ & $0.9 \pm 0$ & $6.6 \pm 0.3$ & $1.2 \pm 0.1$ \\
\hline 1665 & 34.61 & 137 & 27.62 & $24.8 \pm 0.9$ & {$[1.9 \pm 0.1]$} & $3 \pm 0.1$ & $13.8 \pm 0.3$ & $2.7 \pm 0.1$ & $0.8 \pm 0$ & $4.4 \pm 0.2$ & $0.7 \pm 0$ & $5.9 \pm 0.2$ & $1.8 \pm 0.1$ & $6.5 \pm 0.2$ & $1 \pm 0$ & $6.7 \pm 0.2$ & $1.3 \pm 0$ \\
\hline 1750 & 34.63 & 136 & 27.65 & $26.3 \pm 0.9$ & $2.5 \pm 0.1$ & $3.4 \pm 0.1$ & $15 \pm 0.4$ & $3 \pm 0.1$ & $0.9 \pm 0$ & $4.7 \pm 0.2$ & $0.8 \pm 0$ & $6.1 \pm 0.2$ & $1.9 \pm 0.1$ & $6.7 \pm 0.3$ & $1 \pm 0$ & $7 \pm 0.2$ & $1.3 \pm 0$ \\
\hline 1920 & 34.65 & 140 & 27.69 & - & - & - & - & - & - & - & - & - & - & - & - & - & - \\
\hline \multicolumn{18}{|c|}{ Station 036 (July 11, 2012; $11^{\circ} 30^{\prime} 7.2^{\prime \prime} \mathrm{S} ; 154^{\circ} 23^{\prime} 24^{\prime \prime} \mathrm{E}$; depth : 1168m) } \\
\hline 25 & 34.49 & 195 & 22.09 & $7 \pm 0.1$ & $7.1 \pm 0.1$ & $1.8 \pm 0$ & $8.2 \pm 0.1$ & $2 \pm 0.1$ & $0.6 \pm 0$ & $2.8 \pm 0.1$ & $0.4 \pm 0$ & $3.1 \pm 0.1$ & $0.8 \pm 0$ & $2.4 \pm 0.1$ & $0.3 \pm 0$ & $1.7 \pm 0$ & $0.3 \pm 0$ \\
\hline 100 & 35.43 & 163 & 23.89 & $3.7 \pm 0.1$ & $3 \pm 0$ & $0.8 \pm 0$ & $3.9 \pm 0$ & $1 \pm 0$ & $0.3 \pm 0$ & $1.5 \pm 0.1$ & $0.2 \pm 0$ & $1.9 \pm 0$ & $0.5 \pm 0$ & $1.7 \pm 0.1$ & $0.2 \pm 0$ & $1.2 \pm 0$ & $0.2 \pm 0$ \\
\hline 160 & 35.61 & 141 & 24.60 & $4.1 \pm 0.1$ & $2.8 \pm 0.1$ & $0.8 \pm 0$ & $3.8 \pm 0$ & $0.9 \pm 0$ & $0.3 \pm 0$ & $1.4 \pm 0.1$ & $0.2 \pm 0$ & $1.8 \pm 0.1$ & $0.5 \pm 0$ & $1.7 \pm 0.1$ & $0.2 \pm 0$ & $1.2 \pm 0$ & $0.2 \pm 0$ \\
\hline 180 & 35.64 & 144 & 24.96 & $4.4 \pm 0.1$ & $3.1 \pm 0$ & $0.8 \pm 0$ & $3.8 \pm 0$ & $0.9 \pm 0$ & $0.3 \pm 0$ & $1.4 \pm 0$ & $0.2 \pm 0$ & $1.8 \pm 0.1$ & $0.5 \pm 0$ & $1.7 \pm 0$ & $0.2 \pm 0$ & $1.2 \pm 0$ & $0.2 \pm 0$ \\
\hline 400 & 34.94 & 167 & 26.51 & $7.2 \pm 0.2$ & $1.9 \pm 0.1$ & $1.1 \pm 0$ & $5.2 \pm 0.1$ & $1.1 \pm 0$ & $0.3 \pm 0$ & $1.7 \pm 0.1$ & $0.3 \pm 0$ & $2.4 \pm 0.1$ & $0.7 \pm 0$ & $2.5 \pm 0.1$ & $0.4 \pm 0$ & $2.2 \pm 0$ & $0.4 \pm 0$ \\
\hline 700 & 34.46 & 182 & 27.09 & $11.4 \pm 0.4$ & {$[1.4 \pm 0]$} & $1.6 \pm 0$ & $7.2 \pm 0.1$ & $1.5 \pm 0.1$ & $0.4 \pm 0$ & $2.4 \pm 0.1$ & $0.4 \pm 0$ & $3.4 \pm 0.1$ & $1 \pm 0$ & $3.8 \pm 0.1$ & $0.6 \pm 0$ & $3.7 \pm 0.1$ & $0.7 \pm 0$ \\
\hline
\end{tabular}




\begin{tabular}{|c|c|c|c|c|c|c|c|c|c|c|c|c|c|c|c|c|c|}
\hline 900 & 34.46 & 170 & 27.24 & $12.6 \pm 0.4$ & $1.4 \pm 0$ & $1.6 \pm 0$ & $7.5 \pm 0.1$ & $1.5 \pm 0.1$ & $0.5 \pm 0$ & $2.5 \pm 0.1$ & $0.4 \pm 0$ & $3.6 \pm 0.1$ & $1.1 \pm 0$ & $4.1 \pm 0.1$ & $0.6 \pm 0$ & $4.2 \pm 0.1$ & $0.8 \pm 0$ \\
\hline \multicolumn{18}{|c|}{ Station 042 (July 15, 2012; 5 8' 42" S; 153² 17' 24" E; depth : 3081m) } \\
\hline 5 & 34.69 & 192 & 21.71 & $3.6 \pm 0.2$ & $3.1 \pm 0.2$ & $0.8 \pm 0$ & $3.9 \pm 0.2$ & $0.8 \pm 0$ & $0.3 \pm 0$ & $1.4 \pm 0.1$ & $0.2 \pm 0$ & $1.7 \pm 0.1$ & $0.5 \pm 0$ & $1.5 \pm 0.1$ & $0.2 \pm 0$ & $0.9 \pm 0$ & $0.2 \pm 0$ \\
\hline 50 & 34.75 & 192 & 21.75 & - & - & - & - & - & - & - & - & - & - & - & - & - & - \\
\hline 100 & 35.46 & 157 & 22.68 & - & - & - & - & - & - & - & - & - & - & - & - & - & - \\
\hline 180 & 35.65 & 140 & 24.72 & $4.2 \pm 0.2$ & $2.5 \pm 0.1$ & $0.7 \pm 0$ & $3.4 \pm 0.1$ & $0.8 \pm 0$ & $0.3 \pm 0$ & $1.3 \pm 0.1$ & $0.2 \pm 0$ & $1.7 \pm 0.1$ & $0.5 \pm 0$ & $1.7 \pm 0.1$ & $0.2 \pm 0$ & $1.2 \pm 0$ & $0.2 \pm 0$ \\
\hline 225 & 35.35 & 152 & 25.85 & $4.9 \pm 0.2$ & {$[1.4 \pm 0]$} & $0.8 \pm 0$ & $3.8 \pm 0.1$ & $1.5 \pm 0.1$ & $0.3 \pm 0$ & $1.4 \pm 0.1$ & $0.2 \pm 0$ & $2 \pm 0.1$ & $0.5 \pm 0$ & $2 \pm 0.1$ & $0.3 \pm 0$ & $1.6 \pm 0$ & $0.3 \pm 0$ \\
\hline 400 & 34.64 & 174 & 26.84 & $9.8 \pm 0.2$ & {$[1.8 \pm 0]$} & $1.3 \pm 0.1$ & $6.1 \pm 0.1$ & $1.2 \pm 0.1$ & $0.4 \pm 0$ & $2.1 \pm 0.1$ & $0.3 \pm 0$ & $3 \pm 0.1$ & $0.9 \pm 0$ & $3.3 \pm 0.1$ & $0.5 \pm 0$ & $3.1 \pm 0.1$ & $0.6 \pm 0$ \\
\hline 500 & 34.54 & 158 & 27.02 & $11 \pm 0.3$ & $1.7 \pm 0$ & $1.5 \pm 0$ & $6.8 \pm 0.1$ & $1.4 \pm 0$ & $0.4 \pm 0$ & $2.3 \pm 0.1$ & $0.4 \pm 0$ & $3.2 \pm 0.1$ & $1 \pm 0$ & $3.6 \pm 0.2$ & $0.6 \pm 0$ & $3.6 \pm 0.1$ & $0.7 \pm 0$ \\
\hline 750 & 34.48 & 154 & 27.23 & $11.9 \pm 0.3$ & {$[1.6 \pm 0.1]$} & $1.6 \pm 0$ & $7.3 \pm 0.1$ & $1.5 \pm 0$ & $0.4 \pm 0$ & $2.5 \pm 0.1$ & $0.4 \pm 0$ & $3.5 \pm 0.1$ & $1.1 \pm 0$ & $4 \pm 0.1$ & $0.6 \pm 0$ & $4.1 \pm 0$ & $0.8 \pm 0$ \\
\hline 1000 & 34.53 & 137 & 27.41 & $15.8 \pm 0.8$ & $2.1 \pm 0.1$ & $2.1 \pm 0.1$ & $9.4 \pm 0.3$ & $1.9 \pm 0.1$ & $0.6 \pm 0$ & $3.2 \pm 0.2$ & $0.5 \pm 0$ & $4.5 \pm 0.3$ & $1.3 \pm 0.1$ & $5 \pm 0.3$ & $0.7 \pm 0$ & $5.1 \pm 0.2$ & $1 \pm 0.1$ \\
\hline 1200 & 34.56 & 130 & 27.49 & $17.9 \pm 0.6$ & $2.8 \pm 0.1$ & $2.3 \pm 0.1$ & $10.4 \pm 0.2$ & $2 \pm 0.1$ & $0.7 \pm 0$ & $3.5 \pm 0.2$ & $0.6 \pm 0$ & $4.6 \pm 0.2$ & $1.4 \pm 0.1$ & $5.1 \pm 0.2$ & $0.8 \pm 0$ & $5.6 \pm 0.1$ & $1.1 \pm 0$ \\
\hline 1550 & 34.61 & 123 & 27.62 & $24.8 \pm 0.7$ & $5.1 \pm 0.1$ & $3.2 \pm 0.1$ & $14.5 \pm 0.3$ & $2.8 \pm 0.1$ & $0.9 \pm 0$ & $4.4 \pm 0.2$ & $0.7 \pm 0$ & $5.7 \pm 0.2$ & $1.7 \pm 0.1$ & $6.1 \pm 0.3$ & $1 \pm 0$ & $6.6 \pm 0.2$ & $1.2 \pm 0$ \\
\hline 1750 & 34.62 & 124 & 27.64 & $28.6 \pm 0.9$ & $4.6 \pm 0.2$ & $3.3 \pm 0.1$ & $15.8 \pm 0.5$ & $3.1 \pm 0.1$ & $1 \pm 0$ & $5.2 \pm 0.2$ & $0.8 \pm 0$ & $6.5 \pm 0.2$ & $1.8 \pm 0.1$ & $6.7 \pm 0.2$ & $1.1 \pm 0$ & $7.2 \pm 0.2$ & $1.3 \pm 0$ \\
\hline 2000 & 34.64 & 126 & 27.68 & $29.1 \pm 1.6$ & $3.6 \pm 0.2$ & $3.9 \pm 0.2$ & $18 \pm 0.8$ & $3.4 \pm 0.2$ & $1.1 \pm 0.1$ & $5.7 \pm 0.3$ & $0.9 \pm 0$ & $6.8 \pm 0.4$ & $1.9 \pm 0.1$ & $7.3 \pm 0.5$ & $1.1 \pm 0.1$ & $7.7 \pm 0.4$ & $1.4 \pm 0.1$ \\
\hline 2500 & 34.66 & 133 & 27.73 & $32.5 \pm 2.6$ & $4.8 \pm 0.2$ & $4.7 \pm 0.3$ & $21.8 \pm 0.9$ & $4.2 \pm 0.3$ & $1.3 \pm 0.1$ & $6.7 \pm 0.4$ & $1 \pm 0.1$ & $7.9 \pm 0.6$ & $2.2 \pm 0.2$ & $8 \pm 0.6$ & $1.3 \pm 0.1$ & $8.5 \pm 0.4$ & $1.5 \pm 0.1$ \\
\hline \multicolumn{18}{|c|}{ Station 043 (July 17, 2012; 3 59' 52.8" S; 155³5' 38.4" E; depth : 1925m) } \\
\hline 5 & 34.66 & 191 & 21.72 & $3.6 \pm 0.2$ & $2.8 \pm 0.2$ & $0.7 \pm 0$ & $3.5 \pm 0.1$ & $0.7 \pm 0$ & $0.2 \pm 0$ & $1.3 \pm 0.1$ & $0.2 \pm 0$ & $1.6 \pm 0.1$ & $0.5 \pm 0$ & $1.4 \pm 0.1$ & $0.2 \pm 0$ & $0.8 \pm 0$ & $0.1 \pm 0$ \\
\hline 150 & 35.91 & 138 & 23.99 & $4.5 \pm 0.1$ & $2.6 \pm 0.1$ & $0.8 \pm 0$ & $3.7 \pm 0.1$ & $0.7 \pm 0$ & $0.2 \pm 0$ & $1.3 \pm 0.1$ & $0.2 \pm 0$ & $1.7 \pm 0.1$ & $0.5 \pm 0$ & $1.7 \pm 0.1$ & $0.2 \pm 0$ & $1.2 \pm 0$ & $0.2 \pm 0$ \\
\hline 230 & 35.16 & 99 & 26.14 & {$[25.5 \pm 0.8]$} & {$[12.3 \pm 0.3]$} & {$[1.2 \pm 0]$} & {$[5.2 \pm 0.1]$} & {$[0.9 \pm 0]$} & {$[0.3 \pm 0]$} & {$[1.6 \pm 0.1]$} & {$[0.3 \pm 0]$} & {$[2.2 \pm 0.1]$} & {$[0.6 \pm 0]$} & {$[2.3 \pm 0.1]$} & {$[0.3 \pm 0]$} & {$[2.1 \pm 0]$} & {$[0.4 \pm 0]$} \\
\hline 700 & 34.51 & 128 & 27.18 & $13.1 \pm 0.3$ & $1.8 \pm 0$ & $1.7 \pm 0$ & $7.6 \pm 0.1$ & $1.5 \pm 0$ & $0.5 \pm 0$ & $2.5 \pm 0.1$ & $0.4 \pm 0$ & $3.4 \pm 0.1$ & $1.1 \pm 0$ & $4 \pm 0.1$ & $0.6 \pm 0$ & $4.2 \pm 0.1$ & $0.8 \pm 0$ \\
\hline 1200 & 34.56 & 105 & 27.47 & $16.4 \pm 0.5$ & $1.9 \pm 0$ & $2.1 \pm 0$ & $9.6 \pm 0.2$ & $1.9 \pm 0.1$ & $0.6 \pm 0$ & $3.2 \pm 0.1$ & $0.5 \pm 0$ & $4.4 \pm 0.1$ & $1.3 \pm 0$ & $4.9 \pm 0.2$ & $0.8 \pm 0$ & $5.5 \pm 0.1$ & $1 \pm 0$ \\
\hline \multicolumn{18}{|c|}{ Station 046 (July 18, 2012; $4^{\circ} 42^{\prime} 0^{\prime \prime}$ S; $154^{\circ} 52^{\prime} 48^{\prime \prime}$ E; depth : $3117 \mathrm{~m}$ ) } \\
\hline 50 & 34.79 & 190 & 21.85 & $3.6 \pm 0.1$ & $2.2 \pm 0.1$ & $0.7 \pm 0$ & $3.3 \pm 0$ & $0.7 \pm 0$ & $0.2 \pm 0$ & $1.3 \pm 0$ & $0.2 \pm 0$ & $1.5 \pm 0$ & $0.4 \pm 0$ & $1.4 \pm 0$ & $0.2 \pm 0$ & $0.8 \pm 0$ & $0.1 \pm 0$ \\
\hline 150 & 35.97 & 129 & 23.97 & $3.5 \pm 0.1$ & $1.3 \pm 0$ & $0.6 \pm 0$ & $2.6 \pm 0$ & $0.6 \pm 0$ & $0.2 \pm 0$ & $1.1 \pm 0$ & $0.2 \pm 0$ & $1.5 \pm 0$ & $0.4 \pm 0$ & $1.5 \pm 0$ & $0.2 \pm 0$ & $1 \pm 0$ & $0.2 \pm 0$ \\
\hline 400 & 34.65 & 124 & 26.89 & $11.3 \pm 0.3$ & $2.5 \pm 0.1$ & $1.4 \pm 0$ & $6.5 \pm 0.1$ & $1.3 \pm 0.1$ & $0.4 \pm 0$ & $2.1 \pm 0.1$ & $0.4 \pm 0$ & $3 \pm 0.1$ & $0.9 \pm 0$ & $3.4 \pm 0.1$ & $0.5 \pm 0$ & $3.3 \pm 0.1$ & $0.6 \pm 0$ \\
\hline 700 & 34.54 & 89 & 27.19 & $12.5 \pm 0.3$ & $0.9 \pm 0$ & $1.6 \pm 0$ & $7.2 \pm 0.2$ & $1.4 \pm 0.1$ & $0.5 \pm 0$ & $2.5 \pm 0.1$ & $0.4 \pm 0$ & $3.5 \pm 0.1$ & $1 \pm 0$ & $4 \pm 0.1$ & $0.6 \pm 0$ & $4.1 \pm 0.1$ & $0.8 \pm 0$ \\
\hline 1000 & 34.54 & 112 & 27.39 & $15.6 \pm 0.5$ & $2 \pm 0.1$ & $1.9 \pm 0$ & $8.9 \pm 0.2$ & $1.8 \pm 0.1$ & $0.5 \pm 0$ & $3.1 \pm 0.1$ & $0.5 \pm 0$ & $4.2 \pm 0.1$ & $1.2 \pm 0$ & $4.7 \pm 0.1$ & $0.7 \pm 0$ & $4.9 \pm 0.1$ & $0.9 \pm 0$ \\
\hline \multicolumn{18}{|c|}{ Station 047 (July 18, 2012; 4 56' 2.4" S; 154 38' 52.8" E; depth : 1004m) } \\
\hline 25 & 34.67 & 190 & 21.78 & $4.4 \pm 0.1$ & $3.3 \pm 0.1$ & $1 \pm 0$ & $4.4 \pm 0.1$ & $1 \pm 0$ & $0.3 \pm 0$ & $1.6 \pm 0$ & $0.2 \pm 0$ & $1.9 \pm 0.1$ & $0.5 \pm 0$ & $1.6 \pm 0$ & $0.2 \pm 0$ & $1 \pm 0$ & $0.2 \pm 0$ \\
\hline 156 & 36.02 & 126 & 24.41 & $4.6 \pm 0.1$ & $2.6 \pm 0$ & $0.6 \pm 0$ & $3 \pm 0$ & $0.6 \pm 0$ & $0.2 \pm 0$ & $1.2 \pm 0$ & $0.2 \pm 0$ & $1.6 \pm 0$ & $0.5 \pm 0$ & $1.7 \pm 0$ & $0.2 \pm 0$ & $1.2 \pm 0$ & $0.2 \pm 0$ \\
\hline 264 & 35.08 & 106 & 26.27 & {$[7.4 \pm 0.1]$} & $1.7 \pm 0$ & $1.1 \pm 0$ & $4.8 \pm 0.1$ & $0.9 \pm 0$ & $0.3 \pm 0$ & $1.6 \pm 0.1$ & $0.3 \pm 0$ & $2.2 \pm 0.1$ & $0.7 \pm 0$ & $2.4 \pm 0.1$ & $0.3 \pm 0$ & $2.1 \pm 0$ & $0.4 \pm 0$ \\
\hline 635 & 34.52 & 129 & 27.20 & $13.3 \pm 0.3$ & $2.6 \pm 0.2$ & $1.7 \pm 0$ & $7.7 \pm 0.1$ & $1.5 \pm 0$ & $0.5 \pm 0$ & $2.6 \pm 0.1$ & $0.4 \pm 0$ & $3.6 \pm 0.2$ & $1.1 \pm 0$ & $4.1 \pm 0.1$ & $0.7 \pm 0$ & $4.2 \pm 0.1$ & $0.8 \pm 0$ \\
\hline \multicolumn{18}{|c|}{ Station 053 (July 19, 2012; 4 54' 18' S; 152 52' 12" E; depth : 733m) } \\
\hline 25 & 34.88 & 189 & 21.99 & $4.9 \pm 0.2$ & $4.1 \pm 0.2$ & $1.2 \pm 0.1$ & $5.7 \pm 0.3$ & $1.4 \pm 0.1$ & $0.5 \pm 0$ & $2.1 \pm 0.1$ & $0.3 \pm 0$ & $2.5 \pm 0.1$ & $0.7 \pm 0$ & $2.1 \pm 0.1$ & $0.3 \pm 0$ & $1.5 \pm 0.1$ & $0.2 \pm 0$ \\
\hline 149 & 35.61 & 142 & 24.72 & $6.3 \pm 0.2$ & $5.2 \pm 0.1$ & $0.9 \pm 0$ & $4 \pm 0.1$ & $0.9 \pm 0$ & $0.3 \pm 0$ & $1.5 \pm 0.1$ & $0.2 \pm 0$ & $1.8 \pm 0.1$ & $0.5 \pm 0$ & $1.7 \pm 0$ & $0.2 \pm 0$ & $1.2 \pm 0$ & $0.2 \pm 0$ \\
\hline 335 & 34.98 & 161 & 26.45 & {$[7.6 \pm 0.1]$} & $1.8 \pm 0$ & $1.2 \pm 0$ & $5.3 \pm 0.1$ & $1.1 \pm 0$ & $0.3 \pm 0$ & $1.8 \pm 0.1$ & $0.3 \pm 0$ & $2.5 \pm 0.1$ & $0.7 \pm 0$ & $2.6 \pm 0.1$ & $0.4 \pm 0$ & $2.3 \pm 0$ & $0.4 \pm 0$ \\
\hline
\end{tabular}




\begin{tabular}{|c|c|c|c|c|c|c|c|c|c|c|c|c|c|c|c|c|c|}
\hline 719 & 34.48 & 158 & 27.22 & {$[12.6 \pm 0.5]$} & $1.5 \pm 0$ & $1.7 \pm 0$ & $7.8 \pm 0.1$ & $1.5 \pm 0$ & $0.5 \pm 0$ & $2.6 \pm 0.1$ & $0.4 \pm 0$ & $3.7 \pm 0.1$ & $1.1 \pm 0$ & $4.2 \pm 0.1$ & $0.6 \pm 0$ & $4.2 \pm 0.1$ & $0.8 \pm 0$ \\
\hline \multicolumn{18}{|c|}{ Station 056 (July 20, 2012; 4 4' 37.2" S; $152^{\circ} 32^{\prime}$ 20.4" E; depth : 1580m) } \\
\hline 1582 & 34.60 & 125 & 27.59 & $23.4 \pm 0$ & $3.8 \pm 0$ & $3.1 \pm 0$ & $14.3 \pm 0$ & $2.8 \pm 0$ & $0.8 \pm 0$ & $4.8 \pm 0$ & $0.7 \pm 0$ & $5.9 \pm 0$ & $1.8 \pm 0$ & $6.6 \pm 0$ & $0.9 \pm 0$ & $6.7 \pm 0$ & $1.2 \pm 0$ \\
\hline \multicolumn{18}{|c|}{ Station 057 (July 20, 2012; $4^{\circ} 34^{\prime} 12^{\prime \prime} \mathrm{S} ; 152^{\circ} 31^{\prime} 22.8^{\prime \prime} \mathrm{E}$; depth : 2552m) } \\
\hline 25 & 34.77 & 192 & 21.91 & $4.1 \pm 0.1$ & $3.5 \pm 0.1$ & $1 \pm 0$ & $5.2 \pm 0.1$ & $1.3 \pm 0.1$ & $0.5 \pm 0$ & $2.1 \pm 0.1$ & $0.3 \pm 0$ & $2.3 \pm 0.1$ & $0.6 \pm 0$ & $2 \pm 0.1$ & $0.3 \pm 0$ & $1.3 \pm 0$ & $0.2 \pm 0$ \\
\hline 150 & 35.58 & 139 & 24.20 & $3.8 \pm 0.2$ & $2.6 \pm 0.1$ & $0.8 \pm 0$ & $3.7 \pm 0.1$ & $0.9 \pm 0.1$ & $0.3 \pm 0$ & $1.4 \pm 0.1$ & $0.2 \pm 0$ & $1.8 \pm 0.1$ & $0.5 \pm 0$ & $1.7 \pm 0.1$ & $0.2 \pm 0$ & $1.2 \pm 0$ & $0.2 \pm 0$ \\
\hline 250 & 35.27 & 152 & 26.00 & $5.4 \pm 0.2$ & $2.1 \pm 0.1$ & $0.9 \pm 0.1$ & $4.2 \pm 0.1$ & $0.9 \pm 0.1$ & $0.3 \pm 0$ & $1.5 \pm 0.1$ & $0.2 \pm 0$ & $2 \pm 0.1$ & $0.6 \pm 0$ & $2.1 \pm 0.1$ & $0.3 \pm 0$ & $1.7 \pm 0$ & $0.3 \pm 0$ \\
\hline 450 & 34.65 & 171 & 26.85 & $9.3 \pm 0.2$ & $1.5 \pm 0$ & $1.3 \pm 0$ & $6.2 \pm 0.1$ & $1.2 \pm 0.1$ & $0.4 \pm 0$ & $2.1 \pm 0.1$ & $0.3 \pm 0$ & $2.9 \pm 0.1$ & $0.9 \pm 0$ & $3.1 \pm 0.1$ & $0.5 \pm 0$ & $3.1 \pm 0$ & $0.6 \pm 0$ \\
\hline 580 & 34.51 & 177 & 27.02 & $12.1 \pm 0.3$ & $2.5 \pm 0.1$ & $1.5 \pm 0$ & $6.8 \pm 0.1$ & $1.3 \pm 0$ & $0.4 \pm 0$ & $2.2 \pm 0.1$ & $0.4 \pm 0$ & $3.1 \pm 0.1$ & $0.9 \pm 0$ & $3.6 \pm 0.1$ & $0.5 \pm 0$ & $3.6 \pm 0.1$ & $0.7 \pm 0$ \\
\hline 850 & 34.50 & 143 & 27.33 & $13.7 \pm 0.4$ & $1.6 \pm 0$ & $1.7 \pm 0$ & $8.1 \pm 0.2$ & $1.6 \pm 0.1$ & $0.5 \pm 0$ & $2.9 \pm 0.1$ & $0.5 \pm 0$ & $3.9 \pm 0.1$ & $1.2 \pm 0$ & $4.4 \pm 0.1$ & $0.7 \pm 0$ & $4.8 \pm 0.1$ & $0.9 \pm 0$ \\
\hline 1302 & 34.57 & 129 & 27.51 & $19.2 \pm 0.5$ & $2.8 \pm 0.1$ & $2.4 \pm 0.1$ & $11.5 \pm 0.3$ & $2.2 \pm 0.1$ & $0.7 \pm 0$ & $3.9 \pm 0.2$ & $0.6 \pm 0$ & $5.1 \pm 0.2$ & $1.5 \pm 0$ & $5.5 \pm 0.2$ & $0.9 \pm 0$ & $6 \pm 0.1$ & $1.1 \pm 0$ \\
\hline 1650 & 34.61 & 124 & 27.62 & - & - & - & - & - & - & - & - & - & - & - & - & - & - \\
\hline 2201 & 34.65 & 135 & 27.71 & $31.2 \pm 0.9$ & $3.5 \pm 0.1$ & $4.2 \pm 0.1$ & $20 \pm 0.5$ & $3.9 \pm 0.2$ & $1.3 \pm 0$ & $6.3 \pm 0.3$ & $1 \pm 0$ & $7.9 \pm 0.3$ & $2.1 \pm 0$ & $7.7 \pm 0.2$ & $1.2 \pm 0$ & $8.2 \pm 0.2$ & $1.5 \pm 0$ \\
\hline \multicolumn{18}{|c|}{ Station 058 (July 21,$2012 ; 5^{\circ} 30^{\prime} 10.8^{\prime \prime} \mathrm{S} ; 152^{\circ} 5^{\prime} 52.8^{\prime \prime} \mathrm{E}$; depth : $1142 \mathrm{~m}$ ) } \\
\hline 215 & 35.50 & 135 & 25.51 & $4.8 \pm 0.2$ & $2.2 \pm 0.1$ & $0.8 \pm 0$ & $3.9 \pm 0.1$ & $0.8 \pm 0$ & $0.3 \pm 0$ & $1.4 \pm 0.1$ & $0.2 \pm 0$ & $1.8 \pm 0.1$ & $0.5 \pm 0$ & $1.8 \pm 0.1$ & $0.3 \pm 0$ & $1.4 \pm 0$ & $0.2 \pm 0$ \\
\hline 1100 & 34.55 & 133 & 27.47 & $18.9 \pm 0.7$ & $3.1 \pm 0.1$ & $2.3 \pm 0.1$ & $11 \pm 0.3$ & $2.2 \pm 0.1$ & $0.7 \pm 0$ & $3.7 \pm 0.2$ & $0.6 \pm 0$ & $4.9 \pm 0.2$ & $1.4 \pm 0.1$ & $5.4 \pm 0.2$ & $0.8 \pm 0$ & $5.7 \pm 0.2$ & $1 \pm 0$ \\
\hline \multicolumn{18}{|c|}{ 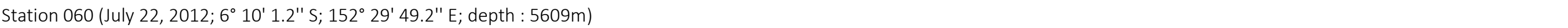 } \\
\hline 35 & 34.74 & 193 & 22.19 & $5 \pm 0.1$ & $4.5 \pm 0.1$ & $1.1 \pm 0$ & $5.3 \pm 0.1$ & $1.2 \pm 0$ & $0.4 \pm 0$ & $1.8 \pm 0.1$ & $0.3 \pm 0$ & $2.1 \pm 0.1$ & $0.6 \pm 0$ & $1.8 \pm 0.1$ & $0.2 \pm 0$ & $1.2 \pm 0$ & $0.2 \pm 0$ \\
\hline 180 & 35.73 & 135 & 24.70 & $4.2 \pm 0.2$ & $2.3 \pm 0.1$ & $0.7 \pm 0$ & $3.4 \pm 0.1$ & $0.7 \pm 0$ & $0.2 \pm 0$ & $1.2 \pm 0.1$ & $0.2 \pm 0$ & $1.6 \pm 0.1$ & $0.5 \pm 0$ & $1.6 \pm 0.1$ & $0.2 \pm 0$ & $1.1 \pm 0$ & $0.2 \pm 0$ \\
\hline 250 & 35.33 & 124 & 25.86 & $7.4 \pm 0.1$ & $3.7 \pm 0.1$ & $1 \pm 0$ & $4.9 \pm 0.1$ & $1 \pm 0$ & $0.3 \pm 0$ & $1.6 \pm 0.1$ & $0.2 \pm 0$ & $2 \pm 0.1$ & $0.6 \pm 0$ & $2.2 \pm 0.1$ & $0.3 \pm 0$ & $1.7 \pm 0$ & $0.3 \pm 0$ \\
\hline 480 & 34.53 & 173 & 27.03 & $11.2 \pm 0.3$ & $2.6 \pm 0.1$ & $1.5 \pm 0.1$ & $6.8 \pm 0.1$ & $1.3 \pm 0.1$ & $0.4 \pm 0$ & $2.3 \pm 0.1$ & $0.4 \pm 0$ & $3.1 \pm 0.1$ & $1 \pm 0$ & $3.5 \pm 0.1$ & $0.6 \pm 0$ & $3.6 \pm 0.1$ & $0.7 \pm 0$ \\
\hline 1000 & 34.53 & 138 & 27.43 & $16.3 \pm 0.3$ & $2.7 \pm 0.1$ & $2 \pm 0$ & $9.4 \pm 0.1$ & $1.8 \pm 0.1$ & $0.6 \pm 0$ & $3 \pm 0.1$ & $0.5 \pm 0$ & $4 \pm 0.1$ & $1.3 \pm 0$ & $4.8 \pm 0.2$ & $0.7 \pm 0$ & $5 \pm 0.1$ & $1 \pm 0$ \\
\hline 1600 & 34.61 & 124 & 27.62 & $23.9 \pm 0.9$ & $5 \pm 0.2$ & $3.2 \pm 0.1$ & $14.5 \pm 0.3$ & $2.8 \pm 0.1$ & $0.9 \pm 0$ & $4.6 \pm 0.2$ & $0.7 \pm 0$ & $5.8 \pm 0.2$ & $1.8 \pm 0$ & $6.2 \pm 0.2$ & $1 \pm 0$ & $6.8 \pm 0.1$ & $1.3 \pm 0$ \\
\hline 1800 & 34.63 & 125 & 27.67 & $28.4 \pm 0.6$ & $7.8 \pm 0.2$ & $3.9 \pm 0.1$ & $18.1 \pm 0.3$ & $3.4 \pm 0.1$ & $1.1 \pm 0$ & $5.4 \pm 0.2$ & $0.8 \pm 0$ & $6.8 \pm 0.3$ & $1.9 \pm 0.1$ & $7 \pm 0.2$ & $1.1 \pm 0$ & $7.4 \pm 0.2$ & $1.4 \pm 0$ \\
\hline 2541 & 34.66 & 132 & 27.73 & $35.4 \pm 1$ & $3.5 \pm 0.1$ & $5.1 \pm 0.1$ & $23.8 \pm 0.5$ & $4.6 \pm 0.2$ & $1.5 \pm 0$ & $7 \pm 0.3$ & $1.1 \pm 0$ & $8.6 \pm 0.4$ & $2.3 \pm 0.1$ & $8.1 \pm 0.4$ & $1.3 \pm 0.1$ & $8.7 \pm 0.2$ & $1.6 \pm 0.1$ \\
\hline 3250 & 34.69 & 155 & 27.76 & $41.1 \pm 1.1$ & $5.8 \pm 0.2$ & $6.1 \pm 0.2$ & $28.1 \pm 0.6$ & $5.3 \pm 0.2$ & $1.7 \pm 0$ & $8 \pm 0.3$ & $1.2 \pm 0$ & $9.1 \pm 0.4$ & $2.6 \pm 0.1$ & $8.3 \pm 0.3$ & $1.4 \pm 0$ & $8.9 \pm 0.2$ & $1.6 \pm 0.1$ \\
\hline 4000 & 34.70 & 158 & 27.77 & $41 \pm 1.4$ & $5.6 \pm 0.2$ & $6.3 \pm 0.2$ & $28.8 \pm 0.8$ & $5.9 \pm 0.2$ & $1.8 \pm 0.1$ & $8.2 \pm 0.3$ & $1.2 \pm 0$ & $9.5 \pm 0.3$ & $2.5 \pm 0.1$ & $8.7 \pm 0.3$ & $1.3 \pm 0$ & $8.9 \pm 0.2$ & $1.6 \pm 0.1$ \\
\hline 4500 & 34.70 & 160 & 27.77 & $41.9 \pm 1.6$ & $8 \pm 0.3$ & $6.8 \pm 0.3$ & $30.2 \pm 1$ & $6 \pm 0.3$ & $1.9 \pm 0.1$ & $8.4 \pm 0.5$ & $1.3 \pm 0.1$ & $9.6 \pm 0.6$ & $2.6 \pm 0.1$ & $8.8 \pm 0.5$ & $1.4 \pm 0.1$ & $8.9 \pm 0.3$ & $1.6 \pm 0.1$ \\
\hline 4750 & 34.70 & 160 & 27.77 & $47.3 \pm 1$ & $14.6 \pm 0.3$ & $7 \pm 0.2$ & $30.4 \pm 0.4$ & $5.6 \pm 0.2$ & $1.8 \pm 0$ & $7.8 \pm 0.3$ & $1.2 \pm 0$ & $8.9 \pm 0.4$ & $2.4 \pm 0.1$ & $8.4 \pm 0.3$ & $1.2 \pm 0$ & $8.3 \pm 0.1$ & $1.6 \pm 0$ \\
\hline 5000 & 34.70 & 161 & 27.77 & $39.3 \pm 0.9$ & $5.3 \pm 0.1$ & $5.4 \pm 0.1$ & $25.4 \pm 0.3$ & $4.8 \pm 0.2$ & $1.5 \pm 0$ & $7 \pm 0.2$ & $1.1 \pm 0$ & $8.1 \pm 0.3$ & $2.3 \pm 0.1$ & $8 \pm 0.3$ & $1.2 \pm 0$ & $7.8 \pm 0.1$ & $1.5 \pm 0$ \\
\hline 5603 & 34.70 & 162 & 27.77 & $41.2 \pm 1.5$ & $5.6 \pm 0.2$ & $6 \pm 0.2$ & $26.3 \pm 0.7$ & $4.9 \pm 0.2$ & $1.4 \pm 0.1$ & $6.8 \pm 0.4$ & $1 \pm 0.1$ & $8 \pm 0.4$ & $2.2 \pm 0.1$ & $7.6 \pm 0.4$ & $1.1 \pm 0.1$ & $7.6 \pm 0.2$ & $1.4 \pm 0$ \\
\hline \multicolumn{18}{|c|}{ Station 071 (July 25, 2012; 8 19' 55.2" S; 151º 17' 27.6" E; depth : 1563m) } \\
\hline 50 & 34.80 & 192 & 22.39 & $3.8 \pm 0.3$ & {$[2.6 \pm 0.2]$} & $0.8 \pm 0.1$ & $4 \pm 0.2$ & $1 \pm 0.1$ & $0.3 \pm 0$ & $1.5 \pm 0.1$ & $0.2 \pm 0$ & $1.8 \pm 0.1$ & $0.5 \pm 0$ & $1.7 \pm 0.1$ & $0.2 \pm 0$ & $1.1 \pm 0$ & $0.2 \pm 0$ \\
\hline 160 & 35.66 & 138 & 24.60 & $4.6 \pm 0.3$ & $5.9 \pm 0.4$ & $0.8 \pm 0$ & $3.9 \pm 0.2$ & $0.7 \pm 0.1$ & $0.2 \pm 0$ & $1.3 \pm 0.1$ & $0.2 \pm 0$ & $1.7 \pm 0.1$ & $0.5 \pm 0$ & $1.7 \pm 0.1$ & $0.2 \pm 0$ & $1.2 \pm 0.1$ & $0.2 \pm 0$ \\
\hline 400 & 34.98 & 165 & 26.47 & $7.9 \pm 0.6$ & $4.6 \pm 0.2$ & $1.1 \pm 0.1$ & $5.2 \pm 0.2$ & $1.1 \pm 0.1$ & $0.3 \pm 0$ & $1.8 \pm 0.1$ & $0.3 \pm 0$ & $2.5 \pm 0.2$ & $0.7 \pm 0$ & $2.5 \pm 0.1$ & $0.4 \pm 0$ & $2.2 \pm 0.1$ & $0.4 \pm 0$ \\
\hline 600 & 34.49 & 178 & 27.06 & $12 \pm 0.9$ & {$[1.9 \pm 0.2]$} & $1.5 \pm 0.1$ & $6.9 \pm 0.4$ & $1.3 \pm 0.1$ & $0.4 \pm 0$ & $2.3 \pm 0.2$ & $0.4 \pm 0$ & $3.3 \pm 0.3$ & $1 \pm 0.1$ & $3.7 \pm 0.2$ & $0.6 \pm 0$ & $3.7 \pm 0.2$ & $0.7 \pm 0.1$ \\
\hline 1100 & 34.52 & 143 & 27.41 & $32.3 \pm 1.2$ & $5.6 \pm 0.2$ & $2.1 \pm 0.1$ & $9.7 \pm 0.2$ & $1.9 \pm 0.1$ & $0.6 \pm 0$ & $3.2 \pm 0.1$ & $0.5 \pm 0$ & $4.3 \pm 0.2$ & $1.3 \pm 0$ & $4.9 \pm 0.2$ & $0.8 \pm 0$ & $5.2 \pm 0.1$ & $1 \pm 0$ \\
\hline
\end{tabular}


Station 073 - Filtrated (July 26, 2012; 7 9' 57.6" S; 149 59' 56.4" E; depth: 5253m)

\begin{tabular}{|c|c|c|c|c|c|c|c|c|c|c|c|c|c|c|c|c|c|}
\hline 50 & 5.06 & 171 & & $4+01$ & $1+0.1$ & $09+0$ & $41+01$ & & $3+0$ & $15+01$ & $02+0$ & $19+01$ & $05+0$ & $17+01$ & $02+0$ & $12+0$ & $02+0$ \\
\hline 170 & 35.59 & 141 & 24.76 & $4 \pm 0.2$ & $2.5 \pm 0.1$ & $0.8 \pm 0$ & $3.6 \pm 0.1$ & $0.7 \pm 0$ & $0.2 \pm 0$ & $1.4 \pm 0.1$ & $0.2 \pm 0$ & $1.8 \pm 0.1$ & $0.5 \pm 0$ & $1.6 \pm 0.1$ & $0.2 \pm 0$ & $1.2 \pm 0$ & $0.2 \pm 0$ \\
\hline 200 & 35.60 & 140 & 24.90 & $3.6 \pm 0.1$ & {$[1.6 \pm 0.1]$} & $0.7 \pm 0$ & $3.3 \pm 0.1$ & $0.7 \pm 0$ & $0.2 \pm 0$ & $1.3 \pm 0.1$ & $0.2 \pm 0$ & $1.7 \pm 0.1$ & $0.5 \pm 0$ & $1.7 \pm 0.1$ & $0.2 \pm 0$ & $1.2 \pm 0$ & $0.2 \pm 0$ \\
\hline 700 & 34.47 & 169 & 27.16 & $11.2 \pm 0.2$ & $1.2 \pm 0$ & $1.5 \pm 0$ & $7.1 \pm 0.1$ & $1.4 \pm 0$ & $0.5 \pm 0$ & $2.4 \pm 0.1$ & $0.4 \pm 0$ & $3.5 \pm 0.1$ & $1 \pm 0$ & $4 \pm 0.1$ & $0.6 \pm 0$ & $4 \pm 0.1$ & $0.7 \pm 0$ \\
\hline $1650^{\mathrm{a}}$ & 34.61 & 123 & 27.62 & $19.6 \pm 0.9$ & $2.2 \pm 0.2$ & $2.5 \pm 0$ & $11.7 \pm 0.2$ & $2.3 \pm 0.1$ & $0.7 \pm 0$ & $3.8 \pm 0$ & $0.6 \pm 0$ & $4.8 \pm 0.1$ & $1.4 \pm 0$ & $5.2 \pm 0$ & $0.8 \pm 0$ & $5.6 \pm 0.1$ & $1.1 \pm 0$ \\
\hline \multicolumn{18}{|c|}{ Station 077 (July 28, 2012; 5 57' 3.6" S; 147³9' 36" E; depth : 1045m) } \\
\hline 25 & 34.77 & 191 & 22.35 & $9.1 \pm 0.2$ & $3.7 \pm 0.1$ & $1 \pm 0$ & $4.9 \pm 0.1$ & $1.1 \pm 0$ & $0.4 \pm 0$ & $1.8 \pm 0.1$ & $0.3 \pm 0$ & $2.2 \pm 0.1$ & $0.6 \pm 0$ & $1.8 \pm 0$ & $0.2 \pm 0$ & $1.3 \pm 0$ & $0.2 \pm 0$ \\
\hline 180 & 35.61 & 140 & 24.85 & $3.9 \pm 0.1$ & $2.3 \pm 0$ & $0.7 \pm 0$ & $3.4 \pm 0$ & $0.8 \pm 0$ & $0.2 \pm 0$ & $1.3 \pm 0$ & $0.2 \pm 0$ & $1.7 \pm 0$ & $0.5 \pm 0$ & $1.6 \pm 0$ & $0.2 \pm 0$ & $1.1 \pm 0$ & $0.2 \pm 0$ \\
\hline 501 & 34.57 & 178 & 26.94 & $13.2 \pm 0.2$ & $5.2 \pm 0.5$ & $1.8 \pm 0$ & $8 \pm 0.1$ & $1.6 \pm 0$ & $0.5 \pm 0$ & $2.4 \pm 0.1$ & $0.4 \pm 0$ & $3.3 \pm 0.1$ & $1 \pm 0$ & $3.6 \pm 0.1$ & $0.5 \pm 0$ & $3.6 \pm 0.1$ & $0.6 \pm 0$ \\
\hline 701 & 34.48 & 159 & 27.20 & $13.1 \pm 0.2$ & {$[1.6 \pm 0]$} & $1.7 \pm 0$ & $7.9 \pm 0.1$ & $1.5 \pm 0$ & $0.5 \pm 0$ & $2.7 \pm 0.1$ & $0.4 \pm 0$ & $3.7 \pm 0.1$ & $1.1 \pm 0$ & $4.3 \pm 0.1$ & $0.7 \pm 0$ & $4.3 \pm 0.1$ & $0.8 \pm 0$ \\
\hline 983 & 34.51 & 145 & 27.35 & $20 \pm 0.7$ & $2.9 \pm 0.1$ & $2.1 \pm 0$ & $9.6 \pm 0.2$ & $1.9 \pm 0.1$ & $0.6 \pm 0$ & $3.1 \pm 0.1$ & $0.5 \pm 0$ & $4.3 \pm 0.2$ & $1.3 \pm 0$ & $4.8 \pm 0.1$ & $0.8 \pm 0$ & $5 \pm 0.1$ & $1 \pm 0$ \\
\hline \multicolumn{18}{|c|}{ Station 082- Non-filtrated (August 03, 2012; $13^{\circ} 59^{\prime} 49.2^{\prime \prime} \mathrm{S} ; 156^{\circ} 0^{\prime} 25.2^{\prime \prime} \mathrm{E}$; depth : $2586 \mathrm{~m}$ ) } \\
\hline 25 & 34.93 & 197 & 22.92 & $6.6 \pm 0.2$ & $4.9 \pm 0.1$ & $0.9 \pm 0$ & $4.2 \pm 0.1$ & $0.9 \pm 0.1$ & $0.4 \pm 0$ & $1.7 \pm 0.1$ & $0.2 \pm 0$ & $1.9 \pm 0.1$ & $0.5 \pm 0$ & $1.7 \pm 0.1$ & $0.2 \pm 0$ & $1.1 \pm 0$ & $0.2 \pm 0$ \\
\hline 180 & 35.79 & 129 & 24.65 & $6.2 \pm 0.3$ & $4.6 \pm 0.2$ & $0.8 \pm 0$ & $3.5 \pm 0.1$ & $0.8 \pm 0$ & $0.2 \pm 0$ & $1.3 \pm 0.1$ & $0.2 \pm 0$ & $1.6 \pm 0.1$ & $0.5 \pm 0$ & $1.6 \pm 0.1$ & $0.2 \pm 0$ & $1.1 \pm 0$ & $0.2 \pm 0$ \\
\hline 700 & 34.47 & 165 & 27.13 & $14 \pm 0.6$ & $4.5 \pm 0.2$ & $1.9 \pm 0.1$ & $8.1 \pm 0.2$ & $1.6 \pm 0.1$ & $0.5 \pm 0$ & $2.9 \pm 0.1$ & $0.4 \pm 0$ & $3.8 \pm 0.2$ & $1.1 \pm 0$ & $4.3 \pm 0.2$ & $0.7 \pm 0$ & $4.1 \pm 0.1$ & $0.7 \pm 0$ \\
\hline 800 & 34.45 & 163 & 27.23 & $15.5 \pm 0.7$ & $4.4 \pm 0.2$ & $2 \pm 0.1$ & $8.6 \pm 0.3$ & $1.7 \pm 0.1$ & $0.5 \pm 0$ & $2.9 \pm 0.1$ & $0.5 \pm 0$ & $3.9 \pm 0.2$ & $1.2 \pm 0.1$ & $4.6 \pm 0.2$ & $0.7 \pm 0$ & $4.5 \pm 0.1$ & $0.8 \pm 0$ \\
\hline 1000 & 34.50 & 151 & 27.38 & $17.3 \pm 0.7$ & $14 \pm 0.3$ & $2.1 \pm 0.1$ & $9.5 \pm 0.2$ & $1.8 \pm 0.1$ & $0.6 \pm 0$ & $3.3 \pm 0.1$ & $0.5 \pm 0$ & $4.2 \pm 0.1$ & $1.3 \pm 0.1$ & $4.9 \pm 0.2$ & $0.8 \pm 0$ & $5 \pm 0.1$ & $0.9 \pm 0$ \\
\hline $1200^{a}$ & 34.54 & 145 & 27.48 & $20 \pm 1.7$ & $6.9 \pm 3$ & $2.2 \pm 0$ & $10 \pm 0.2$ & $1.9 \pm 0.1$ & $0.6 \pm 0$ & $3.3 \pm 0$ & $0.5 \pm 0$ & $4.6 \pm 0.1$ & $1.4 \pm 0$ & $5.3 \pm 0.1$ & $0.8 \pm 0$ & $5.6 \pm 0.1$ & $1.1 \pm 0$ \\
\hline 1350 & 34.57 & 140 & 27.53 & $22.1 \pm 1.2$ & $3 \pm 0.1$ & $2.4 \pm 0.1$ & $11 \pm 0.4$ & $2.3 \pm 0.1$ & $0.6 \pm 0$ & $3.7 \pm 0.2$ & $0.6 \pm 0$ & $5.1 \pm 0.3$ & $1.5 \pm 0.1$ & $5.8 \pm 0.3$ & $0.9 \pm 0$ & $6 \pm 0.2$ & $1.2 \pm 0.1$ \\
\hline 2000 & 34.64 & 141 & 27.67 & $29.1 \pm 1.1$ & $10.7 \pm 0.4$ & $3.6 \pm 0.1$ & $14.5 \pm 0.4$ & $2.7 \pm 0.2$ & $0.9 \pm 0.1$ & $4.7 \pm 0.2$ & $0.7 \pm 0$ & $6.1 \pm 0.2$ & $1.8 \pm 0.1$ & $6.8 \pm 0.3$ & $1 \pm 0$ & $7.3 \pm 0.2$ & $1.5 \pm 0.1$ \\
\hline
\end{tabular}

dREE refer to data with its statistical error bar.

Square brackets indicate data with low recoveries 
Table 3: Average dNd concentrations in the different layers of the box model

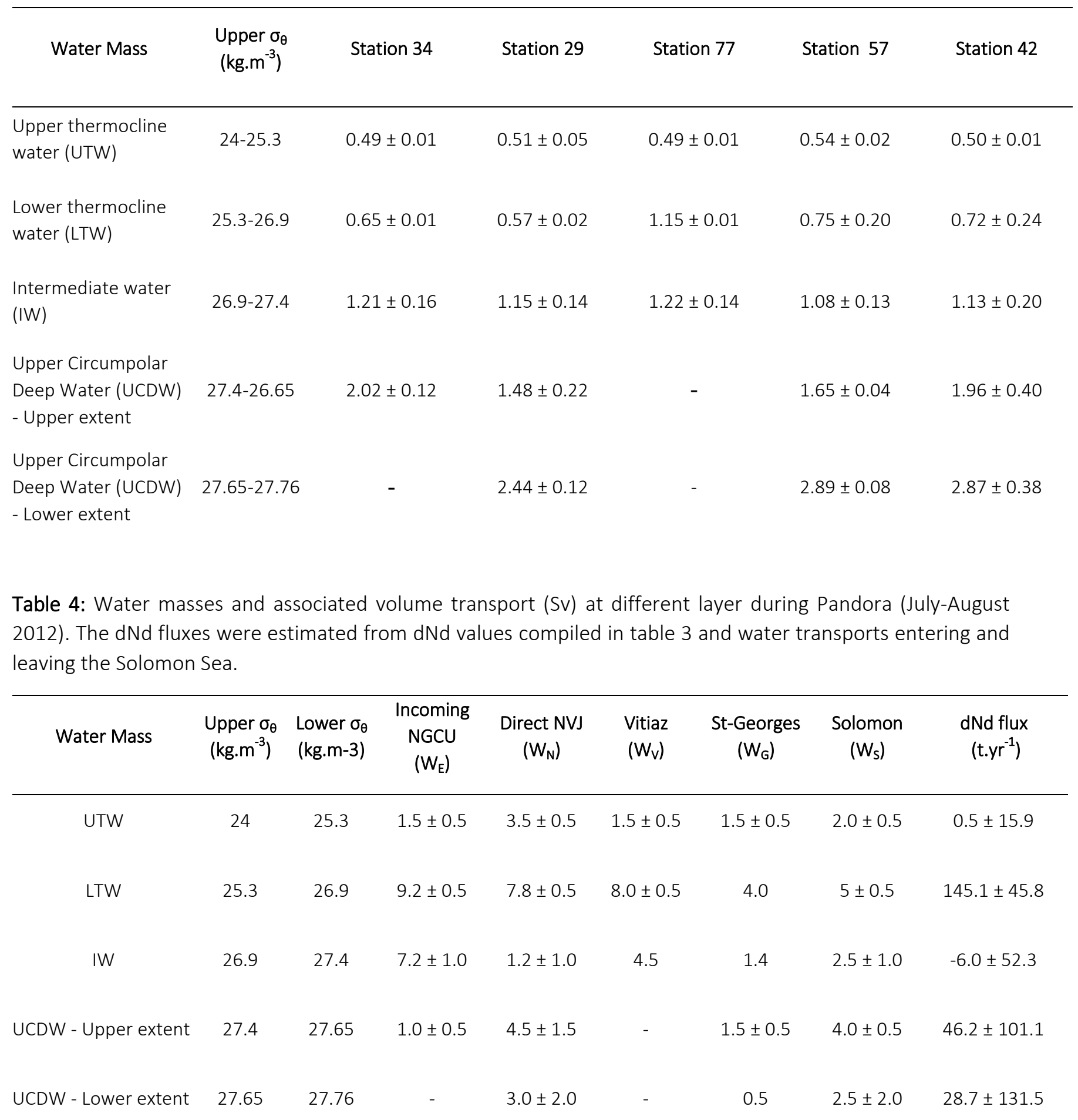

